The nature of the distinctive microscopic features in $\mathbf{R}_{5}\left(\mathrm{Si}_{\mathrm{x}} \mathbf{G e}_{1-\mathrm{x}}\right)_{4}$ magnetic refrigeration materials

by

\title{
Ozan Ugurlu
}

A dissertation submitted to the graduate faculty

in partial fulfillment of the requirements for the degree of

DOCTOR OF PHILOSOPHY

Major: Materials Science and Engineering

Program of Study Committee:

L. Scott Chumbley, Major Professor

Vitalij K. Pecharsky

Alan M. Russell

Xiaoli Tan

Frank Peters

Palaniappa A. Molian

Iowa State University

Ames, lowa

2006

Copyright (C Ozan Ugurlu, 2006. All rights reserved. 


\section{Graduate College \\ Iowa State University}

This is to certify that the doctoral dissertation of

\section{Ozan Ugurlu}

has met the dissertation requirements of Iowa State University

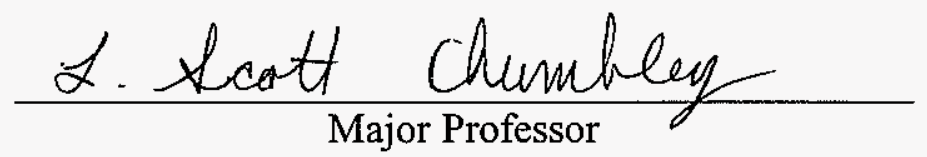

For the Major Program 
TABLE OF CONTENTS

ABSTRACT $\mathrm{v}$

CHAPTER 1: GENERAL INTRODUCTION

Literature Review Crystal Structure Microscopy Background

Dissertation Organization References

CHAPTER 2: IDENTIFICATION OF THIN PLATES SEEN IN $\mathrm{R}_{5}\left(\mathrm{Si}_{\mathrm{x}} \mathrm{Ge}_{1 \cdot \mathrm{x}}\right)_{4}$ ALLOYS, WHERE R IS Gd, Tb, Dy, AND Er 18

Abstract Introduction

Experimental Details

Results

Discussion

Conclusion

Acknowledgements

References

CHAPTER 3: CHARACTERIZATION OF AN ATYPICAL WIDMANSTATTEN

STRUCTURE IN $\mathrm{Gd}_{5} \mathrm{Si}_{2} \mathrm{Ge}_{2}$ ALLOYS

Abstract

Introduction

Experimental Details

Results

Discussion

Conclusion

Acknowledgements

References

CHAPTER 4: ORIENTATION AND FORMATION OF ATYPICAL WIDMANSTATTEN

PLATES IN THE $\mathrm{Gd}_{5}\left(\mathrm{Si}_{\mathrm{X}} \mathrm{Ge}_{1-\mathrm{X}}\right)_{4}$ SYSTEM

Abstract

Introduction

Experimental Details

Results

Discussion

Conclusion

Acknowledgements

References

GENERAL CONCLUSIONS 
APPENDIX A: LINEAR MICROSTRUCTURAL FEATURES IN RE $5(\mathrm{Si}, \mathrm{Ge})_{4}$-TYPE ALLOYS: DIFFICULTIES IN IDENTIFICATION ...................................................... 72

Abstract $\quad 72$

Introduction $\quad 73$

Microscopical Observations and Diffraction Data $\quad 75$

$\begin{array}{ll}\text { Magnetometer Measurements } & 81\end{array}$

Compositional Measurements $\quad 83$

$\begin{array}{ll}\text { Summary } & 87\end{array}$

References $\quad 87$

APPENDIX B: Persistence of 5:3 plates in $\mathrm{RE}_{5}\left(\mathrm{Si}_{\mathrm{x}} \mathrm{Ge}_{1-\mathrm{x}}\right)_{4}$ Alloys ................................... 89

$\begin{array}{ll}\text { Abstract } & 89\end{array}$

$\begin{array}{ll}\text { Introduction } & 90\end{array}$

Experimental Procedure $\quad 91$

Experimental Results $\quad 92$

Thermal Effects: $\quad 92$

Composition Effects: $\quad 95$

Discussion $\quad 97$

$\begin{array}{lr}\text { Conclusion } & 99\end{array}$

Acknowledgements $\quad 99$

$\begin{array}{ll}\text { References } & 100\end{array}$

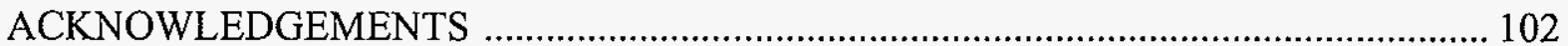




\section{ABSTRACT}

Magnetic refrigeration is a promising technology that offers a potential for high energy efficiency. The giant magnetocaloric effect of the $\mathrm{R}_{5}\left(\mathrm{Si}_{\mathrm{x}}, \mathrm{Ge}_{1-\mathrm{x}}\right)_{4}$ alloys (where $\mathrm{R}=$ rare-earth and $0 \leq \mathrm{x} \leq 1$ ), which was discovered in 1997 , make them perfect candidates for magnetic refrigeration applications. In this study the microstructures of $\mathrm{Gd}_{5}\left(\mathrm{Si}_{\mathrm{x}} \mathrm{Ge}_{1-\mathrm{x}}\right)_{4}$ alloys have been characterized using electron microscopy techniques, with the focus being on distinctive linear features first examined in 1999. These linear features have been observed

in $\mathrm{R}_{5}\left(\mathrm{Si}_{\mathrm{x}}, \mathrm{Ge}_{\mathrm{l-x}}\right)_{4}$ alloys prepared from different rare-earths ( $\mathrm{Gd}, \mathrm{Tb}$, Dy and $\mathrm{Er}$ ) with different crystal structures $\left(\mathrm{Gd}_{5} \mathrm{Si}_{4}\right.$-type orthorhombic, monoclinic and $\mathrm{Gd}_{5} \mathrm{Ge}_{4}$-type orthorhombic). Systematic scanning electron microscope studies revealed that these linear features are actually thin-plates, which grow along specific directions in the matrix material. The crystal structure of the thin-plates has been determined as hexagonal with lattice parameters $\mathrm{a}=\mathrm{b}=8.53 \AA$ and $\mathrm{c}=6.40 \AA$, using selected area diffraction (SAD). Energy dispersive spectroscopy analysis, carried out in both scanning and transmission electron microscopes, showed that the features have a composition approximating to $\mathrm{R}_{5}\left(\mathrm{Si}_{\mathrm{x}}, \mathrm{Ge}_{1-\mathrm{x}}\right)_{3}$.phase. Orientation relationship between the matrix and the thin-plates has been calculated as [$1010](1-211)_{\mathrm{p}} / /[010](10-2)_{\mathrm{m}}$. The growth direction of the thin plates are calculated as $(220$ $19)$ and (-22 019$)$ by applying the $\Delta \mathrm{g}$ approach of Zhang and Purdy to the SAD patterns of this system. High Resolution TEM images of the $\mathrm{Gd}_{5} \mathrm{Ge}_{4}$ were used to study the crystallographic relationship. A terrace-ledge structure was observed at the interface and a $7^{\circ}$ rotation of the reciprocal lattices with respect to each other, consistent with the determined orientation relationship, was noted. Both observations are consistent with the stated hypothesis that the growth direction of the thin-plates is parallel to an invariant line direction. Based on the terrace-ledge structure of the thin-plate interface a displacive-diffusional 
growth mechanism has been proposed to explain the rapid formation of the $\mathrm{R}_{5}\left(\mathrm{Si}_{\mathrm{x}}, \mathrm{Ge}_{1-\mathrm{x}}\right)_{3}$ plates. 


\section{CHAPTER 1: GENERAL INTRODUCTION}

Refrigerators from the late 1800 s until 1929 used the toxic gases ammonia $\left(\mathrm{NH}_{3}\right)$, methyl chloride $\left(\mathrm{CH}_{3} \mathrm{Cl}\right)$, and sulfur dioxide $\left(\mathrm{SO}_{2}\right)$ as refrigerants. Several fatal accidents occurred in the 1920s when methyl chloride leaked out of refrigerators. Three American corporations (Frigidaire, General Motors and DuPont ${ }^{\circledR}$ ) launched collaborative research efforts to develop a less dangerous method of refrigeration; their efforts led to the discovery of Freon, a chlorofluorocarbon compound of composition $\mathrm{C}_{n} \mathrm{Cl}_{x} \mathrm{~F}_{(2 n+2-x)}$. In just a few years, compressor refrigerators using Freon would become the standard for almost all home kitchens. Only decades later would people realize that these chlorofluorocarbons endangered the ozone layer of the entire planet.

Now magnetocaloric materials that change temperature in response to an applied magnetic field, are being studied as a means of creating an entirely new class of refrigeration technologies. Magnetic refrigeration, based on magnetocaloric materials, is an environmentally safe and energy efficient method when compared to conventional vaporcycle refrigerators.

Magnetic refrigeration uses the magnetocaloric effect (MCE). Magnetocaloric materials heat when they are magnetized and cool when removed from the magnetic field[1]. MCE was first discovered in iron by Warburg [2] in 1881; 50 years later Debye[3] and Giauque[4] independently suggested the use of MCE to reach ultra-low temperatures. Early magnetic refrigerators used large superconducting magnets, but on September 18, 2001 the world's first permanent magnet, room temperature, magnetic refrigerator, developed by the Astronautics Corporation of America and Ames Laboratory, became operational, Figure 1. 


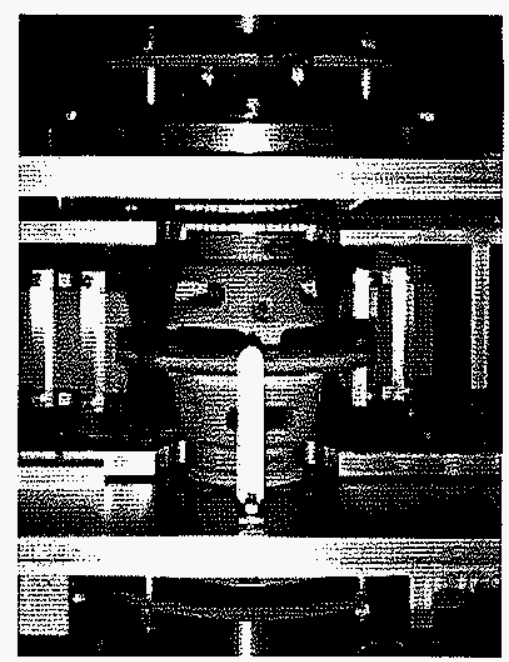

Figure 1 -- Magnetic refrigerator prototype

All magnetic materials have a magnetocaloric effect, and this is due to the coupling of the magnetic sub-lattice with the magnetic field, which changes the magnetic part of the entropy of a solid. As in the compression of a gas, the isothermal magnetizing of a paramagnet or a soft ferromagnet reduces the entropy, and demagnetizing restores the zerofield magnetic entropy of a system. The magnetic refrigerator in Figure 1 employs a rotary design, which uses this principle, Figure 2. It consists of a wheel that contains segments of gadolinium powder and a high-field rare-earth magnet. The wheel is arranged to pass through a gap in the magnet where the magnetic field is concentrated. Initially in the absence of a magnetic field, the spins of the unpaired electrons are random in gadolinium (Figure 2a). As it passes through this field, the gadolinium in the wheel exhibits a large magnetocaloric effect, and the spins align causing the sample to heat (magnetic entropy decreases because of increasing magnetic order in the system), Figure $2 \mathrm{~b}$. After the gadolinium enters the field, water is circulated to draw the heat out of the metal. As the material leaves the magnetic field spins randomize, cooling the magnetic material (gadolinium). A second stream of water is then cooled by the gadolinium. This water is then circulated through the refrigerator's 
cooling coils. This unit does not use ozone-depleting gases and runs virtually silent when compared to vapor-compression style refrigeration systems.
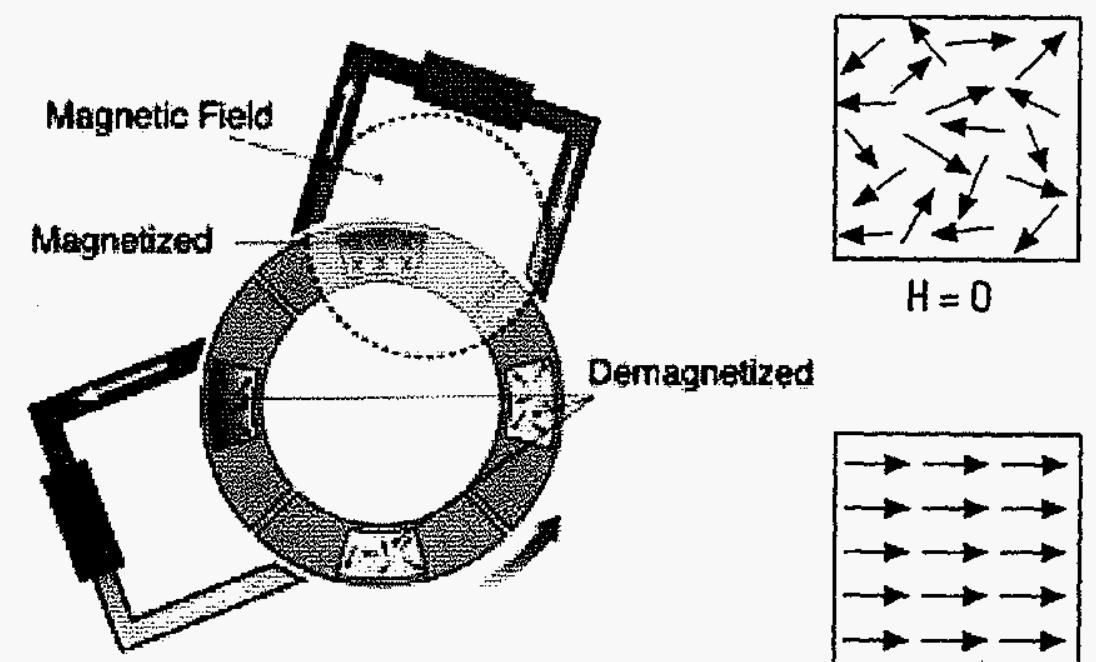

Figure 2 -- Schematic of a magnetic refrigerator

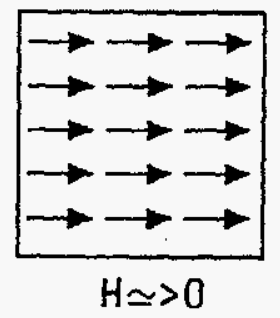

Magnetic refrigeration had been thought to be practical only at low temperatures where lattice entropy is small compared to the magnetic entropy. However, gadolinium has a high magnetic entropy around room temperature, and $\mathrm{a} \mathrm{Gd}_{5} \mathrm{Si}_{2} \mathrm{Ge}_{2}$ alloy has at least $30 \%$ higher magnetic entropy than the Gd metal itself around room temperature, Figure 3 . These magnetic properties make Gd and its alloys a unique material for magnetic refrigeration and have resulted in considerable scientific interest in this class of rare-earth-based alloy systems.

If these alloys are to become commercially viable, a complete understanding of the material is needed. This includes knowledge of the crystal structures, phases, and phase transitions present in these materials. The purpose of this research is to examine themicrostructure of rare-earth based alloys of the form $\mathrm{R}_{5}\left(\mathrm{Si}_{\mathrm{x}} \mathrm{Ge}_{1-\mathrm{x}}\right)_{4}$, with special emphasis on the Gd-based alloy, to obtain a better understanding of the microstructure-property relationships which exist. 


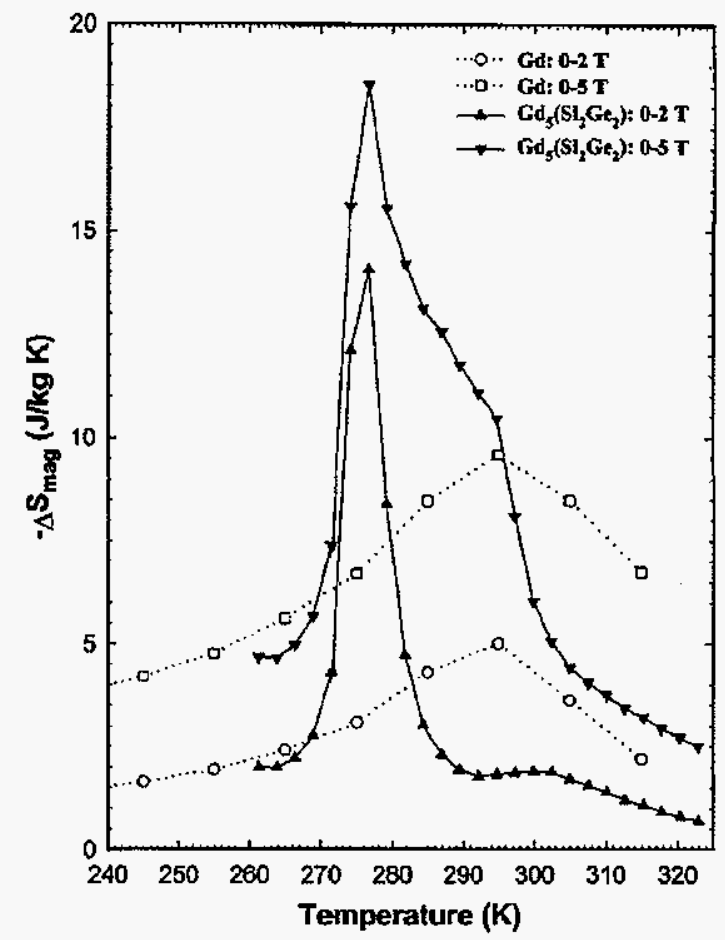

Figure 3 -- Magnetic entropy change of the $\mathbf{G d}_{5}\left(\mathrm{Si}_{2} \mathbf{G e}_{2}\right)$ and pure $\mathrm{Gd}$ for a magnetic field change of 0 to 2 and 0 to 5 between 240 and 325K.

\section{Literature Review}

$\mathrm{R}_{5} \mathrm{Ge}_{4}$ and $\mathrm{R}_{5} \mathrm{Si}_{4}$ are rare earth compounds where $\mathrm{R}$ is any of a number of lanthanides, and they were discovered by Smith et al. [5]. It was reported [6] that both the $\mathrm{R}_{5} \mathrm{Si}_{4}$ phases with $\mathrm{R}=\mathrm{Sm}, \mathrm{Gd}, \mathrm{Tb}, \mathrm{Dy}, \mathrm{Er}$ and $\mathrm{Y}$, and the $\mathrm{R}_{5} \mathrm{Ge}_{4}(\mathrm{R}=\mathrm{La}, \mathrm{Ce}, \mathrm{Pr}, \mathrm{Nd}, \mathrm{Sm}, \mathrm{Gd}, \mathrm{Tb}, \mathrm{Dy}, \mathrm{Ho}$, $\mathrm{Er}, \mathrm{Tm}, \mathrm{Lu}$ and $\mathrm{Y}$ ) alloys crystallize in the $\mathrm{Sm}_{5} \mathrm{Ge}_{4}$-type orthorhombic structure. Holtzberg et al. [7] confirmed the X-ray data collected by Smith et al. and also found an undetermined intermediate phase in $\mathrm{Gd}_{5}\left(\mathrm{Si}_{\mathrm{X}} \mathrm{Ge}_{1-\mathrm{x}}\right)_{4}$ alloys for $0.24 \leq \mathrm{X} \leq 0.5$. In 1997 Pecharsky and Gschneidner [8] showed that this phase has a monoclinic structure at room temperature and also discovered a second order transition, $\mathrm{T}_{c}$, followed very closely by a first order phase transition that produced an adiabatic temperature rise in the $\mathrm{Gd}_{5} \mathrm{Si}_{2} \mathrm{Ge}_{2}$. In addition, it was determined that the first order transition could be triggered by a magnetic field, producing a giant magnetocaloric effect, which is at least 2 times greater than any known magnetic material [9]. Further studies of Pecharsky and Gschneidner [10] have shown that the 
transition temperature is tunable between $\sim 30 \mathrm{~K}$ and $\sim 276 \mathrm{~K}$ by adjusting the $\mathrm{Si}$ :Ge ratio without losing the giant magnetocaloric effect. $\mathrm{Gd}_{5}\left(\mathrm{Si}_{\mathrm{x}} \mathrm{Ge}_{1-\mathrm{x}}\right)_{4}$ alloys have many important properties besides giant magnetocaloric effect $[9,10]$, like strong magnetoelastic effects $[11$, 12], giant magnetoresistance [13, 14], unusual Hall effect [15] and spontaneous generation of voltage[16]. This study will only focus on crystal structure phase assemblages and phase transitions associated with the $\mathrm{R}-\mathrm{Si}-\mathrm{Ge}$ alloys.

Percharsky and Gschneidner [8] examined the phase relations and the crystallography of alloys in $\mathrm{Gd}_{5} \mathrm{Si}_{4}-\mathrm{Gd}_{5} \mathrm{Ge}_{4}$ pseudobinary systems and reported the crystal data in Table 1. During this study they noticed that $\mathrm{Gd}_{5} \mathrm{Si}_{2} \mathrm{Ge}_{2}$ samples were twinned with an average full width of the diffraction peaks during $\omega$-scans approaching $1.5^{\circ}$ for $\mathrm{MoK}_{\alpha}$ radiation at Bragg angles $(2 \theta)$ between 15 and $25^{\circ}$. Those twins caused overlapping diffraction data which made it difficult to analyze the structure. This was the first study which showed the twinned nature of the $\mathrm{Gd}_{5} \mathrm{Si}_{2} \mathrm{Ge}_{2}$ alloys.

Table I -- Crystal data and structure refinement. [8]

\begin{tabular}{lccc}
\hline & $\mathbf{G d}_{\mathbf{5}} \mathbf{S i}_{\mathbf{4}}$ & $\mathbf{G d}_{\mathbf{5}}\left(\mathbf{S i}_{\mathbf{2}} \mathbf{G e}_{2}\right)$ & $\mathbf{G d}_{\mathbf{5}} \mathbf{G e}_{\mathbf{4}}$ \\
\hline Space Group & Pnma & $\mathrm{P} 1122_{\mathrm{J}} / \mathbf{a}$ & Pnma \\
$\mathrm{a}(\mathrm{A})$ & $7.4857(8)$ & $7.5808(5)$ & $7.6968(5)$ \\
$\mathrm{b}$ & $14.750(1)$ & $14.802(1)$ & $14.831(1)$ \\
$\mathrm{c}$ & $7.7514(8)$ & $7.7799(5)$ & $7.7851(5)$ \\
$\gamma\left({ }^{\circ}\right)$ & 90 & $93.190(4)$ & 90 \\
$\mathrm{~V}(\AA$ & $855.9(3)$ & $871.6(2)$ & $888.7(2)$ \\
$\rho\left(\mathrm{g} / \mathrm{cm}^{3}\right)$ & $6.974(2)$ & $7.256(2)$ & $8.046(2)$ \\
Wavelength, $\lambda \mathrm{K} \alpha_{1}(\mathrm{~A})$ & 1.5406 & 1.5406 & 1.5406 \\
$2 \Theta$ range & $20-80^{\circ}$ & $20-80^{\circ}$ & $20-80^{\circ}$ \\
Possible reflections & 270 & 515 & 282 \\
Profile points & 1501 & 2001 & 2001 \\
Free Parameters (including profiles) & 25 & 40 & 25 \\
Refinement Method & Full Profile & Full Profile & Full Profile \\
Final $\mathrm{R}_{\mathbf{l}}$ & 0.070 & 0.059 & 0.091 \\
\hline
\end{tabular}


Morellon et al. in 1998 reported that $\mathrm{MCE}$ in $\mathrm{Gd}_{5}\left(\mathrm{Si}_{\mathrm{x}} \mathrm{Ge}_{1-\mathrm{x}}\right)_{4}$ resulted from a single first-order structural transition from a monoclinic (paramagnetic) to an orthorhombic (ferromagnetic) structure[11], not from two transitions as first reported[8]. His following research showed that $\mathrm{Gd}_{5}\left(\mathrm{Si}_{\mathrm{x}} \mathrm{Ge}_{1-\mathrm{x}}\right)_{4}$ alloys are also magnetoresistant [17].

Gschneidner and Pecharsky [18] summarized some of the recent data on pseudobinary alloys along with their results for $\mathrm{R}=\mathrm{La}, \mathrm{Ce}, \mathrm{Pr}, \mathrm{Nd}, \mathrm{Sm}, \mathrm{Gd}, \mathrm{Tb}, \mathrm{Dy}, \mathrm{Ho}, \mathrm{Er}, \mathrm{Tm}, \mathrm{Yb}$ and Lu. Figure 4 shows an updated version of the original diagram of this study.

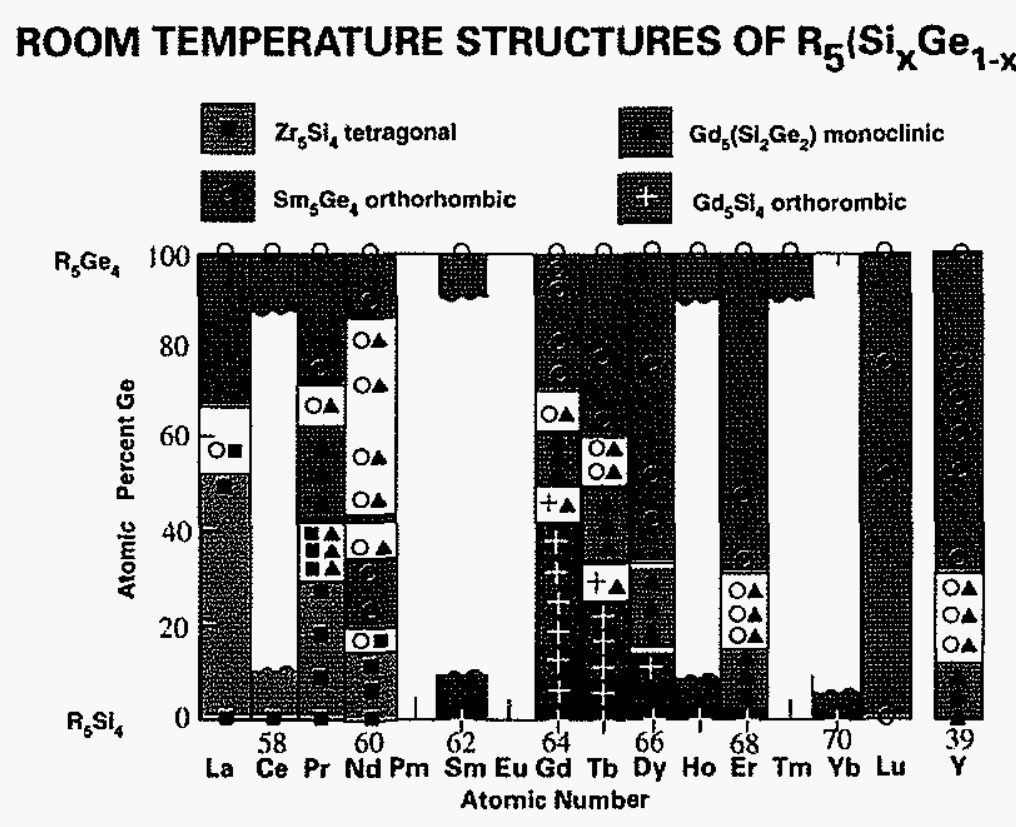

Figure 4 -- Existence diagram for the $\mathbf{R}_{5} \mathrm{Si}_{4}-\mathbf{R}_{5} \mathrm{Ge}_{4}$ pseudo-binary alloys. (Updated: 10/03) $[18]$

\section{Crystal Structure}

Since the discovery of the $\mathrm{Gd}_{5} \mathrm{Si}_{4}$ and $\mathrm{Gd}_{5} \mathrm{Ge}_{4}$ intermetallics [5, 6], their crystal structures were thought to be the same (orthorhombic $\mathrm{Sm}_{5} \mathrm{Ge}_{4}$ type), but Choe et al., Pecharsky and Gschneidner showed that they have different bond arrangements $[19,20]$. 
Both structures consist of 36 atoms per unit cell spread among six to nine independent crystallographic sites, and both contain similarly arranged layers of atoms (slabs), which are infinite in two dimensions ( $\mathrm{a}$ and c), Figure $5 \mathrm{a} . \mathrm{Gd}_{5} \mathrm{Si}_{4}$ is ferromagnetic and has an orthorhombic crystal structure in which all the slabs are interconnected by partially covalent $\mathrm{Si}-\mathrm{Si}$ bonds at room temperature, Figure $5 \mathrm{~b} . \mathrm{Gd}_{5} \mathrm{Ge}_{4}$ has the same orthorhombic crystal structure, but in this case Ge atoms, which occupy the Si lattice, do not form bonds between slabs, as shown in Figure $5 \mathrm{~d}$. In a range where $\mathrm{X}$ is between 0.5 and $1, \mathrm{Gd}_{5}\left(\mathrm{Si}_{\mathrm{X}} \mathrm{Ge}_{1-\mathrm{x}}\right)_{4}$ has the same crystal structure as $\mathrm{Gd}_{5} \mathrm{Si}_{4}$ with partially covalent bonds between slabs, Figure $5 \mathrm{~b}$. When $0.24 \leq \mathrm{X} \leq 0.5$, half of the inter-slab bonds are broken and in this state the material changes from ferromagnetic to paramagnetic while the crystal structure changes from orthorhombic Pnma to monoclinic P112 $/$ a. Between $X=0$ and 0.2 the structure is the same as $\mathrm{Gd}_{5} \mathrm{Ge}_{4}$, which is orthorhombic, Figure $5 \mathrm{~d}$. There is an uncertainty from $\mathrm{X}=0.2$ to 0.24 because of insufficient data.

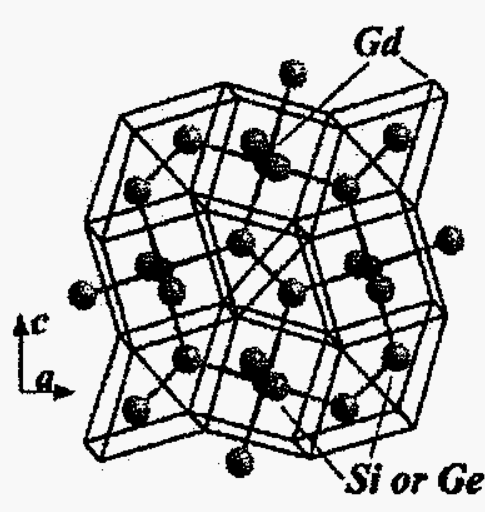

a

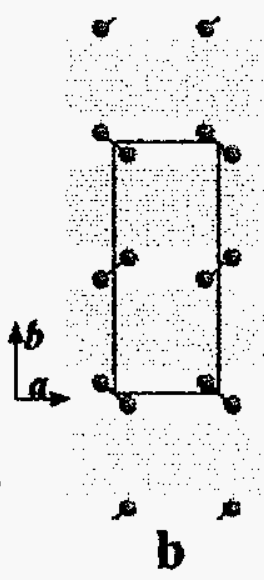

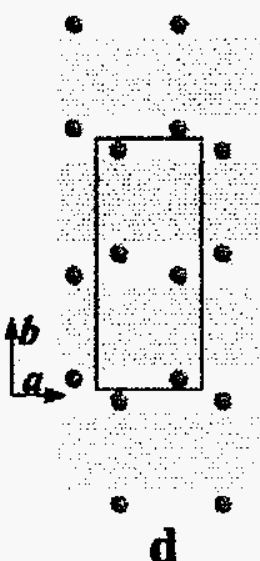

d

Figure 5 -- The basic building block (slab) of $\mathrm{Gd}_{5}\left(\mathrm{Si}_{\mathrm{x}} \mathrm{Ge}_{1-\mathrm{x}}\right)_{4}$ phases (a) and relationships between their room temperature crystal structures for $0.5<\mathrm{x} \leq 1.0(\mathrm{~b}), 0.24 \leq \mathrm{X} \leq 0.5$ (c) and $0 \leq x \leq 0.2$ (d). [19] 
When $\mathrm{X}$ is between 0.24 and $0.5, \mathrm{Gd}_{5}\left(\mathrm{Si}_{\mathrm{X}} \mathrm{Ge}_{1-\mathrm{x}}\right)_{4}$ becomes an extraordinary material. The broken bonds between slabs can be reformed reversibly by changing the temperature and/or magnetizing-demagnetizing the material. Long range ferromagnetic order is destroyed when some or all of the bonds are broken. These changes in structural and magnetic properties of the material occur by huge shear movements of the slabs, which cause a volume change during transformation. Figure 6 shows the effect of temperature and magnetic field on the $\mathrm{Gd}_{5}\left(\mathrm{Si}_{\mathrm{x}} \mathrm{Ge}_{1-\mathrm{x}}\right)_{4}$ material.

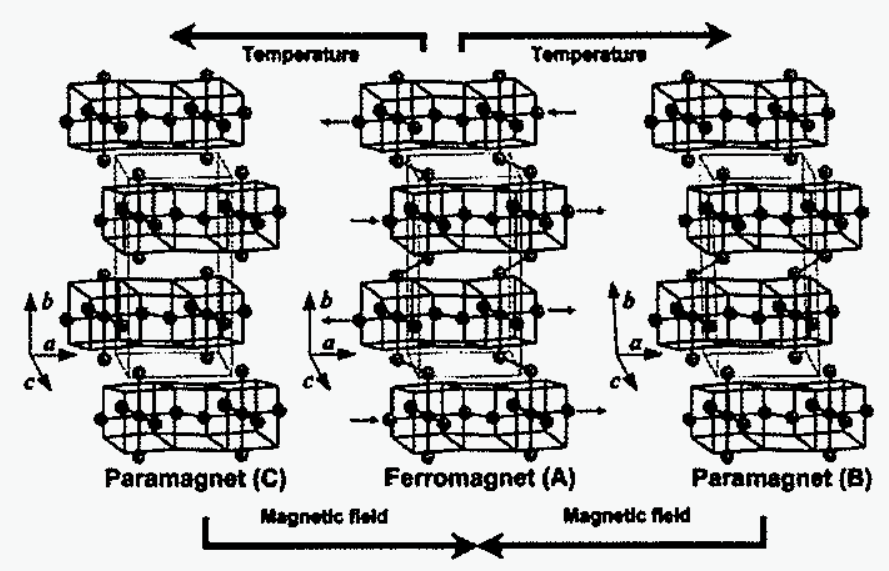

Figure 6 -- Effect of temperature and magnetic field on the $\mathrm{Gd}_{5}\left(\mathrm{Si}_{\mathbf{x}} \mathrm{Ge}_{1-\mathrm{x}}\right)_{4}$ material. [19]

There are two structural transformations in $\mathrm{Gd}_{5}\left(\mathrm{Si}_{\mathrm{X}} \mathrm{Ge}_{1-\mathrm{x}}\right)_{4}$ where $0.24 \leq \mathrm{X} \leq 0.5$. One is a low temperature transformation between the orthorhombic and monoclinic structure, which is reversible, but a similar high temperature transformation is irreversible. Temperatures of the transformations depend on the alloy composition. The low temperature transformation can be adjustable between $\sim 30 \mathrm{~K}-\sim 276 \mathrm{~K}[10]$ depending on the Si:Ge ratio of the alloy. The irreversible high temperature crystallographic phase change in monoclinic $\mathrm{Gd}_{5}\left(\mathrm{Si}_{2.09} \mathrm{Ge}_{1.91}\right)$ 
alloy begins at $\sim 500 \mathrm{~K}$, but is not complete until $\sim 650 \mathrm{~K}[21]$. The low temperature phase transformation has been studied more intensely than the high temperature transformation. Figure 7 shows a low temperature transformation phase diagram of the $\mathrm{Gd}_{5} \mathrm{Si}_{4}-\mathrm{Gd}_{5} \mathrm{Ge}_{4}$ pseudobinary system [10]. Low temperature phase transformation proceeds completely in a narrower temperature range than the high temperature transformation.

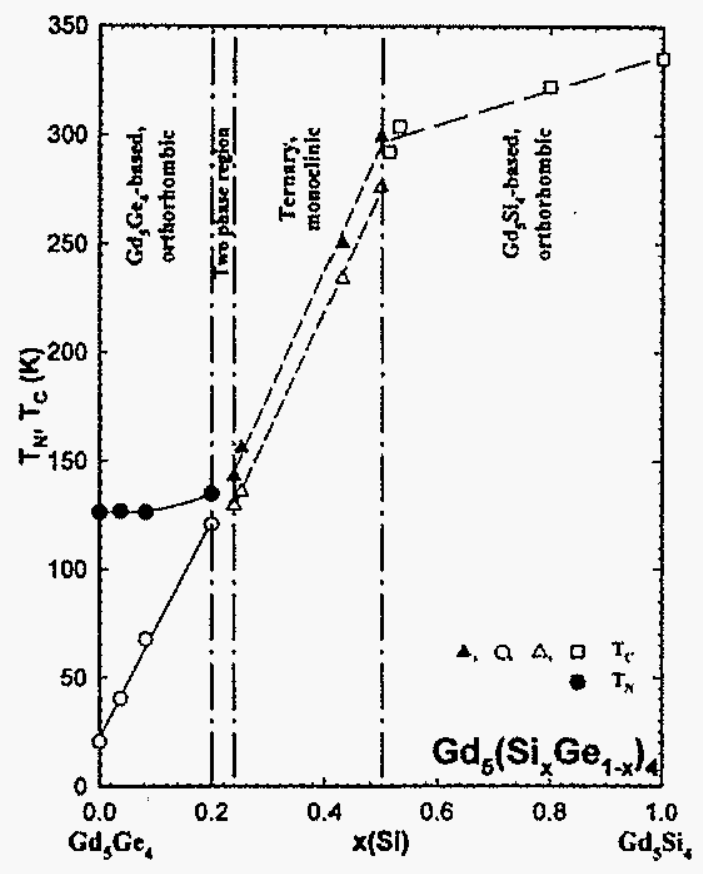

Figure 7. -- Phase diagram of $\mathrm{Gd}_{5} \mathrm{Ge}_{4}-\mathrm{Gd}_{5} \mathrm{Si}_{4}$ system at zero magnetic field. Solid and dashed lines: magnetic phase boundaries, dot-dashed lines: crystallographic phase boundaries. $[10]$

\section{Microscopy Background}

Szade et al.[22], who worked on single crystals of $\mathrm{Gd}_{5} \mathrm{Si}_{4}, \mathrm{Gd}_{5} \mathrm{Si}_{2} \mathrm{Ge}_{2}$ and $\mathrm{Gd}_{5} \mathrm{Ge}_{4}$ compounds, was the first to look at the surface structure of $\mathrm{Gd}_{5}\left(\mathrm{Si}_{\mathrm{x}} \mathrm{Ge}_{1-\mathrm{x}}\right)_{4}$ alloys. During their microscopic examination they noticed sets of parallel lines with a constant angle between them for each compound, Figure 8 . The angle was about $80^{\circ}\left( \pm 2^{\circ}\right)$ for all 
compounds. They concluded that the lines are not grain boundaries, and by using backscattered Laue reflection method they showed that the lines were not parallel to any crystallographic direction with low indexes. Auger Electron Spectroscopy (AES) studies showed that there were chemical composition differences along the path perpendicular to a line, Figure 9.

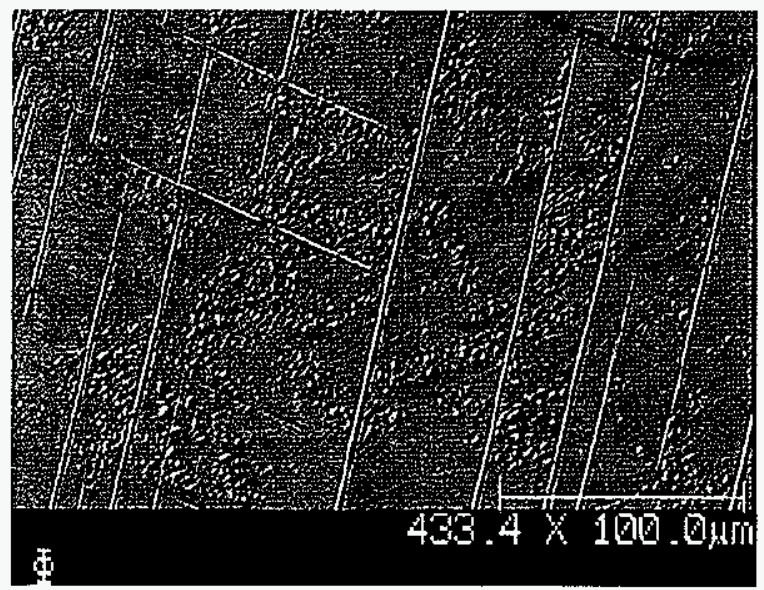

Figure 8 -- The SEM image of the surface structure on the $\mathrm{Gd}_{5} \mathrm{Si}_{4}$ plate. [22]

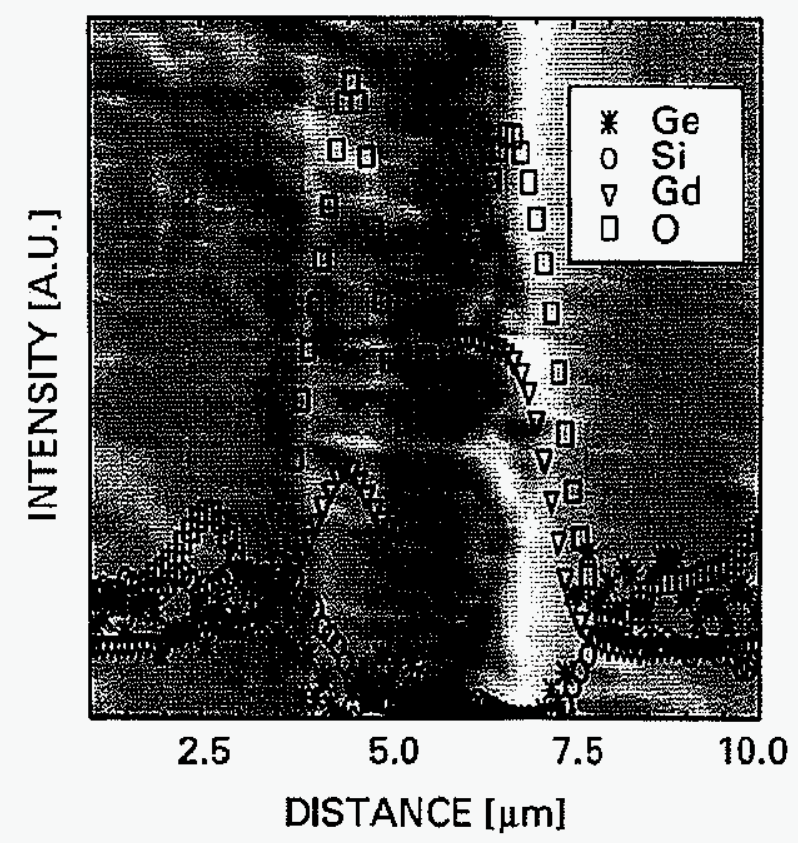

Figure 9 -- Chemical composition along the line perpendicular to linear feature (AES). [22] 
Meyers et al.[23] looked at $\mathrm{Gd}_{5} \mathrm{Si}_{1.95} \mathrm{Ge}_{2.05}$ compounds and used Energy Dispersive Spectrometry (EDS) to determine the composition of the lines. His early EDS results, Figure 10, differ slightly from the results of Szade et al.[22] where a drop in both Si and Ge was seen using AES. These measurements confirmed that the lines have a different composition than the bulk, the composition being approximately $\mathrm{Gd}_{5}(\mathrm{Si}, \mathrm{Ge})_{3}$. Meyer et al. implied that the lines could be a Widmanstatten structure.

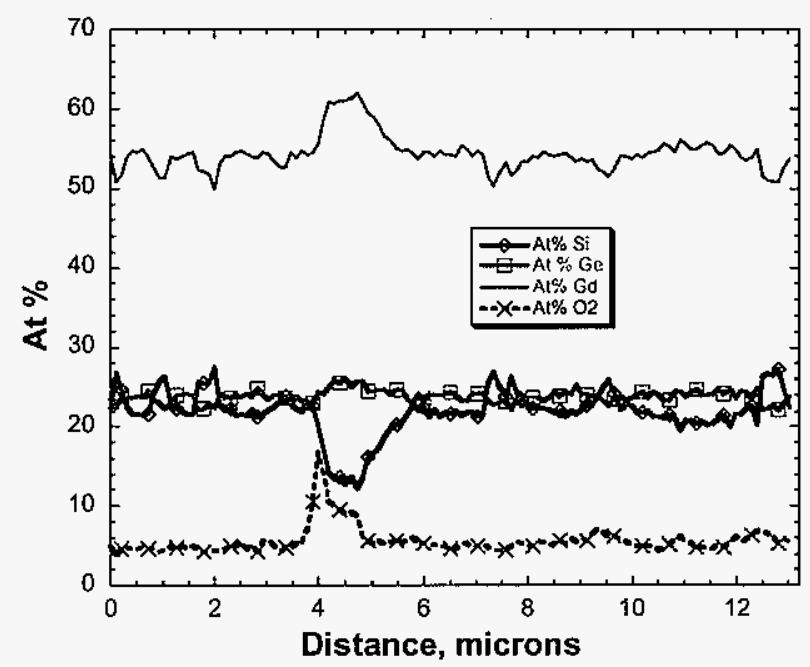

Figure 10 -- EDS results obtained from a linear feature. [23]

TEM analysis of the $\mathrm{Gd}_{5} \mathrm{Si}_{2} \mathrm{Ge}_{2}$ alloy has been done by Meyers et al. [24]. This study focused on the room temperature (monoclinic) and below room temperature (orthorhombic) structure of the alloy. Figure 11a. shows a large-scale structure similar in appearance to "twins" at low magnification. In addition to large scale faulting, there is fine scale faulting in the structure as shown in the high magnification, high resolution image of Figure $11 \mathrm{~b}$.

When the sample was cooled in-situ below the monoclinic to orthorhombic transformation temperature $0^{\circ} \mathrm{C}$, little difference was seen in the appearance of the microstructure. The only noticeable change was the movement of the sample and some cracking that resulted due to lattice contraction from the phase transformation, Figure 12a. However, the monoclinic to orthorhombic phase transformation was confirmed by SAD 

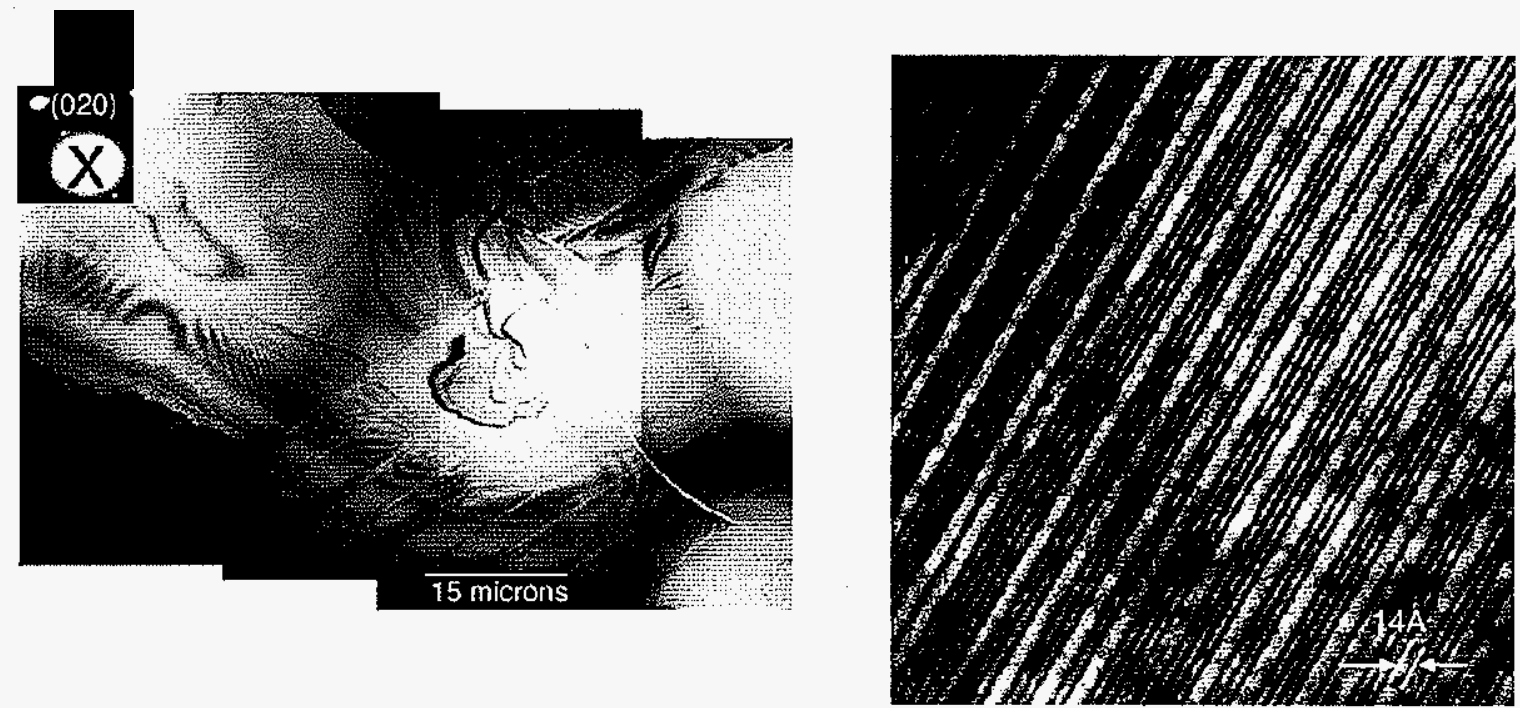

Figure 11 -- (a) Bright field image of the apparent "twins". (b) HRTEM bright field image showing fine-scale faulting. [24]

patterns which were taken from the [103] zone axis, Figure 12b. The angle between planes changed from $93.4^{\circ}$ to $90^{\circ}$ as expected from the lattice parameters shown in Table 1 . As an indication of the magnetic phase change from paramagnetic to ferromagnetic, the electron beam was seriously affected by the sample at low temperatures.

Meyers et al. [24] also studied the fine-scale "twinned" structure of $\mathrm{Gd}_{5} \mathrm{Si}_{2} \mathrm{Ge}_{2}$ samples. He saw that the material was heavily twinned on an extremely fine scale along [100]. HRTEM images taken along [100] (plane of the twins) and [001] (perpendicular to twin plane) shows the fine twinned structure of the material, Figure 13. In addition to HRTEM images, SAD patterns along [100] and [001] indicated a distinct difference. The patterns taken from [100] were circular while the patterns taken from [001], which are perpendicular to the twin plane, were streaky along the (020) plane. 

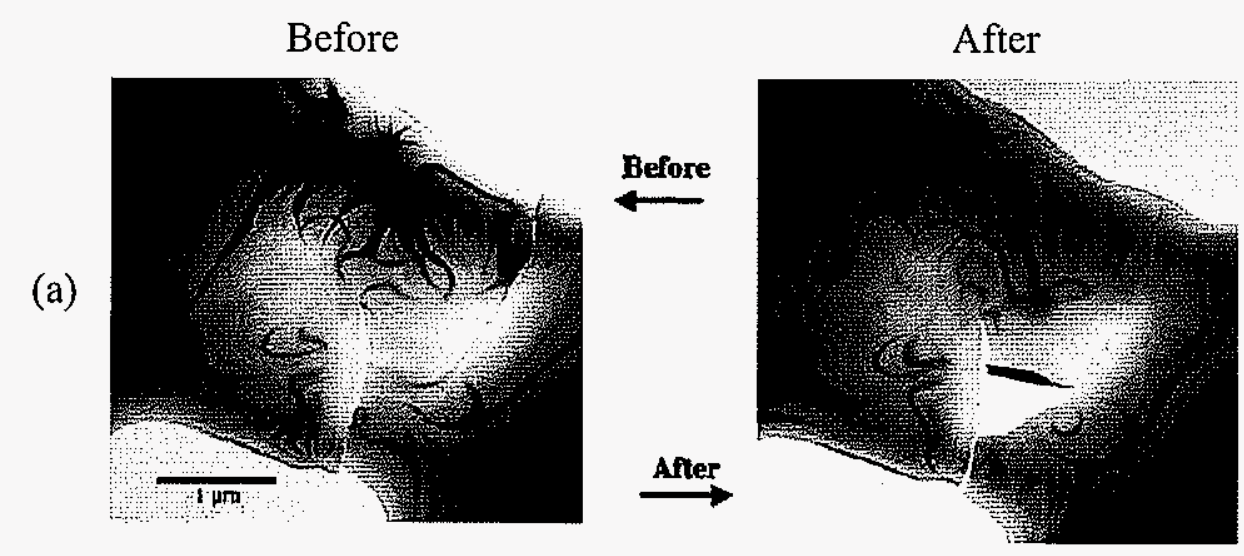

(b)
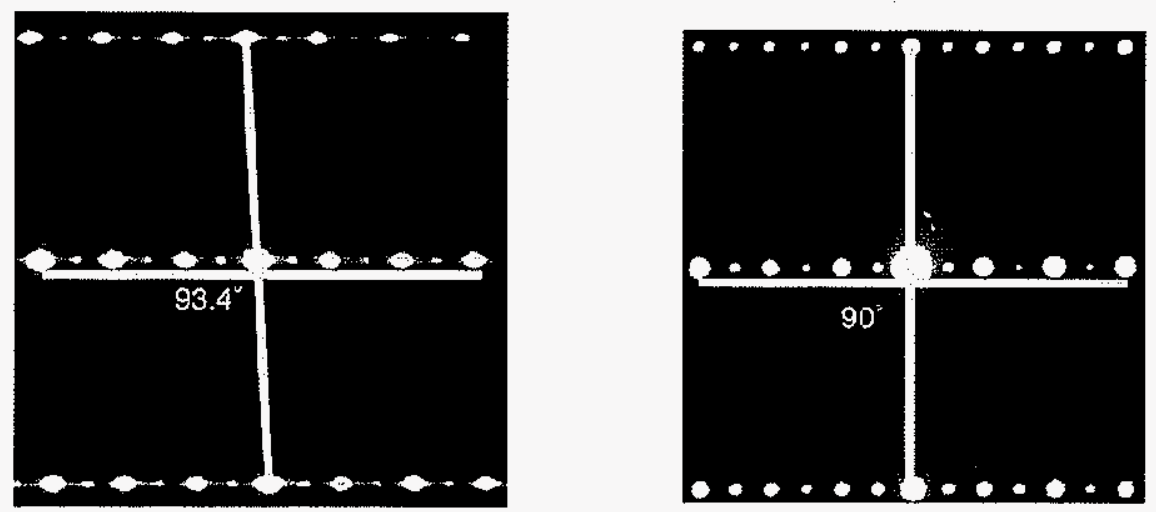

Figure 12 -- (a) Bright Field images taken before and after low temperature transformation. (b) SAD's taken from before and after low temperature transformation. [24]

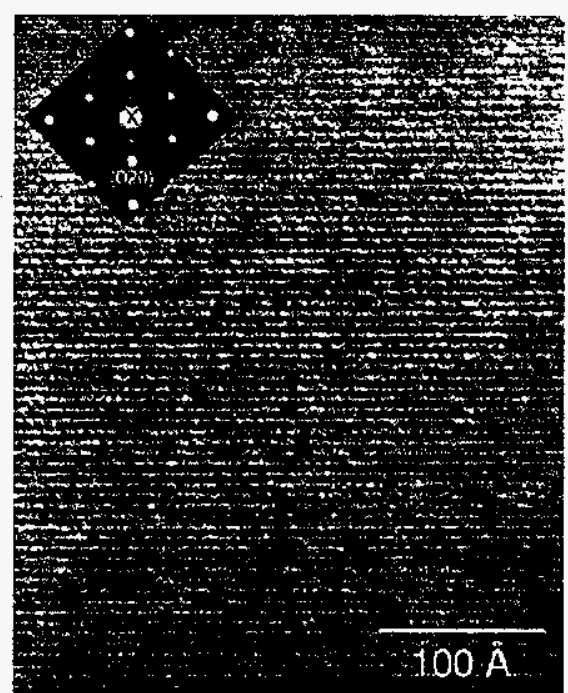

(a)

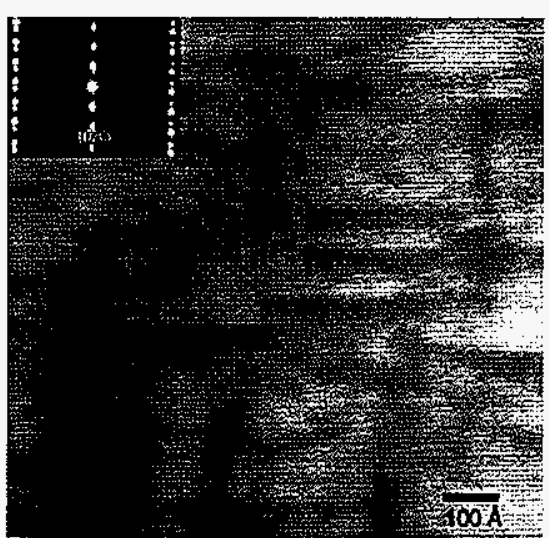

(b)

Figure 13 -- Lattice fringes shown by HRTEM bright field image, (a) on [100] (b) on [001]. [24] 


\section{Dissertation Organization}

This dissertation is written in an alternate format composed of original manuscripts, preceded with general introduction and conclusion chapters. References cited within each chapter have been placed immediately after the chapter.

The first manuscript, presented in Chapter 2, "Identification of thin plates seen in $\mathrm{R}_{5}\left(\mathrm{Si}_{\mathrm{x}} \mathrm{Ge}_{1-\mathrm{x}}\right)_{4}$ alloys, where $\mathrm{R}$ is $\mathrm{Gd}, \mathrm{Tb}, \mathrm{Dy}$, and Er," was published in Scripta Materialia in 2005. The authors were Ozan Ugurlu (graduate student and primary researcher at the Materials Science and Engineering Department of lowa State University and the Ames Laboratory of the U.S. Department of Energy (DOE)), L. Scott Chumbley (graduate advisor at the Materials Science and Engineering Department of Iowa State University and the Ames Laboratory of the U.S. Department of Energy (DOE)), Deborah L. Schlagel (supporting scientist at the Ames Laboratory of the U.S. Department of Energy (DOE)), Thomas A. Lograsso (principal scientist at the Ames Laboratory of the U.S. Department of Energy (DOE)) and Alexandra O. Tsokol (supporting scientist at the Ames Laboratory of the U.S. Department of Energy (DOE)). This manuscript reveals the existence of the linear features in all of the $\mathrm{R}_{5}\left(\mathrm{Si}_{\mathrm{x}} \mathrm{Ge}_{1-\mathrm{x}}\right)_{4}$ alloys, where $\mathrm{R}=\mathrm{Gd}, \mathrm{Tb}$, Dy and Er. Also, the EDS results show a rare-earth rich composition in all the linear features seen in different alloys.

The second manuscript, presented in Chapter 3, "Characterization of an Atypical Widmanstatten structure in $\mathrm{Gd}_{5} \mathrm{Si}_{2} \mathrm{Ge}_{2}$ alloys," was published in Acta Materialia in 2005. The authors were Ozan Ugurlu, L. Scott Chumbley, Deborah L. Schlagel and Thomas A. Lograsso. This manuscript presents the first conclusive identification of the linear features and suggests that the features might possibly be a Widmanstatten structure that forms during solidification.

The third manuscript, presented in Chapter 4, "Orientation and formation of atypical Widmanstaetten plates in the $\mathrm{Gd}_{5}\left(\mathrm{Si}_{\mathrm{x}} \mathrm{Ge}_{1-\mathrm{x}}\right)_{4}$ system," was published in Acta Materialia in 2006. The authors were Ozan Ugurlu, L. Scott Chumbley, Deborah L. Schlagel and Thomas 
A. Lograsso. This manuscript explains the reason for the growth of the thin-plates along irrational directions and proposes a possible growth mechanism.

The fourth manuscript, presented in Appendix A, "Linear microstructural features in $\mathrm{RE}_{5}(\mathrm{Si}, \mathrm{Ge})_{4}$ alloys: difficulties in identification" will be submitted to Physical Review $B$ Condensed Matter and Materials Physics in 2006. The authors are Ozan Ugurlu and L. Scott Chumbley. This manuscript highlights the difficulties encountered during the identification of the thin-plates using different techniques like XRD, EDS, magnetometer and heat capacity.

\section{References}

1. Pecharsky, V.K. and K.A. Gschneidner Jr., The Giant Magnetocaloric Effect In $\mathrm{Gd}_{5}\left(\mathrm{Si}_{x} \mathrm{Ge} \mathrm{I}_{-\mathrm{x}}\right)_{4}$ Materials for Magnetic Refrigeration. Advances in Cryogenic Engineering, 1998. 43: p. 1729 - 1736.

2. Warburg, E., Magnetische Untersuchungen. Annalen Der physik, 1881. 13: p. 141.

3. Debye, P., Einige Bemerkungen zur Mgneisierung bei tiefer Temperatur. Annalen Der physik, 1926. 81: p. 1154.

4. Giauque, W.F., A thermodynamic treatment of certain magnetic effects. A proposed method of producing temperatures considerably below 1-degree absolute. Journal of the American Chemical Society, 1927. 49: p. 1864.

5. Smith, G.S., A.G. Tharp, and Q. Johnson, Crystallographic Data on New Rare EarthGermanium and Silicon Compounds. Nature, 1966. 210: p. 1148 - 1149.

6. Smith, G.S., A.G. Tharp, and Q. Johnson, Rare earth-germanium and-silicon compounds at 5:4 and 5:3 compositions. Acta Crystallographica, 1967. 22: p. 940 943. 
7. Holtzberg, F., R.J. Gambino, and T.R. McGuire, New Ferromagnetic 5:4 compounds in the rare earth silicon and germanium. Journal of Physics and Chemistry of Solids, 1967. 28: p. 2283 - 2289.

8. Pecharsky, V.K. and K.A. Gschneidner Jr., Phase relationships and crystallography in the pseudobinary system $\mathrm{Gd}_{5} \mathrm{Si}_{4}-\mathrm{Gd}_{5} \mathrm{Ge}_{4}$. Journal of Alloys and Compounds, 1997. 260: p. $98-106$.

9. Pecharsky, V.K. and K.A. Gschneidner Jr., Giant Magnetocaloric effect in $\mathrm{Gd}_{5}\left(\mathrm{Si}_{2} \mathrm{Ge}_{2}\right)$. Physical Review Letters, 1997. 78(23): p. 4494 - 4497.

10. Pecharsky, V.K. and K.A. Gschneidner Jr., Tunable magnetic regenerator alloys with a giant magnetocaloric effect for magnetic refrigeration from $\sim 20$ to $290 \mathrm{~K}$. Applied Physics Letter, 1997. 70(24): p. 3299 - 3301.

11. Morellon, L., et al., Magnetic-field-induced structural phase transition in $G d_{5}\left(\mathrm{Si}_{1.8} G e_{2.2}\right)$. Physical Review B, 1998. 58(22): p. R14721 - R14724.

12. Morellon, L., et al., Nature of the first-order antiferromagnetic-ferromagnetic transition in the Ge-rich magnetocaloric compounds $G d_{5}\left(S i_{x} G e_{1-x}\right)_{4}$. Physical Review B, 2000. 62: p. 1022 .

13. Morellon, L., et al., Giant magnetoresistance near the magnetostructural transition in $G d_{5}\left(S i_{1.8} G e_{2.2}\right)$. Applied Physics Letters, 1998. 73(23): p. 3462.

14. Levin, E.M., V.K. Pecharsky, and K.A. Gschneidner Jr., Magnetic-field and temperature dependencies of the electrical resistance near the magnetic and crystallographic first-order phase transition of $\mathrm{Gd}_{5}\left(\mathrm{Si}_{2} \mathrm{Ge}_{2}\right)$. Physical Review B, 1999. 60(11): p. 7993.

15. Stankiewicz, J., et al., Hall effect in $G d_{5}\left(\mathrm{Si}_{1.8} G e_{2.2}\right)$. Physical Review B, 2000. 61(19): p. 12651. 
16. Levin, E.M., V.K. Pecharsky, and K.A. Gschneidner Jr., Spontenous generation of voltage in $\mathrm{Gd}_{5}\left(\mathrm{Si}_{x} \mathrm{Ge}_{4-x}\right)$ during a first-order phase transition induced by temperature or magnetic field. 2001.

17. Morellon, L., et al., Giant magnetoresistance in the Ge-rich magnetocaloric compound, $G d_{5}\left(S i_{0.1} G e_{0.9}\right)_{4}$. Journal of Magnetism and Magnetic Materials, 2001. 237: p. $119-123$.

18. Gschneidner Jr., K.A. and V.K. Pecharsky, The nonpareil $R_{5}\left(\mathrm{Si}_{x} G e_{I_{-x}}\right)_{4}$ phases. Journal of Alloys and Compounds, 2000. 303 - 304: p. 214 - 222.

19. Pecharsky, V.K. and J. Gschneidner K.A., Gd5(SixGe1-x)4: An extremum material. Advanced Materials, 2001. 13(9): p. 683-686.

20. Choe, W., et al., Making and breaking covalent bonds across the magnetic transition in the giant magnetocaloric material $\mathrm{Gd}_{5}\left(\mathrm{Si}_{2} \mathrm{Ge}_{2}\right)$. Physical Review Letters, 2000. 84(20): p. 4617.

21. Pecharsky, A.O., K.A. Gschneidner Jr., and V.K. Pecharsky. Uncovering the structure-property relationships in $R_{5}\left(\mathrm{Si}_{x} G e_{4-x}\right)$ intermetallic phases. in Rare Earths 2001, Oct 7 2002. 2002. Sao Paulo, Brazil: Elsevier Science Ltd.

22. Szade, J., G.Skorek, and A. Winiarski, Surface structure of $\mathrm{G} d_{5}(\mathrm{Si}, \mathrm{Ge})_{4}$ crystals. Journal of Crystal Growth, 1999. 205: p. 289 - 293.

23. Meyers, J.S., et al., Determination of phases in as prepared $G d_{5}\left(S i_{x} G e_{I_{-x}}\right)_{4}$ where $x=$ 1/2. Scripta Materialia, 2002. 47: p. 509 - 514.

24. Meyers, J.S., et al., TEM analysis of $G d_{5}\left(\mathrm{Si}_{x} G e_{1-x}\right)_{4}$, where $x=1 / 2$. Acta Materialia, 2003. 51(1): p. 61-70.

25. Verhoven, J.D., Fundamentals of Physical Metallurgy. 1975, John Wiley \& Sons, Inc. p. 376-377. 


\title{
CHAPTER 2: IDENTIFICATION OF THIN PLATES SEEN IN $\mathrm{R}_{5}\left(\mathrm{Si}_{\mathrm{x}} \mathrm{Ge}_{1-\mathrm{x}}\right)_{4}$ ALLOYS, WHERE R IS Gd, Tb, Dy, AND Er
}

\author{
A paper published in Scripta Materialia ${ }^{I}$ \\ O. Ugurlu $^{2,3}$, L.S. Chumbley ${ }^{2,3}$, D. L. Schlagel ${ }^{3}$, T.A. Lograsso ${ }^{3}$, and A.O.Tsokol ${ }^{3}$
}

\begin{abstract}
$\mathrm{R}_{5}\left(\mathrm{Si}_{\mathrm{x}} \mathrm{Ge}_{1-\mathrm{x}}\right)_{4}$ alloys, where $\mathrm{R}$ is $\mathrm{Tb}$, Dy, and $\mathrm{Er}$, have been examined. Their microstructures consisted of large grains with thin plates of a second phase. Energy Dispersive Spectrometry (EDS) of the plates revealed a rare-earth rich composition. It is proposed that the plates are $\mathrm{R}_{5}\left(\mathrm{Si}_{\mathrm{x}} \mathrm{Ge}_{1-\mathrm{x}}\right)_{3}$ compounds, similar to results seen in $\mathrm{Gd}_{5}\left(\mathrm{Si}_{\mathrm{x}} \mathrm{Ge}_{1-\mathrm{x}}\right)_{4}$.
\end{abstract}

\section{Introduction}

The $\mathrm{R}_{5} \mathrm{Si}_{4}$ and $\mathrm{R}_{5} \mathrm{Ge}_{4}$ intermetallic phases, where $\mathrm{R}=$ rare earth metal, were discovered in 1967 [1]. Three single-phase regions exist in the pseoudo-binary system formed by $\mathrm{Gd}_{5} \mathrm{Si}_{4}$ and $\mathrm{Gd}_{5} \mathrm{Ge}_{4}$ [2], two solid solutions based on the $\mathrm{Gd}_{5} \mathrm{Si}_{4}$ and $\mathrm{Gd}_{5} \mathrm{Ge}_{4}$ orthorhombic structures, and a third phase intermediate between the two identified as $\mathrm{Gd}_{5}\left(\mathrm{Si}_{0.5} \mathrm{Ge}_{0.5}\right)_{4}$ and having a monoclinic crystal structure[3]. After the discovery of the magnetocaloric effect (MCE) in $\mathrm{Gd}_{5}\left(\mathrm{Si}_{0.5} \mathrm{Ge}_{0.5}\right)_{4}$ [3], more detailed study was directed toward

\footnotetext{
${ }^{1}$ Reprinted with permission of Scripta Materialia, 2005, 53, 373-377

${ }^{2}$ Department of Materials Science and Engineering, lowa State University, Ames IA 5001 1-3020 USA

${ }^{3}$ Ames Laboratory (DOE), lowa State University, Ames IA 50011-3020, USA
} 
these compounds as well as other 5:4 compounds in the lanthanide series [4-7]. The crystal structures and phase transitions of a number of these compounds have been explored [8]. In general all the $\mathrm{R}_{5}\left(\mathrm{Si}_{\mathrm{x}} \mathrm{Ge}_{1-\mathrm{x}}\right)_{4}$ compounds possess similar crystal lattices where differences in atomic bonding can produce either one of two orthorhombic structures or a monoclinic structure [8].

While the structures are known, the properties associated with these alloys have been studied to a lesser extent. Also, relatively unknown is the microstructure of these alloys, which has only been examined by a few researchers. The first microstructure examination of $\mathrm{Gd}_{5}\left(\mathrm{Si}_{\mathbf{x}} \mathrm{Ge}_{1-\mathrm{x}}\right)_{4}$ alloys studied the surface structure of grown single crystals [9]. A regular system of lines was noted on the surface of the single crystalline plates. Auger electron microscopy (AES) showed a decrease in germanium and silicon and an increase in gadolinium and oxygen amounts on the lines as compared to the matrix. A subsequent study on the microstructure of $\mathrm{Gd}_{5}\left(\mathrm{Si}_{\mathrm{x}} \mathrm{Ge}_{1-\mathrm{x}}\right)_{4}$ alloys [10] using induction and arc-melted samples examined the bulk structure with scanning electron microscopy (SEM) and confirmed the linear features reported previously [9]. Energy dispersive spectroscopy (EDS) studies showed an increase in gadolinium and oxygen and a decrease in only $\mathrm{Si}$, as opposed to the drop seen in both germanium and silicon in [9]. A recent study using SEM [11], showed that the linear features in $\mathrm{Gd}_{5}\left(\mathrm{Si}_{\mathrm{x}} \mathrm{Ge}_{1-\mathrm{x}}\right)_{4}$ alloys are plates, not rods as suggested in [10]. The crystal structure of the plates was determined as hexagonal and their composition measured more accurately employing selected area diffraction (SAD) and EDS in the transmission electron microscope (TEM). This study conclusively showed that the plates were a second phase with a composition near $\mathrm{Gd}_{5} \mathrm{Si}_{1} \mathrm{Ge}_{2}$.

Until now studies on the microstructure of $\mathrm{R}_{5}\left(\mathrm{Si}_{\mathrm{x}} \mathrm{Ge}_{1-\mathrm{x}}\right)_{4}$ alloys have all concentrated on the Gd rare earth based alloys. The aim of this paper is to extend microstructural characterization studies of the 5:4 lanthanides to a wider range of elements and alloys, specifically, compounds in the Tb, Dy, and Er systems. 


\section{Experimental Details}

Seven $\mathrm{R}_{5}\left(\mathrm{Si}_{\mathrm{x}} \mathrm{Ge}_{1-\mathrm{x}}\right)_{4}$ samples were prepared by arc-melting, where $\mathrm{R}$ is $\mathrm{Gd}, \mathrm{Tb}, \mathrm{Dy}$ and Er. Compositions were chosen to cover the range from the Ge-rich $\mathrm{Sm}_{5} \mathrm{Ge}_{4}$-type orthorhombic through the intermediate $\mathrm{Gd}_{5} \mathrm{Si}_{2} \mathrm{Ge}_{2}$-type monoclinic to the Si-rich $\mathrm{Gd}_{5} \mathrm{Si}_{4}$-type orthorhombic structures. Table I shows the compositions of the alloys used in this study. The room temperature crystal structure types adopted by all alloys studied are included in Table I.

Table I -- Alloys used in this study and their crystal structures. The crystal structure type is shown in italics.

\begin{tabular}{cc}
\hline Sample & Crystal Structure \\
\hline $\mathrm{Gd}_{5} \mathrm{Si}_{4}$ & $G d_{5} \mathrm{Si}_{4}$ \\
& Orthorhombic \\
$\mathrm{Gd}_{5} \mathrm{Ge}_{4}$ & $S m_{5} G e_{4}$ \\
& Orthorhombic \\
& $G d_{5} \mathrm{Si}_{2} G e_{2}$ \\
$\mathrm{Gd}_{5} \mathrm{Si}_{2} \mathrm{Ge}_{2}$ & Monoclinic \\
& $G d_{5} \mathrm{Si}_{4}$ \\
$\mathrm{Dy}_{5} \mathrm{Si}_{4}$ & Orthorhombic \\
& $S m_{5} G e_{4}$ \\
$\mathrm{Dy}_{5} \mathrm{Si}_{2.5} \mathrm{Ge}_{1.5}$ & Orthorhombic \\
& $G d_{5} S_{2} G e_{2}$ \\
$\mathrm{Dy}_{5} \mathrm{Si}_{3.0} \mathrm{Ge}_{1.0}$ & Monoclinic \\
& $G d_{5} \mathrm{Si}_{4}$ \\
$\mathrm{~Tb}_{5} \mathrm{Si}_{4}$ & Orthorhombic \\
& $S m_{5} \mathrm{Ge}_{4}$ \\
$\mathrm{~Tb}_{5} \mathrm{Ge}_{4}$ & Orthorhombic \\
& $G d_{5} \mathrm{Si}_{2} G e_{2}$ \\
$\mathrm{~Tb}_{5} \mathrm{Si}_{2.25} \mathrm{Ge}_{1.75}$ & Monoclinic \\
$\mathrm{Er}_{5} \mathrm{Si}_{4}$ & $G d_{5} \mathrm{Si}_{4}$ \\
& Orthorhombic \\
\hline
\end{tabular}

Gd, Dy, Tb and Er metals of 99.99 wt.\% purity were prepared by the Material Preparation Center of the Ames Laboratory. The major impurities were (in wt. ppm) $\mathrm{O}<20$, $\mathrm{C}<10, \mathrm{~N}<1, \mathrm{Fe}<4, \mathrm{~F}<0.9$. Si of 99.9999 wt.\% and Ge of 99.999 wt.\% purity were purchased from commercial vendors. For each alloy, the stoichiometric mixture of the 
components was arc-melted six times, flipping the button each time, to ensure homogeneity. The weight of each alloy did not exceed $20 \mathrm{~g}$, which provided fast cooling of the buttons. Xray powder diffraction was used for the alloy purity determination, and full profile Rietveld technique was used for crystal structure refinement. According to the x-ray data, all of the arc-melted Dy and Er alloys contained a second phase of about $2 \mathrm{wt} . \%$. For the Tb alloys, all of the arc-melted phases appeared by $\mathrm{x}$-ray to be single phase materials.

Examination of all specimens was carried out using SEM equipped with EDS. The arc-melted specimens were first polished and then ion-sputtered to slightly etch the surface and reveal any linear features that may be present. Cold stage ion-sputtering was used to prevent any phase change due to heating of the specimen. The single crystal sample was examined in the as-polished condition with back-scattered electron imaging using SEM. All the alloys were examined in the as-cast state, i.e. no heat treatments were done to the samples.

\section{Results}

Random surfaces of the $\mathrm{R}_{5}\left(\mathrm{Si}_{1-\mathrm{x}} \mathrm{Ge}_{\mathrm{x}}\right)_{4}$ arc melted polycrystalline samples with the Gd, $\mathrm{Tb}, \mathrm{Dy}$, and Er lanthanides were examined and the results are shown in Figure 1. Thin plates were prevalent in all samples, although they were more evident in the Gd, $\mathrm{Tb}$ and $\mathrm{Er}$ lanthanides as compared to alloys with Dy.

The micrographs also show that the second phase exists in all alloys independent of whether the matrix is orthorhombic (either $\mathrm{Sm}_{5} \mathrm{Ge}_{4}$ or $\mathrm{Gd}_{5} \mathrm{Si}_{4}$ - type) or monoclinic. However, the features are crystallographically related to the matrix crystal structure as illustrated in Figure 1 (j) where two grains and a grain boundary can be observed easily with the plates aligned in fixed directions within each grain. The size of the plates varies with alloy and viewing direction, but in general they all maintain a high length to width aspect 

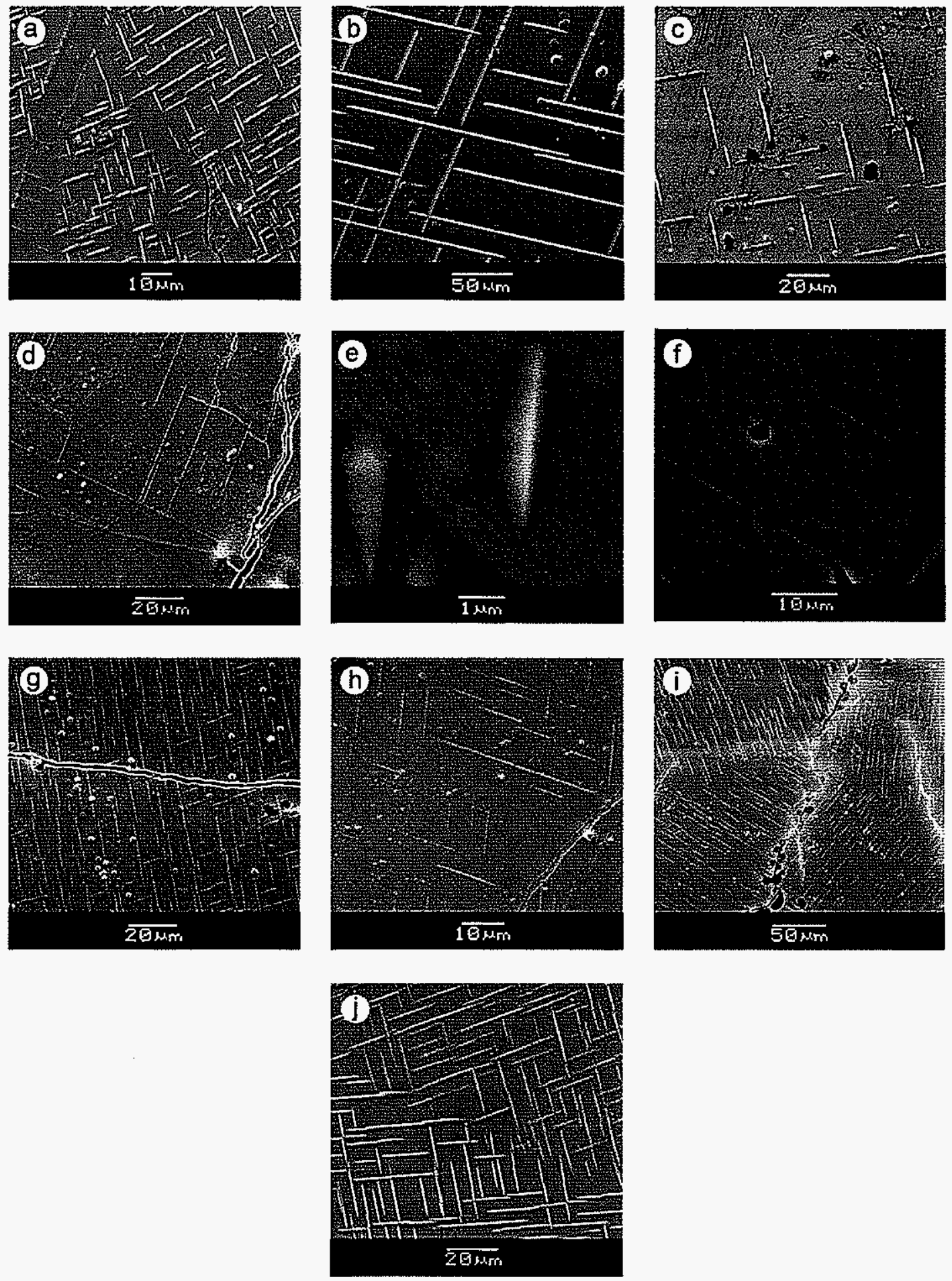

Figure 1. -- SEM micrographs of (a) $\mathrm{Gd}_{5} \mathrm{Si}_{4}$, (b) $\mathrm{Gd}_{5} \mathrm{Ge}_{4}$, (c) $\mathrm{Gd}_{5} \mathrm{Si}_{2} \mathrm{Ge}_{2}$, (d) $\mathrm{Dy}_{5} \mathrm{Si}_{4}$, (e) $\mathrm{Dy}_{5} \mathrm{Si}_{2.5} \mathrm{Ge}_{1.5}$, (f) $\mathrm{Dy}_{5} \mathrm{Si}_{3.0} \mathrm{Ge}_{1.0}$, (g) $\mathrm{Tb}_{5} \mathrm{Si}_{4}$, (h) $\mathrm{Tb}_{5} \mathrm{Ge}_{4}$, (i) $\mathrm{Tb}_{5} \mathrm{Si}_{2.25} \mathrm{Ge}_{1.75}$, (j) $\mathrm{Er}_{5} \mathrm{Si}_{4}$ 
ratio with the average width being on the order of a few microns maximum.

EDS studies have been done in an attempt to determine the composition of the plates of the other lanthanide series (Tb, Dy and Er) and the results are shown in Table II. Surface oxidation is prevalent in these alloys due to the high rare earth content. Therefore, EDS results neglecting oxygen are initially shown in Table II, and these values are expected to be a more accurate measurement of the composition of the bulk alloy. Previous studies [11] have pointed out that the small scale of the features and the large interaction area of the SEM probe prohibits accurate EDS analysis from being carried out using SEM. Thus, the results in Table II should not be taken as representing an accurate value for the true composition of the plates. However, the relative changes in bulk composition when compared to data obtained from the matrix are meaningful. The values obtained when oxygen is neglected in the calculation show a consistent shift in composition from the $\mathrm{R}_{5}(\mathrm{Si}, \mathrm{Ge})_{4}$ compound to a composition enriched in the rare earth and decreased in $\mathrm{Si}$ and Ge. When taking oxygen into account, the thin plates show a slight increase in oxygen over the matrix.

A limited amount of TEM analysis has been carried out on samples prepared from the arc-melted buttons of $\mathrm{Er}_{5} \mathrm{Si}_{4}$, Figure 2. Tilting experiments and indexed $\mathrm{SAD}$ patterns, taken from [0001] and [1-216], confirmed the second phase as hexagonal with lattice parameters $\mathrm{a}=8.22 \mathrm{~A}$ and $\mathrm{c}=6.29 \mathrm{~A}$.

\section{Discussion}

Ugurlu et al. [11] have shown that the thin plates in $\mathrm{Gd}_{5} \mathrm{Si}_{2} \mathrm{Ge}_{2}$ system have a composition of $\mathrm{Gd}_{5}(\mathrm{Si}, \mathrm{Ge})_{3}$ using EDS in the TEM. Phase diagrams of both $\mathrm{Gd}_{5} \mathrm{Si}_{4}$ (Figure 3a) and $\mathrm{Gd}_{5} \mathrm{Ge}_{4}$ (Figure 3b) alloys show that the $\mathrm{Gd}_{5} \mathrm{Si}_{3}$ and $\mathrm{Gd}_{5} \mathrm{Ge}_{3}$ phases are line compounds in these binary systems. Similarly, 5:3 phases exist in all the other lanthanide systems (Tb, Dy and Er [12]) examined in this study. Although the EDS results using SEM 
Table II -- Composition of the second phase as compared to the matrix phase, with and without oxygen. Note that the second phase is consistently slightly enriched in oxygen as compared to the matrix (Numbers in parentheses indicates the Std. deviation)

\begin{tabular}{llllll}
\hline \multirow{2}{*}{ Sample } & \multicolumn{3}{c}{ Matrix (at\%) } & \multicolumn{2}{c}{ Second Phase (at\%) } \\
\cline { 2 - 6 } & & w/o Oxygen & w Oxygen & w/o Oxygen & w Oxygen \\
\hline \multirow{2}{*}{$\mathrm{Tb}_{5} \mathrm{Si}_{2.25} \mathrm{Ge}_{1.75}$} & $\mathrm{~Tb}$ & $55.6(0.1)$ & $53.6(0.3)$ & $57.0(0.3)$ & $54.2(0.3)$ \\
& $\mathrm{Ge}$ & $25.2(0.2)$ & $23.0(0.3)$ & $24.1(0.4)$ & $21.6(0.5)$ \\
& $O$ & $19.2(0.3)$ & $19.3(0.4)$ & $18.9(0.4)$ & $18.8(0.5)$ \\
& $\mathrm{Dy}$ & $55.6(0.4)$ & $57.4(0.7)$ & & $5.1(0.5)$ \\
\hline \multirow{2}{*}{$\mathrm{Dy}_{5} \mathrm{Si}_{2.5} \mathrm{Ge}_{1.5}$} & $\mathrm{Si}$ & $27.9(0.7)$ & $28.4(0.3)$ & $56.8(0.7)$ & $57.6(0.4)$ \\
& $\mathrm{Ge}$ & $16.5(0.6)$ & $11.3(0.2)$ & $16.9(0.2)$ & $26.6(0.5)$ \\
& $O$ & & $3.5(0.5)$ & $11.4(0.6)$ \\
& $\mathrm{Er}$ & $55.6(0.1)$ & $55.3(0.2)$ & $57.2(0.4)$ & $56.6(0.5)$ \\
$\mathrm{Er}_{5} \mathrm{Si}_{4}$ & $\mathrm{Si}$ & $44.4(0.1)$ & $40.0(0.2)$ & $42.8(0.4)$ & $38.6(0.8)$ \\
& $O$ & & $4.6(0.3)$ & & $4.8(0.9)$ \\
\hline \multirow{4}{*}{$\mathrm{Gd}_{5} \mathrm{Si}_{2} \mathrm{Ge}_{2}$} & $\mathrm{Gd}$ & $55.9(0.1)$ & $52.7(0.3)$ & $58.1(0.3)$ & $52.7(0.4)$ \\
& $\mathrm{Si}$ & $22.2(0.3)$ & $19.8(0.5)$ & $19.4(0.3)$ & $22.4(0.6)$ \\
& $\mathrm{Ge}$ & $21.9(0.2)$ & $21.8(0.4)$ & $22.5(0.3)$ & $16.2(0.5)$ \\
& $O$ & & $5.7(0.5)$ & & $8.8(0.8)$ \\
\hline
\end{tabular}

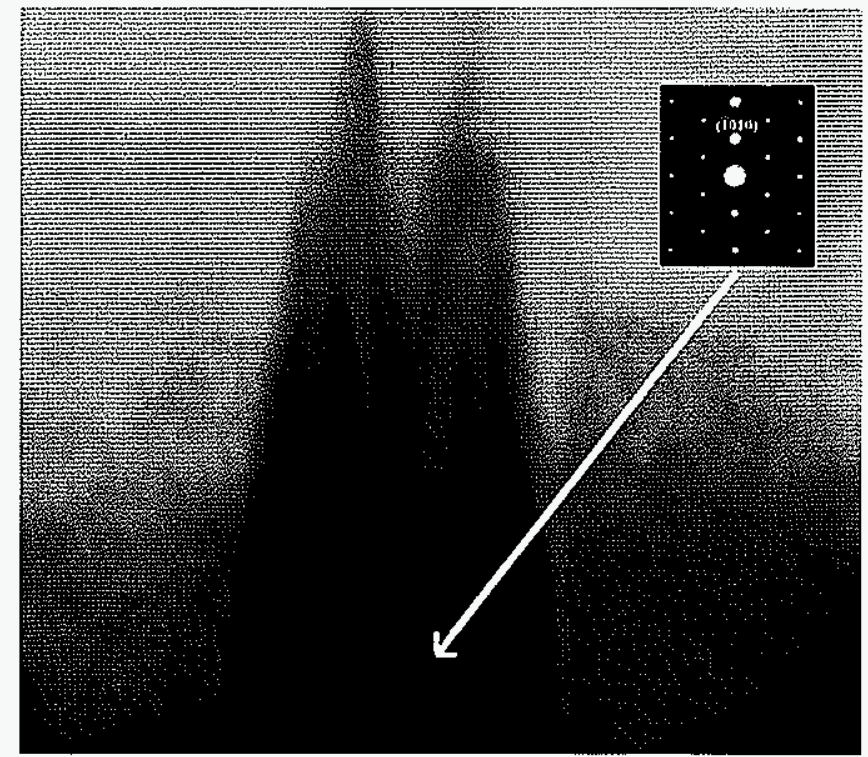

Figure 2 -- Bright field TEM micrograph and the [0001] SAD pattern of a thin-plate in a $\mathrm{Er}_{5} \mathrm{Si}_{4}$ sample 
are not accurate, all results indicate the plates are becoming enriched in the rare earth, as if the plates are moving from a stoichiometric $5: 4$ towards the $\mathrm{R}_{5}(\mathrm{Si}, \mathrm{Ge})_{3}[\mathrm{R}=62.5$ at $\%$, $(\mathrm{Si}, \mathrm{Ge})=37.5$ at $\%]$ phase. If one compares the $\mathrm{SEM}$ results obtained from a $\mathrm{Gd}_{5} \mathrm{Si}_{2} \mathrm{Ge}_{2}$ alloy, where the plates have conclusively been identified using TEM as being $\mathrm{Gd}_{5}(\mathrm{Si}, \mathrm{Ge})_{3}[11]$, to the results of this study (Table II), the measured values show the same trends. This suggests that the second phases noted in all samples in Figure 1 are $\mathrm{R}_{5}(\mathrm{Si}, \mathrm{Ge})_{3}$ type compounds. This hypothesis is confirmed in the case of $\mathrm{Er}_{5} \mathrm{Si}_{4}$ by the TEM data of this study, where the determined crystal structure and lattice parameters match well with the reported values for
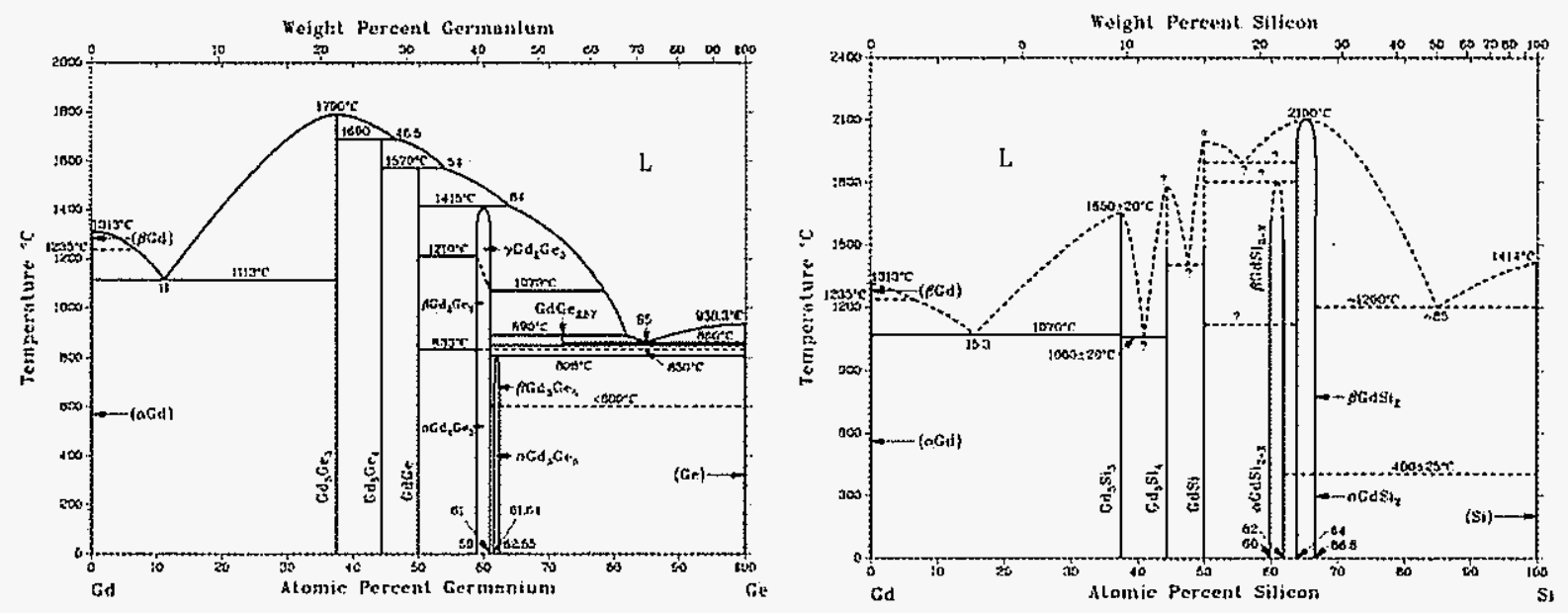

$\mathrm{Er}_{5} \mathrm{Si}_{3}$ of $\mathrm{a}=8.325 \mathrm{~A}$ and $\mathrm{c}=6.259 \mathrm{~A}[13]$.

(a)

(b)

Figure 3 -- Binary phase diagrams of (a) Gd-Ge and (b) Gd-Si [12]

The measured lattice parameters for the Gd [11] and Er 5:3 phases match extremely well with published values. Thus, it is unlikely that oxygen is being incorporated into the structure to any significant degree suggesting that the oxygen detected using SEM and shown in Table II is due to the thin oxide layer present on the surface. All the samples examined are susceptible to oxidation due to their rare earth content. The slightly higher oxygen levels on 
the $5: 3$ second phase relative to the $5: 4$ matrix phase may be due to the higher rare earth content of the $5: 3$ phase as compared to $5: 4$.

Crystallographic alignment of the linear features suggests a formation mechanism similar to a Widmanstatten-type structure, which forms via a solid-state reaction from a supersaturated solid solution. However, all the phase diagrams show the 5:4 compounds as being line compounds, which means that the required supersaturation for the Widmanstatten structure is missing. This might be an indication of a solid solubility at high temperatures that is not shown on any of the current phase diagrams. The fact that all alloys studied exhibit the same general shape and alignment of the second phase also suggests formation in a common high-temperature crystallographic structure.

The presence of plates of $\mathrm{R}_{5}(\mathrm{Si}, \mathrm{Ge})_{3}$ in all of the alloys studied, their large dimensions in certain directions, and their appearance in the as-arc-melted state suggests that formation of this phase is extremely rapid and energetically favorable. Diffusion must be occurring in order to produce the shift in composition from 5:4 to 5:3; however, the speed at

which the $\mathrm{R}_{5}(\mathrm{Si}, \mathrm{Ge})_{3}$ phases must form is truly remarkable given the rapid cooling present in the buttons. This would indicate that a favorable structural relationship must exist between the parent matrix and the precipitate in order for such rapid and widespread growth to occur in all these rare earth compounds. It is possible that another factor is assisting in the formation of these large plates, such as a strain induced driving force similar to what is present in the formation of bainite in steels.

\section{Conclusion}

This study showed that the linear second phase in $\mathrm{Gd}_{5}\left(\mathrm{Si}_{\mathrm{x}}, \mathrm{Ge}_{1-\mathrm{x}}\right)_{4}$, noted by previously $[9,10]$, and identified in $\mathrm{Gd}_{5}(\mathrm{Si}, \mathrm{Ge})_{4}$ by Ugurlu et al. exists in many 5:4 lanthanide compounds ( $\mathrm{Gd}, \mathrm{Tb}, \mathrm{Dy}, \mathrm{Er}$ ), independent of the specific crystal structure. In the case of $\mathrm{Er}_{5} \mathrm{Si}_{4}$ it was confirmed that the second phase is $\mathrm{Er}_{5} \mathrm{Si}_{3}$, with an hexagonal crystal 
structure and lattice parameters similar to the $\mathrm{Gd}_{5}(\mathrm{Si}, \mathrm{Ge})_{3}$ compound identified in [11]. EDS results show that the second phase plates seen in the $\mathrm{Tb}$ and Dy alloys studied are enriched in the rare earth as compared to the matrix, similar to what is seen in the Gd and Er systems. It is hypothesized that the thin plates forming in specific crystallographic directions in these $\mathrm{R}_{5}\left(\mathrm{Si}_{\mathrm{x}} \mathrm{Ge}_{1-\mathrm{x}}\right)_{4}$ alloys are also 5:3 compounds.

\section{Acknowledgements}

This work was preformed at Ames Laboratory under contract No. W-7405-Eng-82 with the US Department of Energy. This research was supported by the Office of Basic Energy Sciences, Materials Science Division of the US DOE. The authors wish to thank V.K. Pecharsky for helpful discussions in the preparation of this manuscript.

\section{References}

1. Smith GS, Johnson Q, Tharp AG. Crystal structure of Sm5Ge4. Acta Crystall 1967;22:269-72.

2. Holtzberg F, Gambino RJ, McGuire TR. New Ferromagnetic 5:4 compounds in the rare earth silicon and germanium. J Phys Chem Solids 1967;28:2283-9.

3. Pecharsky VK, Gschneidner Jr KA. Giant Magnetocaloric effect in Gd5(Si2Ge2). Phys Rev Lett 1997;78(23):4494-7.

4. Morellon L, Magen C, Algarabel PA, Ibarra MR, Ritter C. Magnetocaloric effect in Tb5(SixGe1_x)4. Appl Phys Lett 2001;79(9):1318.

5. Ritter C, Morellon L, Algarabel PA, Magen C, Ibarra MR. Magnetic and structural phase diagram of Tb5(SixGe1_x)4. Phys Rev B 2002;65(1-8):094405.

6. Ivtchenko VV, Pecharsky VK, Gschneidner Jr KA. Magnetothermal properties of Dy5(SixGe1_x)4 alloys. Adv Cryogenic Eng 1999;46A:405-12. 
7. Pecharsky AO, Gschneidner Jr KA, Schlagel DL, Lograsso TA. Phase relationships, structural, magnetic, and thermodynamic properties of alloys in the pseudobinary Er5Si4-Er5Ge4 systems. Phys Rev B, in press.

8. Gschneidner Jr KA, Pecharsky VK, Pecharsky AO, Ivtchenko VV, Levin EM. The nonpareil R5(SixGe1_x)4 phases. J Alloys Compd 2000;303-304:214-22.

9. Szade J, Skorek G, Winiarski A. Surface structure of $\mathrm{Gd} 5(\mathrm{Si}, \mathrm{Ge}) 4$ crystals. J Cryst Growth 1999;205:289-93.

10. Meyers JS, Chumbley LS, Laabs F, Pecharsky AO. Determination of phases in as prepared Gd5(SixGe1_x 4 where $\mathrm{x}=1 / 2$. Scripta Mater 2002;47:509-14.

11. Ugurlu O, Chumbley LS, Lograsso TA, Schlagel DL. Characterization of an atypical Widmanstatten structure in $\mathrm{Gd} 5 \mathrm{Si} 3 \mathrm{Ge} 2$ alloys. Acta Mater, in press.

12. Massalski TB. 2nd ed. Binary alloy phase diagrams, vol. 2. Materials Park, OH: ASM International; 1990.

13. Sharey A, Jones DW, McColm IJ, Syeadman R. The reaction of carbon with rare earth silicides 1: the system $\mathrm{Er}_{5} \mathrm{Si}_{3}-\mathrm{C}$. J Less-Common Met 1982;85:233-45. 


\title{
CHAPTER 3: CHARACTERIZATION OF AN ATYPICAL WIDMANSTATTEN STRUCTURE IN Gd $\mathrm{Si}_{2} \mathrm{Ge}_{2}$ ALLOYS
}

\author{
A paper published in Acta Materialia ${ }^{4}$ \\ O. Ugurlu, ${ }^{5,6}$, L.S. Chumbley ${ }^{2,3}$, D. L. Schlagel ${ }^{3}$, and T.A. Lograsso ${ }^{3}$
}

\begin{abstract}
Bulk microstructures of $\mathrm{Gd}_{5} \mathrm{Si}_{2} \mathrm{Ge}_{2}$ alloys have been examined using scanning electron microscopy (SEM) and transmission electron microscopy (TEM). The microstructure of all samples showed existence of long linear features. The features in general are on the order of one micron or less in width and may be hundreds of microns in length. Oriented single crystals of $\mathrm{Gd}_{5} \mathrm{Si}_{2} \mathrm{Ge}_{2}$ have been used to study the crystal orientation of the linear features by using a combination of back-reflection Laue x-ray diffraction, SEM and TEM. It has been shown that these linear features grow as thin plates oriented in specific directions. Systematic Energy Dispersive Spectrometry (EDS) and selected area diffraction (SAD) studies revealed that these thin plates have an hexagonal crystal structure and a composition consistent with $\mathrm{Gd}_{5}\left(\mathrm{Si}_{\mathrm{x}} \mathrm{Ge}_{1-\mathrm{x}}\right)_{3}$. These results present the first conclusive identification of this phase and confirm an earlier study that suggested the features might possibly be a Widmanstätten structure that forms during the solidification.

\footnotetext{
${ }^{4}$ Reprinted with permission of Scripta Materialia, 2005, 53, 373-377

${ }^{5}$ Department of Materials Science and Engineering, Iowa State University, Ames IA 50011-3020 USA

${ }^{6}$ Ames Laboratory (DOE), lowa State University, Ames IA 50011-3020, USA
} 


\section{Introduction}

$\mathrm{R}_{5} \mathrm{Ge}_{4}$ and $\mathrm{R}_{5} \mathrm{Si}_{4}$ are intermetallic compounds containing rare earth metals where $\mathrm{R}$ is any of a number of lanthanide elements. They were initially reported by Smith et al. [1], who pointed out that both the $\mathrm{R}_{5} \mathrm{Si}_{4}$ phase with $\mathrm{R}=\mathrm{Sm}, \mathrm{Gd}, \mathrm{Tb}, \mathrm{Dy}, \mathrm{Er}$, and $\mathrm{Y}$, and the $\mathrm{R}_{5} \mathrm{Ge}_{4}(\mathrm{R}=\mathrm{La}, \mathrm{Ce}, \mathrm{Pr}, \mathrm{Nd}, \mathrm{Sm}, \mathrm{Gd}, \mathrm{Tb}, \mathrm{Dy}, \mathrm{Ho}, \mathrm{Er}, \mathrm{Tm}, \mathrm{Lu}$, and $\mathrm{Y})$ alloys crystallize in the $\mathrm{Sm}_{5} \mathrm{Ge}_{4}$-type orthorhombic structure [2]. Holtzberg et al. [3] confirmed the x-ray data collected by Smith et al. and also found an intermediate phase, $\mathrm{Gd}_{5} \mathrm{Si}_{2} \mathrm{Ge}_{2}$, with unknown crystal structure. In 1997, Pecharsky and Gschneidner [4] showed that this phase has a monoclinic structure at room temperature and that $\mathrm{R}_{5} \mathrm{Si}_{4}$ and $\mathrm{R}_{5} \mathrm{Ge}_{4}$ have different orthorhombic structures. They also discovered a first order phase transition in $\mathrm{Gd}_{5} \mathrm{Si}_{2} \mathrm{Ge}_{2}$. It was determined that the first order transition could be triggered by a magnetic field, producing a giant magnetocaloric effect (MCE), which is at least two times greater than any known magnetic material [5]. Choe et al. subsequently reported that the MCE in $\mathrm{Gd}_{5}\left(\mathrm{Si}_{x} \mathrm{Ge}_{1}\right.$. x) 4 resulted from a single first-order structural transition from a monoclinic (paramagnetic) to an orthorhombic (ferromagnetic) structure upon cooling [6]. Further studies by Pecharsky and Gschneidner [7] have shown that the transition temperature is tunable to between $\sim 210 \mathrm{~K}$ and $\sim 276 \mathrm{~K}$ by adjusting the Si:Ge ratio without losing the giant magnetocaloric effect for the room temperature monoclinic alloys. Recent studies showed that the homogeneity of the $\mathrm{Gd}_{5}\left(\mathrm{Si}_{\mathrm{x}} \mathrm{Ge}_{1-\mathrm{x}}\right)_{4}$ alloys may be improved by heat treating at $1300^{\circ} \mathrm{C}$ for one hour, which increases the $\mathrm{MCE}$ for about two times[8, 9]. The newly reported $\mathrm{Gd}_{5}\left(\mathrm{Si}_{\mathbf{x}} \mathrm{Ge}_{1-\mathrm{x}}\right)_{4}$ phase diagram [10] is in excellent agreement with earlier results [4].

The discovery of the giant magnetocaloric effect in the $\mathrm{Gd}_{5}\left(\mathrm{Si}_{\mathrm{x}} \mathrm{Ge}_{1-\mathrm{x}}\right)_{4}$ pseudobinary alloys started intensive research on the crystal structures and phase transitions of these rare earth materials. While the crystallographic nature and many physical properties are known, the microstructures associated with these alloys have been studied to a much lesser extent, which has only been examined by a few researchers. 
The microstructures of $\mathrm{Gd}_{5}\left(\mathrm{Si}_{\mathrm{x}} \mathrm{Ge}_{1-\mathrm{x}}\right)_{4}$ alloys were first examined by Szade et al. [11] who studied the surface structure of grown single crystals. They reported that the surface of the single crystalline plates show a regular system of lines and an increase of gadolinium and oxygen was observed in these linear features using Auger Electron Microscopy (AES). The authors determined that the lines were not grain boundaries, nor were they parallel to any crystallographic directions with low indexes. A later study by Meyers et al. [12] of induction and arc-melted $\mathrm{Gd}_{5} \mathrm{Si}_{1.95} \mathrm{Ge}_{2.05}$ alloys confirmed the linear features noted by Szade et al. as well as a number of impurities. $\mathrm{Ta}_{2} \mathrm{Si}$, which forms by reaction of the constituents with $\mathrm{Ta}$ crucible in induction melted samples, and $\mathrm{Gd}(\mathrm{Si}, \mathrm{Ge})$ were identified using scanning electron microscopy (SEM) and energy dispersive spectroscopy (EDS). When EDS was used to analyze the linear features, an increase in Gd and $\mathrm{O}$ along with a decrease in $\mathrm{Si}$ was observed. These results differed slightly from the results of Szade, where a decrease in both Si and Ge was seen using AES. Meyers et al. concluded that the linear features were a separate phase forming in a manner indicative of a Widmanstätten structure and hypothesized that they were possibly rods of $\mathrm{Gd}_{5}(\mathrm{Si}, \mathrm{Ge})_{3}$.

The Widmanstätten structure forms by a solid-state precipitation reaction from a supersaturated solid solution and usually results in the precipitate phase having a characteristic shape such as plates or needles. The name comes from a paper published by Carl von Schreibers who published the micrograph of an iron-nickel meteorite in 1820 , which was prepared by Aloys von Widmanstätten using nitric acid to etch the polished surface [13]. A Widmanstätten type precipitate generally forms along a specific set of $\{\mathrm{hkl}\}$ planes or directions in the matrix. For a plate shaped precipitate these planes are called the habit planes and for the needle shaped ones these directions are called habit directions of the matrix.

The aim of this paper is to examine the microstructure of the second phase, which have been seen in $\mathrm{Gd}_{5}\left(\mathrm{Si}_{\mathrm{x}} \mathrm{Ge}_{\mathrm{I}-\mathrm{x}}\right)_{4}$ alloys, in more detail using SEM, TEM and EDS. 
Specifically, this paper addresses formation and the shape of the linear feature in the bulk microstructure of $\mathrm{Gd}_{5}\left(\mathrm{Si}_{\mathrm{x}} \mathrm{Ge}_{1-\mathrm{x}}\right)_{4}$ alloys..

\section{Experimental Details}

Single crystals of $\mathrm{Gd}_{5} \mathrm{Si}_{2} \mathrm{Ge}_{2}$ samples were prepared using a tri-arc crystal pulling method to study the alignment of the linear features with respect to the lattice directions of the crystal. Appropriate quantities of Gd 99.996 wt.\%, Si 99.9999 wt.\% and Ge 99.999 wt.\% were cleaned and arc melted several times under an argon atmosphere. The arc melted button was then used as the charge material in the tri-arc crystal pulling unit. A tungsten rod was used as the seed material which resulted in a randomly oriented $\mathrm{Gd}_{5} \mathrm{Si}_{2} \mathrm{Ge}_{2}$ crystal with monoclinic crystal structure in agreement to what has been reported [5]. The as-grown crystal was oriented using back-reflection Laue x-ray diffraction and the crystallographic directions were assigned via two-theta $\mathrm{x}$-ray diffraction scans of the single crystal. The oriented specimens were cut by spark erosion and the oriented faces were prepared using standard metallographic techniques.

Examination of all specimens was carried out using SEM, TEM and EDS. One of the [010]-direction oriented $\mathrm{Gd}_{5} \mathrm{Si}_{2} \mathrm{Ge}_{2}$ specimens was chosen and etched using an ion-sputter gun to reveal the linear features on the polished surface. Other oriented single crystal $\mathrm{Gd}_{5} \mathrm{Si}_{2} \mathrm{Ge}_{2}$ specimens were examined in the as-polished condition with back-scattered electron imaging using SEM. For the TEM part, single crystal specimens were cut by spark erosion, mechanically thinned, dimpled, and cold-stage ion-milled to get thin area $(<100$ $\mu \mathrm{m})$. Bright field (BF) images and selected area diffraction (SAD) patterns of the thin-plates and the matrix phase were taken using a Philips CM30 TEM at 300kV. Desktop Microscopist software was used to simulate diffraction patterns. Qualitative and quantitative EDS results were obtained with a Thermo Noran EDS on the TEM. 


\section{Results}

The ion-etched surface of the [010]-direction oriented single crystal sample is shown in Figure 1. Linear features were arranged as sets of thin white parallel lines in two constant directions with an angle of $\sim 80^{\circ}$ between them, as noted by Szade et al. [11]. The surface appears to be raised around the lines and circular raised regions also appear in Figure 1 (b), although no contrast differences are observed within these regions. In general, the lines all maintain a high length to width aspect ratio with lengths up to $100 \mu \mathrm{ms}$ and thicknesses less than $1 \mu \mathrm{m}$.

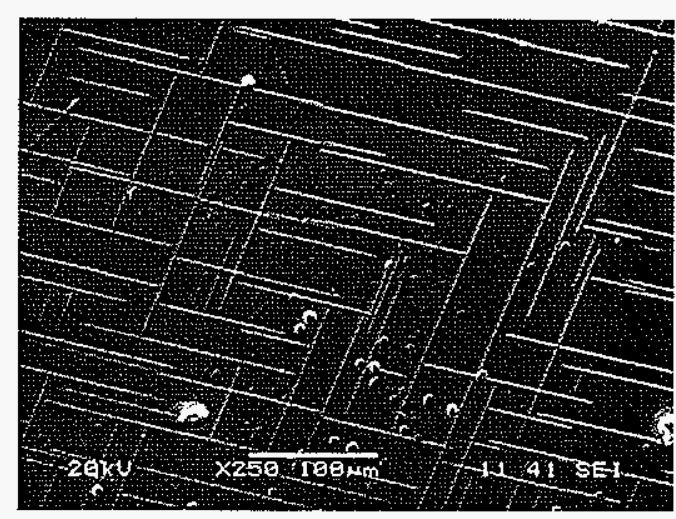

(a)

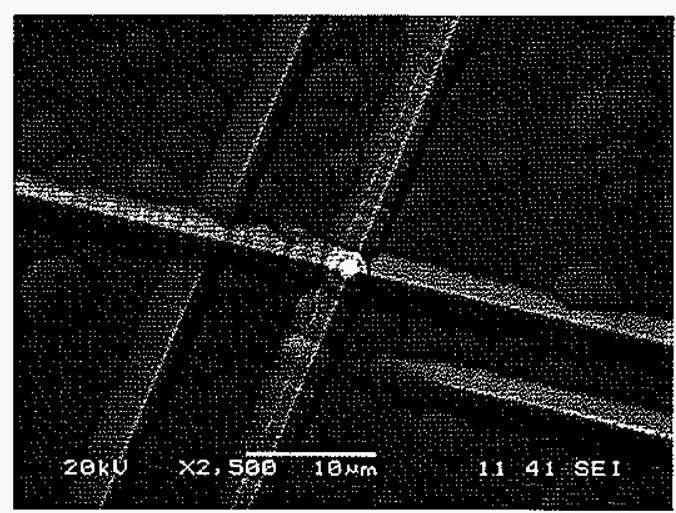

(b)

Figure 1 -- SEM micrograph of an ion-etched oriented $\mathrm{Gd}_{5} \mathrm{Si}_{2} \mathrm{Ge}_{2}$ single crystal. (a) lowmagnification, (b) high-magnification (arrows show thin white lines)

In Figure 2 are shown backscattered electron (BSE) images of three samples that were aligned using back-reflection Laue $\mathrm{x}$-ray diffraction. These monoclinic samples were spark cut along the [100], [010], and [001] directions and the faces mechanically polished. Black lines show traces of the low order planes for each zone direction.

When examined along [100], the linear features lie nearly parallel to the (001); they lie parallel to (100) when observed from the [001]. When viewed from the [010] of the 
crystal the linear features lie in two directions with an $80^{\circ}$ angle between them. They are aligned approximately $\pm 40^{\circ}$ of $(100)$ and $\pm 50^{\circ}$ of the (001) of the crystal.

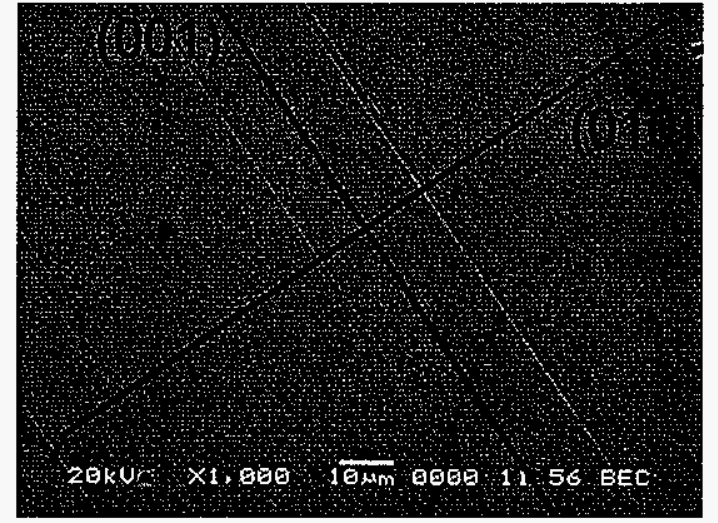

(a)

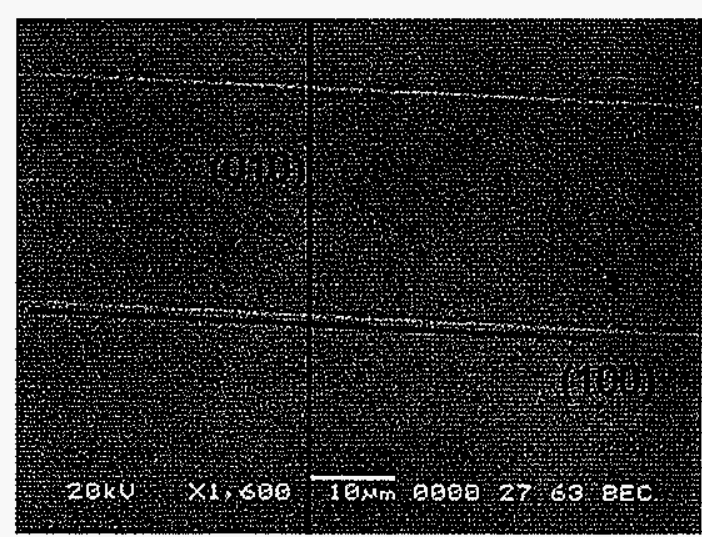

(c)

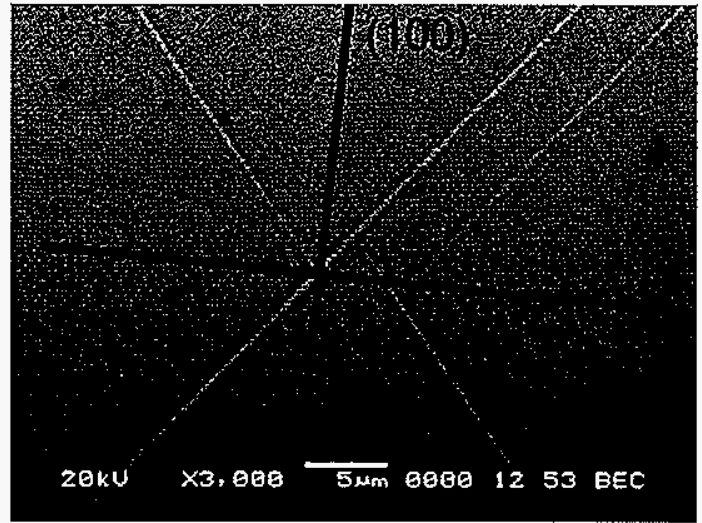

(b)

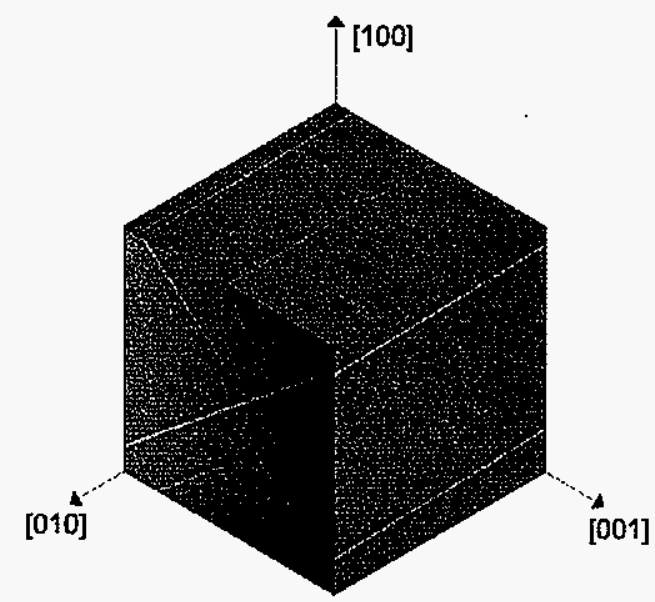

(d)

Figure 2 -- Backscattered SEM micrographs, of single crystal $\mathrm{Gd}_{5} \mathrm{Si}_{2} \mathrm{Ge}_{2}$, taken from (a) [100], (b) [010] and (c) [001]. (d) Digitally rendered 3-D image of a single crystal $\mathbf{G d}_{5} \mathbf{S i}_{2} \mathbf{G e}_{2}$, showing the linear features.

Meyers et al. [12] proposed that these linear features were "Widmanstätten rods". From the micrographs of Figures 1 and 2 it is difficult to determine whether this is the case since rods or thin plates might produce the same configuration of traces in the three views presented, the only difference being that (assumed round) rods should be seen as small circles in some views where they would appear in cross section. Circular features were seen 
using secondary electron imaging (Figure 1.), however, these appeared to be due to etching effects and not associated with a separate phase. Some might argue that the end-on rods could easily have been missed in the BSE images of Figure 2 due to the small size cross section, or if, for example, the rods intersected other rods such that the cross-section was not visible. In order to determine unambiguously whether the features are rods or thin plates, a controlled series of sectioning and polishing was carried out.

Initially, the single crystal sample of $\mathrm{Gd}_{5} \mathrm{Si}_{2} \mathrm{Ge}_{2}$ specimen was cut along the $\mathrm{AA}$ section as shown in Figure 3 (a). The cut was made parallel to one of the sets of lines that are seen on the (010) face. Such a cut should produce different images depending upon whether rods or plates are present, and these predicted shapes are illustrated schematically in Figures 3 (b) and 3 (c). As can be seen in Figure 3 (d), lines lie along the [010] on the AA cross section of the crystal as would be expected for line plates. No circles are seen as would be expected for rods when viewed in cross-section. Thus, the circular regions seen in Figure 1 do appear to be an effect of ion-etching as suspected.

To further confirm that the features are plates a controlled polishing was carried out to observe if the width of the features changed as a function of angle. If the features are indeed plates, a change in polishing angle will produce a change in measured thickness. The true thickness will only be apparent when viewed in cross-section; polishing at any angle other than $90^{\circ}$ to the plane of the plate will produce increasing measured thickness. For this experiment, the crystal was initially viewed along the [100], Figure 2 (d). Viewing along [010] reveals that the features, if plates, should be intersecting the [100] viewing direction at a $50^{\circ}$ degree angle. A $20^{\circ}$ tilt was introduced along [010] axis of the sample and the (100) surface of the sample was repolished, producing plates aligned at $70^{\circ}$ and $30^{\circ}\left(50^{\circ}+20^{\circ}, 50^{\circ}\right.$ $20^{\circ}$ ) with respect to the polished surface. Images and the measured results are summarized in Figure 4. Before tilting, backscattered electron (BSE) images of all the lines can be obtained fairly easily, but suffer from poor resolution, Figure 4 (a), and show a fairly 

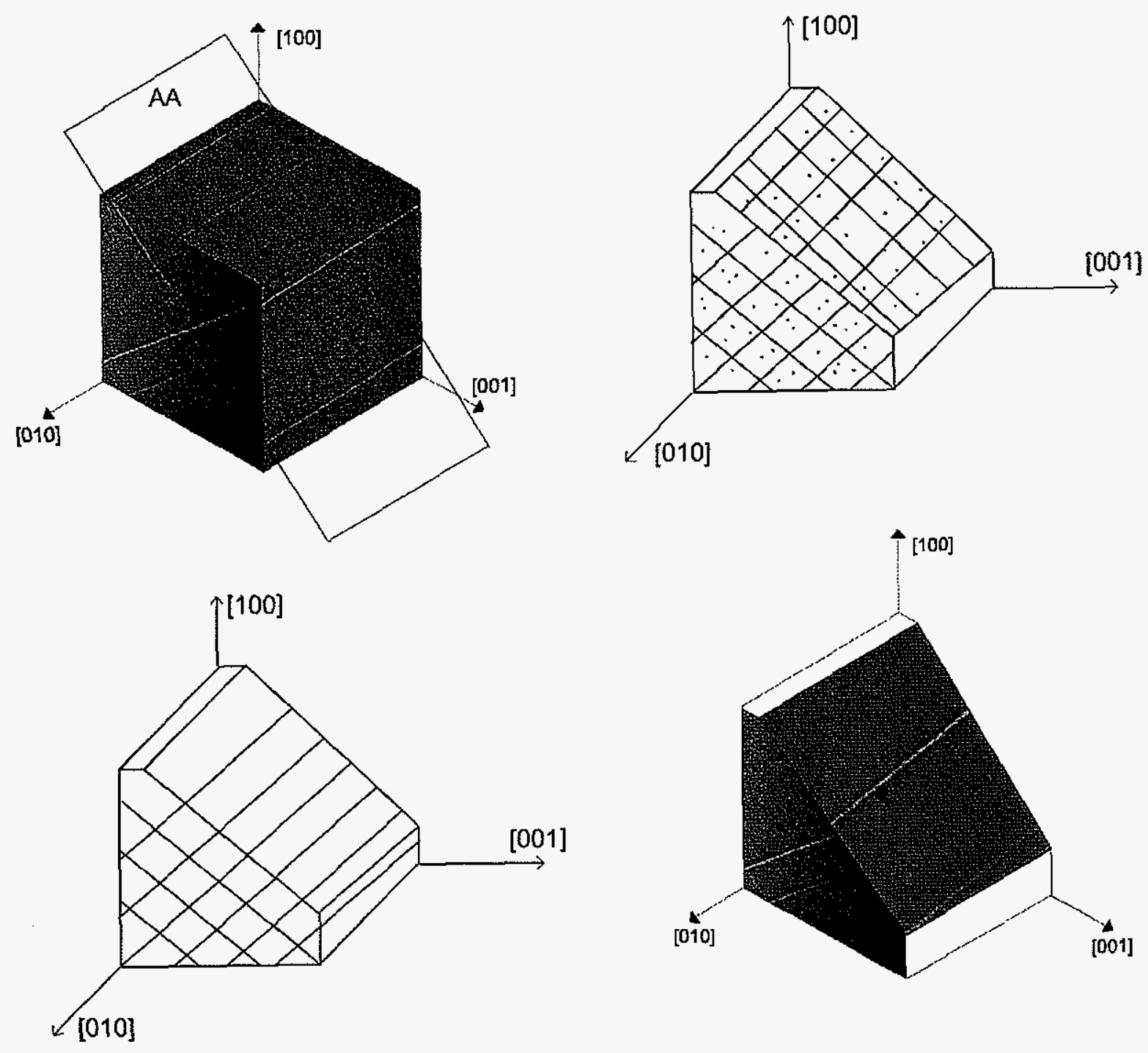

Figure 3 -- (a) Digitally rendered 3-D backscattered image of the $\mathrm{Gd}_{5} \mathrm{Si}_{2} \mathrm{Ge}_{2}$ sample. Schematic showing the possible surface if the linear features are (b) rods (c) plates. (d) Digitally rendered 3-D backscattered image showing the cut surface along AA section.

tight distribution about an average width of $\approx 1 \mu \mathrm{m}$, Figure 4 (b). After tilting the image changes; some lines become much easier to see while others become even fainter and more indistinct, Figures 5 (a) and 5 (b). The distribution of measured widths becomes bimodal with peaks at $\approx 1.5 \mu \mathrm{m}$ and $0.5 \mu \mathrm{m}$, Figure 5 (c). 


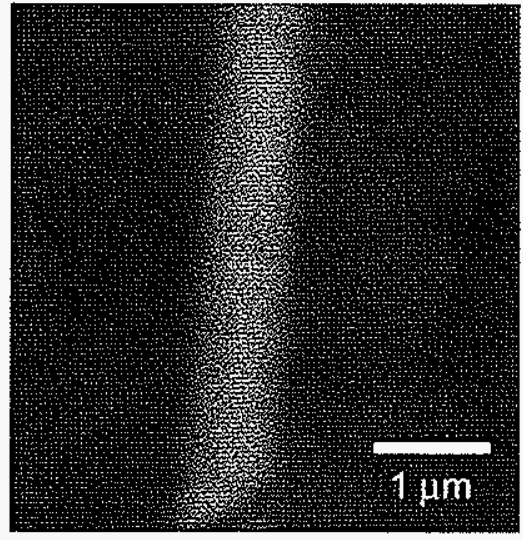

(a)

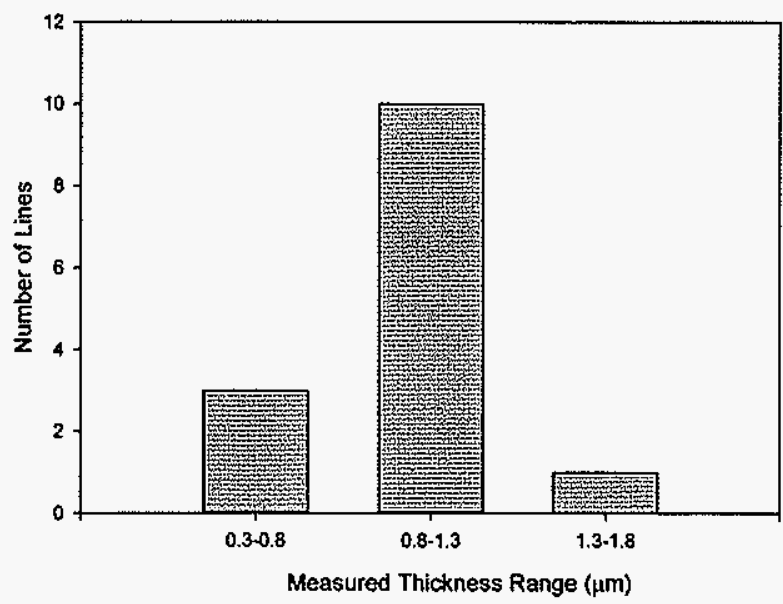

(b)

Figure 4 -- (a) Surface is perpendicular to [100]-direction, and (b) the distribution of measured widths.

These results agree with the hypothesis that the features are thin plates and not rods. The true thickness of the plates is extremely thin. When properly aligned, the true width of a typical plate can be seen to be on the order of 100-250 nm.

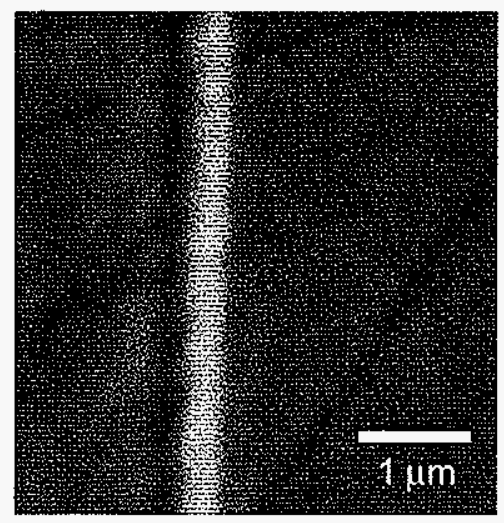

(a)

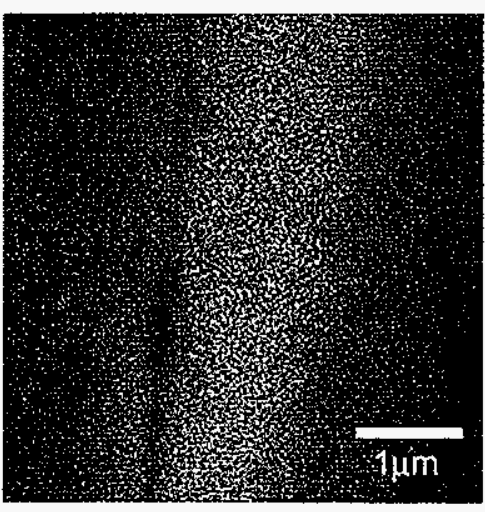

(b) 


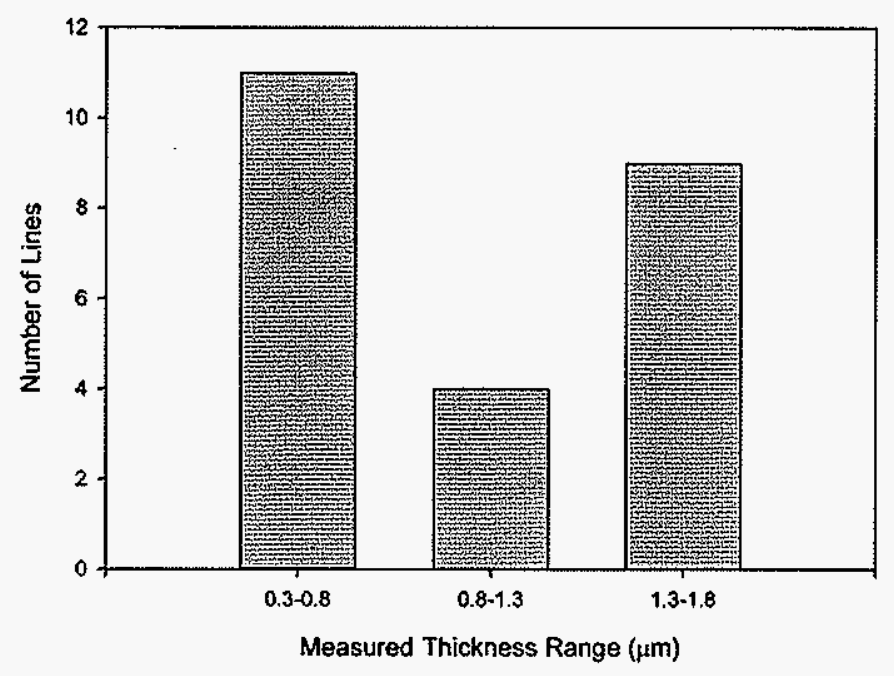

(c)

Figure $5--(100)$ surface tilted $20^{\circ}$ about $[010]$ and repolished. Some features become thinner (a), while others become thicker (b). Measured distribution of sizes is shown in (c).

Due to the small size of the plates and the extreme brittleness of the material many different thin-foil samples were examined before the plates could be found and identified using TEM. Figure 6 shows three different cross-section bright field images of the thinplates viewing from the three major zone directions of the monoclinic matrix phase. The average thickness of the plates when viewed using TEM ranges between $80 \mathrm{~nm}$ and $500 \mathrm{~nm}$, depending upon the viewing direction.

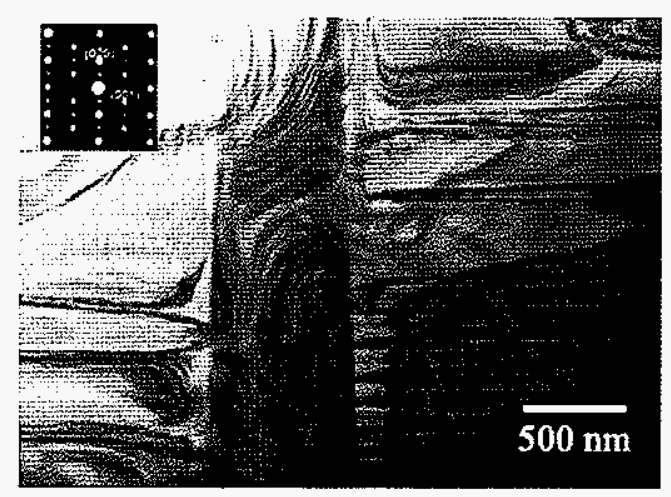

(a)

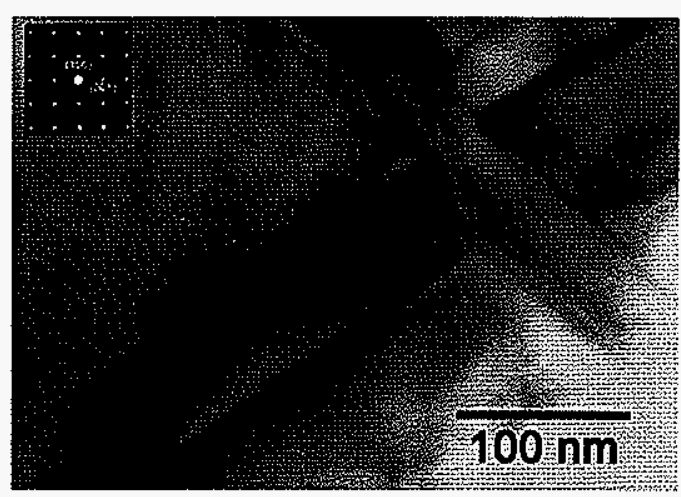

(b) 


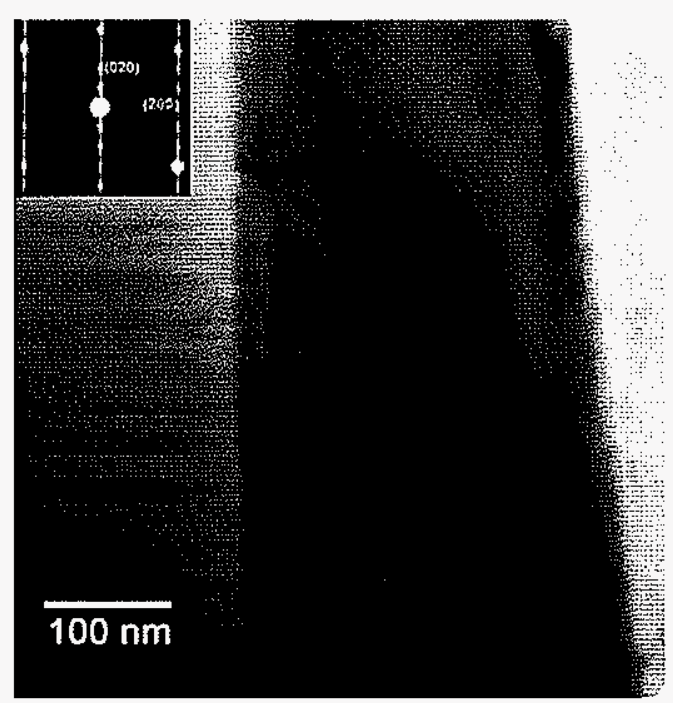

(c)

Figure 6 -- Bright field images of the thin-plates viewing from (a) [100], (b) [010] and (c) [001] zones of monoclinic matrix phase. Plate thickness in (a) and (c) appears wider since plate is inclined with respect to the viewing direction.

A large number of SAD patterns were obtained and all could consistently be indexed using an hexagonal crystal structure. Figure 7 shows the actual diffraction pattern and the simulated pattern of each for the [0001], [10-10], and [1-210] zone axes of the plates. Note that in Figure 7 (b) (the [10-10] direction) the thin dimension of the plates was such that for the SAD aperture used diffracted intensity was obtained from both the matrix and plates. The diffraction pattern related to the [10-10] zone of the plates is outlined in white with the remaining reflections belonging to the $[010]$ zone of the matrix, which was located nearby within a few degrees.

Based on the diffracted information the crystal structure and lattice parameters of the plates were determined to be hexagonal with $a=b=8.53 \mathrm{~A}, \mathrm{c}=6.40 \mathrm{~A}$, respectively. Quantitative EDS studies in the TEM showed that the plates have a composition approaching $\mathrm{Gd}_{5}(\mathrm{Si}, \mathrm{Ge})_{3}$, Table I. These results match very well with a phase based on a $\mathrm{Gd}_{5}(\mathrm{Si}, \mathrm{Ge})_{3}$ type compound. According to the literature $\mathrm{Gd}_{5} \mathrm{Si}_{3}[14]$ and $\mathrm{Gd}_{5} \mathrm{Ge}_{3}[15]$ both have space 

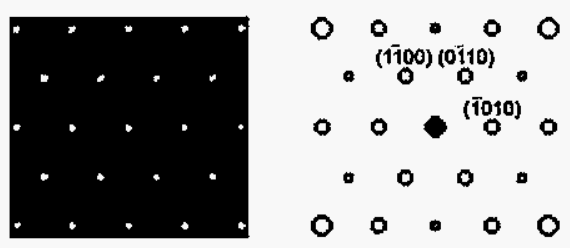

(a)
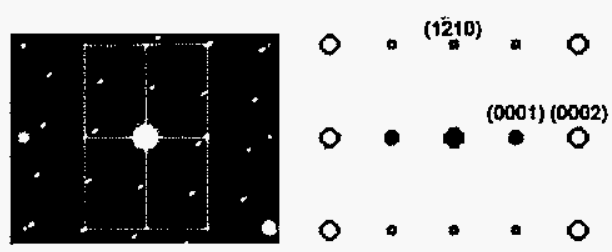

(b)

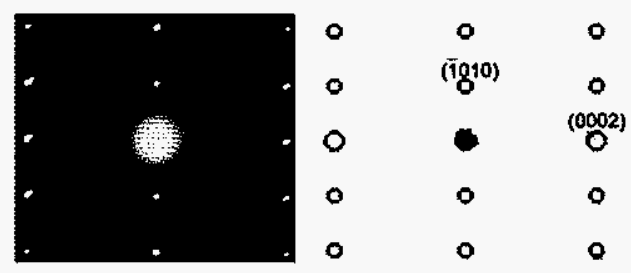

(c)

Figure 7 -- Experimental and simulated SAD patterns of thin-plates, along zone directions (a) [0001], (b) [10-10] and (c) [1-210]

group P63 $/ \mathrm{mcm}$ with lattice parameters of $\mathrm{a}=\mathrm{b}=8.517, \mathrm{c}=6.404$ and $\mathrm{a}=\mathrm{b}=8.546, \mathrm{c}=6.410$, respectively.

Table I -- Quantitative change of elements on the second phase relative to matrix phase.

\begin{tabular}{cccc}
\hline Sample & & Matrix (at\%) $( \pm 3 \%)$ & $\begin{array}{c}\text { Thin-plate (at\%) } \\
( \pm 3 \%)\end{array}$ \\
\hline & $\mathrm{Gd}$ & 58.7 & 64.3 \\
* Excluding Oxygen & $\mathrm{Si}$ & 20.5 & 13.6 \\
& $\mathrm{Ge}$ & 20.8 & 22.1 \\
\hline
\end{tabular}




\section{Discussion}

Formation of the second phase is in the form of extremely thin plates, as confirmed by the tilting experiments. The change in appearance of the plates as a function of tilt when viewed in the SEM, as seen in Figures 4 and 5, can be understood as being related to the depth of penetration of the SEM electron beam. When viewed at a high angle to the plane of the plate, beam penetration occurs through the narrow thickness of the plate. The BSE signal from the phase subsequently is lessened since most of the interaction volume consists of the surrounding matrix, and a poor, low contrast image results. As the tilt angle changes such that the beam is more nearly parallel to the plane of the plates, interaction with the second phase increases producing a higher signal-to-noise ratio from the plate and a stronger, higher contrast image is produced.

The SEM studies showing the second phase as large, extremely thin plates are in agreement with TEM observations. The same alignment seen in SEM (e.g. Fig. 2) is seen in the TEM data, Figure 6. The somewhat thicker appearance of the thin plates in Figures 6 (a) and 6 (c) can be explained by the angle the plates make with the (100) and (001) planes of the matrix. The observed thickness of the plates in Figure $6(\mathrm{~b})([010]$ direction) more closely represents the true thickness because in this view the plates are nearly perpendicular to the $(010)$ plane.

Composition results from previous studies have been somewhat contradictory [11, 12], but in general have shown a relative composition change of the second phase when compared to matrix toward a more Gd-rich composition. The contradictory nature of these results are believed due to the differences in techniques employed as well as the small scale of the features prohibiting accurate analysis from being carried out. In order to get accurate results with quantitative EDS, the area of interest should fill the interaction area [16], and this is clearly not the case for a SEM beam. The TEM provides a much more accurate result due to the ability to converge the beam to a much smaller spot, thereby minimizing beam 
spreading, and the fact that the plate comprises the majority of the volume sampled. As can

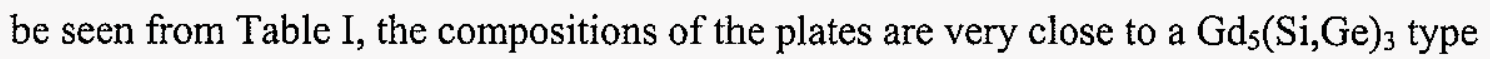
phase $[\mathrm{Gd}=62.5$ at $\%(\mathrm{Si}, \mathrm{Ge})=37.5 \mathrm{at} \%]$. This agrees with what is predicted by the phase diagram, where $\mathrm{Gd}_{5}(\mathrm{Si}, \mathrm{Ge})_{3}$ is a line compound in the ternary Gd-Si-Ge system, as shown in Figure 8 [17].

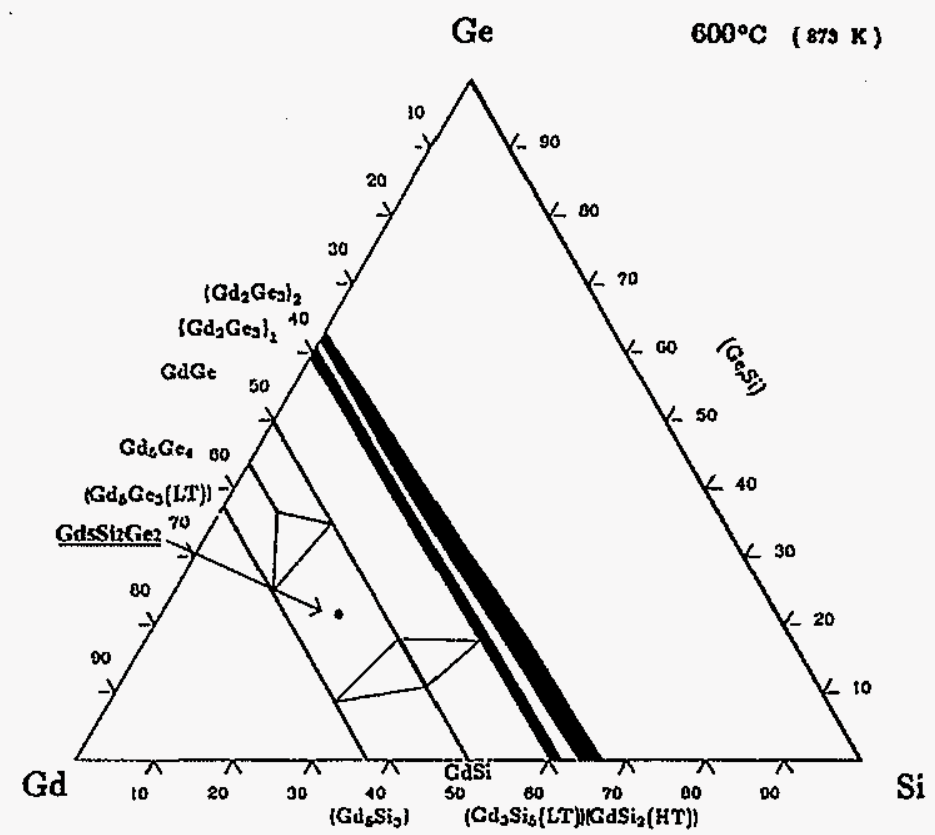

Figure 8 -- Ternary phase diagram of Gd-Si-Ge alloy system [18]

The lattice parameters of the thin-plates were in between the lattice parameters of $\mathrm{Gd}_{5} \mathrm{Si}_{3}$ and $\mathrm{Gd}_{5} \mathrm{Ge}_{3}$. While the exact ratio of $\mathrm{Si}: \mathrm{Ge}$ is not precisely known standardless EDS results give a composition closely approximating $\mathrm{Gd}_{5} \mathrm{Si}_{1} \mathrm{Ge}_{2}[\mathrm{Gd}=62.5 \mathrm{at} \% \mathrm{Si}=12.5 \mathrm{at} \%$ $\mathrm{Ge}=25 \mathrm{at} \%$ ]. Applying the same 1:2 ratio of $\mathrm{Si}: \mathrm{Ge}$ to the lattice parameters of $\mathrm{Gd}_{5} \mathrm{Si}_{3}$ and $\mathrm{Gd}_{5} \mathrm{Ge}_{3}$ one can calculate the lattice parameters of (assumed) $\mathrm{Gd}_{5} \mathrm{Si}_{1} \mathrm{Ge}_{2}$ to be $\mathrm{a}=\mathrm{b}=8.536 \mathrm{~A}$, $c=6.406 \mathrm{~A}$. This is in excellent agreement with the experimentally determined lattice parameters of $\mathrm{a}=\mathrm{b}=8.53 \mathrm{~A}, \mathrm{c}=6.40 \mathrm{~A}$ for the plates. 
Szade et al. [11] reported linear features existed in $\mathrm{Gd}_{5} \mathrm{Ge}_{4}$ and $\mathrm{Gd}_{5} \mathrm{Si}_{4}$ samples as well as $\mathrm{Gd}_{5} \mathrm{Si}_{2} \mathrm{Ge}_{2} . \mathrm{Gd}_{5} \mathrm{Ge}_{4}$ has the same orthorhombic crystal structure as the high temperature $\mathrm{Gd}_{5} \mathrm{Si}_{2} \mathrm{Ge}_{2}$ phase. The presence of plates of $\mathrm{Gd}_{5} \mathrm{Si}_{3}$ in both crystal structures upon cooling with no heat treatment suggests that formation of this phase is extremely rapid and energetically favorable and the growth of $\mathrm{Gd}_{5}(\mathrm{Si}, \mathrm{Ge})_{3}$ phase in certain directions would suggest that some structural relationship must exist between the parent matrix and the precipitate in order for such widespread growth to occur in these rare earth compounds. Generally, in Widmanstätten structures the matrix-precipitate interface has a low energy along the habit plane and usually requires a specific crystallographic orientation between the matrix and the precipitate. One can easily see from Figures 2 and 6 that the $\mathrm{Gd}_{5} \mathrm{Si}_{3}$ phase grows along the [010] direction when the crystal is viewed along [100] and [001]. However, when the crystal is examined from [010], the plates grow in two different directions with an approximate habit plane of $<807>$, which is not a low index plane as expected for a regular widmanstatten structure. This indicates that the orientation relationship may be more complex than is typical for Widmanstätten precipitation.

Concerning the mechanism of formation of the $\mathrm{Gd}_{5} \mathrm{Si}_{1} \mathrm{Ge}_{2}$ phase it should be noted that the binary systems Gd-Ge [18] and Gd-Si [18] and the ternary Gd-Si-Ge [17] systems all show the $\mathrm{Gd}_{5}(\mathrm{Si}, \mathrm{Ge})_{4}$ compounds as being line compounds. Strictly speaking, this would preclude Widmanstätten-like precipitation of a second phase since the required supersaturated solution is absent. This may suggest that at high temperature a region of solid solubility does exist which is not adequately represented on any current phase diagrams. Another possible explanation is that the intended target composition is off-stoichiometry such that the alloy is Gd-rich. This would move the alloy system into a two-phase region where a $\mathrm{Gd}_{5}(\mathrm{Si}, \mathrm{Ge})_{3}$ phase may be expected to form. However, this would presumably result in the $\mathrm{Gd}_{5}(\mathrm{Si}, \mathrm{Ge})_{3}$ forming directly from the melt. From the optical [12] and SEM micrographs it appears evident that the observed structures form via a solid-state 
transformation rather than during solidification. It is also clear that the structures form directly upon cooling rather than as a result of heat treatment, which is the normal method for

producing a Widmansatten structure. All of the samples examined were prepared using a triarc method where the cooling rates are quite rapid. This would limit the amount of time available for diffusion to take place, and considering the large extent of the plates (up to hundreds of microns) this may indicate some special structural relationship that allows rapid phase formation. Finally, it is somewhat unusual for an intermetallic phase to nucleate and precipitate from another intermetallic compound. All of these conditions suggest that the observed phase formation is atypical of the traditional Widmanstätten precipitation and may constitute a new subclass of this type of precipitation event.

\section{Conclusion}

Detailed single crystal examination of $\mathrm{Gd}_{5} \mathrm{Si}_{2} \mathrm{Ge}_{2}$ samples have conclusively identified a second phase, consisting of extremely thin plates growing in specific directions, that has been observed in previous studies. The average width of the plates is on the order of $250 \mathrm{~nm}$ with plate dimensions running to hundreds of microns. EDS and SAD studies using the TEM indicate that the second phase in $\mathrm{Gd}_{5} \mathrm{Si}_{2} \mathrm{Ge}_{2}$ alloys is hexagonal with composition and lattice parameters that match extremely well to a compound of the type $\mathrm{Gd}_{5} \mathrm{Si}_{1} \mathrm{Ge}_{2}$. The appearance and crystallographic orientation of the plates with the parent grain is reminiscent of Widmanstätten precipitation, although the conditions for formation appear atypical of what is traditionally expected. The prevalence of the plates in all samples studied and the high aspect ratio they possess point to some type of planar alignment of atoms between matrix and precipitate. Work on the orientation relationship between the plates and the matrix is continuing and will be presented in an upcoming paper. 


\section{Acknowledgements}

This work was preformed at Ames Laboratory under contract No. W-7405-Eng-82 with the US Department of Energy. This research was supported by the Office of Basic Energy Sciences, Materials Science Division of the US DOE. The authors wish to thank V.K. Pecharsky for helpful discussions in the preparation of this manuscript.

\section{References}

1. Smith GS, Tharp AG, Johnson Q. Nature 1966;210:1148-9.

2. Smith GS, Tharp AG, Johnson Q. Acta Crystall 1967;22:940-3.

3. Holtzberg F, Gambino RJ, McGuire TR. J Phys Chem Solids 1967;28:2283-9.

4. Pecharsky VK, Gschneidner Jr KA. J Alloys Compd 1997;260:98-106.

5. Pecharsky VK, Gschneidner Jr KA. Phys Rev Lett 1997;78(23):4494-7.

6. Choe W, Pecharsky VK, Pecharsky AO, Gschneidner KAJ, Young VGJ, Miller GJ. Phys Rev Lett 2000;84(20):4617-20.

7. Pecharsky VK, Gschneidner Jr KA. Appl Phys Lett 1997;70(24):3299-301.

8. Pecharsky AO, Gschneidner Jr KA, Pecharsky VK. J Appl Phys 2003;93(8):4722-8.

9. Pecharsky AO, Gschneidner Jr KA, Pecharsky VK. J Magnet Magnet Mater $2003 ; 267(1): 60-8$.

10. Pecharsky AO, Gschneidner Jr KA, Pecharsky VK, Schindler CE. J Alloys Compd 2002;338(1-2 SPEC):126-35.

11. Szade J, Skorek G, Winiarski A. J Cryst Growth 1999;205:289-93.

12. Meyers JS, Chumbley LS, Laabs F, Pecharsky AO. Scripta Mater 2002;47:509-14.

13. Hunsicker HY, Stumpf HC. On the Widmanstatten structure. In: Smith CS, editor. The Sorby centennial symposium on the history of metallurgy. 1968. p. 245-69.

14. Tchemev DI. IEEE Trans Magnet 1969;5:222. 
15. Baenziger NC, Hegenbarth JJ. Acta Crystall 1964;17:620-1.

16. Goldstein J, Newbury D, Echlin P, Joy D, Fiori C, Lifshin E. Scanning electron microscopy and X-ray microanalysis. New York (NY): Plenum Press; 1984. p. $267-$ 9.

17. Muratova LA. Visnik L_Vivs_Kogo Derzhavnogo Universitetu, Seriya Khimichna 1974;15:15-8.

18. Massalski TB. 2nd ed.. Binary alloy phase diagrams, vol. 2. Metals Park (OH): ASM International; 1990. 


\title{
CHAPTER 4: ORIENTATION AND FORMATION OF ATYPICAL WIDMANSTATTEN PLATES IN THE $\mathrm{Gd}_{5}\left(\mathrm{Si}_{\mathrm{X}} \mathrm{Ge}_{1-\mathrm{X}}\right)_{4}$ SYSTEM
}

\author{
A paper published in Acta Materialia ${ }^{7}$ \\ O. Ugurlu ${ }^{8,9}$, L.S. Chumbley ${ }^{2,3}$, D. L. Schlagel ${ }^{3}$, and T.A. Lograsso ${ }^{3}$
}

\begin{abstract}
Scanning electron microscopy (SEM) and transmission electron microscopy (TEM) have been used to examine the bulk microstructure of $\mathrm{Gd}_{5} \mathrm{Si}_{2} \mathrm{Ge}_{2}$ and $\mathrm{Gd}_{5} \mathrm{Ge}_{4}$ compounds, and specifically the $\mathrm{Gd}_{5}(\mathrm{Ge}, \mathrm{Si})_{3}$ thin plates seen in these systems. The orientation relationship between the matrix and the precipitate thin-plates was determined as [-1010](1$211)_{\mathrm{p}} / /[010](10-2)_{\mathrm{m}}$. High-resolution TEM images of the $\mathrm{Gd}_{5} \mathrm{Ge}_{4}$ were used to study the crystallographic relationship between the parent and matrix that exists along the interface boundary. The observed planar alignment and microscopic structure of the interface, which consists of ledges and terraces, indicate the presence of invariant line strain. The results are also consistent with the $\Delta \mathrm{g}$ approach suggested by Zhang and Purdy. A displacive / diffusional mechanism is proposed to explain the rapid formation of the precipitate $\mathrm{Gd}_{5}(\mathrm{Ge}, \mathrm{Si})_{3}$ plates.
\end{abstract}

\footnotetext{
${ }^{7}$ Reprinted with permission of Acta Materialia, 2006, 54, 121 1-1219

${ }^{8}$ Department of Materials Science and Engineering, Iowa State University, Ames IA 50011-3020 USA

${ }^{9}$ Ames Laboratory (DOE), Iowa State University, Ames IA 50011-3020, USA
} 


\section{Introduction}

The family of $\mathrm{RE}_{5}\left(\mathrm{Si}_{\mathrm{x}} \mathrm{Ge}_{1-\mathrm{x}}\right)_{4}$ compounds where $\mathrm{RE}$ is one of the lanthanide rare earths presents a unique opportunity to study the interaction that exists between crystal structure and any number of unusual and interesting physical properties, including the magnetocaloric, magnetostrictive and magnetoresistive effects. Indeed, the scale of the changes in properties in these intermetallics, particularly in the case where $\mathrm{RE}=\mathrm{Gd}$, are so great that they are described as showing a giant magnetocaloric effect [1, 2], colossal magnetostriction [3] and giant magnetoresistance $[4,5]$. It is for this reason that these compounds have received great attention in recent years as possible candidates for numerous applications such as magnetic refrigeration $[6,7]$ and transducers $[8-10]$.

Initial studies of the $\mathrm{R}_{5}\left(\mathrm{Si}_{\mathrm{x}} \mathrm{Ge}_{1-\mathrm{x}}\right)_{4}$ system (often referred to as 5:4 compounds) reported that the structures of $\mathrm{Gd}_{5} \mathrm{Si}_{4}$ and $\mathrm{Gd}_{5} \mathrm{Ge}_{4}$ belong to the orthorhombic $\mathrm{Sm}_{5} \mathrm{Ge}_{4}$ [11]. An intermediate phase, $\mathrm{Gd}_{5} \mathrm{Si}_{2} \mathrm{Ge}_{2}$, also was observed, but it's crystal structure could not be determined [12]. The discovery of the giant magnetocaloric effect prompted more detailed studies of the crystal structure in order to explain the observed magnetic-related effects. It is now known that $\mathrm{Gd}_{5} \mathrm{Si}_{4}, \mathrm{Gd}_{5} \mathrm{Ge}_{4}$, and $\mathrm{Gd}_{5} \mathrm{Si}_{2} \mathrm{Ge}_{2}$ adopt three different structures $\left(\mathrm{Gd}_{5} \mathrm{Si}_{4}\right.$-type orthorhombic, $\mathrm{Gd}_{5} \mathrm{Si}_{2} \mathrm{Ge}_{2}$-type monoclinic, and $\mathrm{Sm}_{5} \mathrm{Ge}_{4}$-type orthorhombic) depending on their composition [13], temperature [2] and magnetic field [1]. However, those three crystal structures are very similar in terms of their lattice parameters and atom positions [13], and consist of layers of atoms infinite in two dimensions (called "slabs") where the bonding between the layers ultimately determines the dominant crystal structure [14].

Given the interest in these compounds and the large number of papers concerning crystal structure and physical property measurements it is somewhat surprising that studies of the microstructures of this family of compounds as a function of processing are more limited. The first microstructural study was conducted by Szade et al. [15], who examined the surface of as cast $\mathrm{Gd}_{5}\left(\mathrm{Si}_{\mathrm{x}} \mathrm{Ge}_{1-\mathrm{x}}\right)_{4}$ compounds using scanning electron microscopy (SEM) and Auger 
electron spectroscopy (AES) in 1999. The results of this study revealed a series of regular "lines" on the surface of Gd-based 5:4 compounds. Auger results showed that the "lines" exhibited an increase in Gd and Ge content together with a decrease in Si. Subsequent SEM studies showed that the "lines" were not a surface effect, but were present in the bulk of the sample, while energy dispersive spectroscopy (EDS) studies showed an approximate composition for the linear features as $\mathrm{Gd}_{5}(\mathrm{Si}, \mathrm{Ge})_{3}$, which has a $\mathrm{Mn}_{5} \mathrm{Si}_{3}$-type hexagonal crystal structure [16]. The presence of these "lines" has been confirmed in essentially every compound in the $\mathrm{R}_{5}\left(\mathrm{Si}_{\mathrm{x}} \mathrm{Ge}_{1-\mathrm{x}}\right)_{4}$ family including $\mathrm{RE}=\mathrm{Gd}, \mathrm{Tb}, \mathrm{Dy}$ and $\mathrm{Er}$, independent from their crystal structures [17]. The overall volume percent of "lines" is low, resulting in there often being no indication when simply using $x$-ray diffraction (XRD) to determine phase purity. However, their presence is ubiquitous in this family of alloys. The features were conclusively identified in a study using $\mathrm{Gd}_{5} \mathrm{Si}_{2} \mathrm{Ge}_{2}$ single crystals as being thin plates of $\mathrm{Mn}_{5} \mathrm{Si}_{3}$-type hexagonal $\mathrm{Gd}_{5} \mathrm{Si}_{1} \mathrm{Ge}_{2}$ with $\mathrm{a}=\mathrm{b}=8.53 \AA$ and $\mathrm{c}=6.4 \AA$ using a combination of selected area diffraction (SAD) and EDS, and were described as being an Atypical Widmanstaetten structure [18]. Similar to the earlier SEM studies, plates were observed growing in two different directions neither of which were parallel to any low index planes of the matrix. A similar hexagonal $\mathrm{Er}_{5}\left(\mathrm{Si}_{x} \mathrm{Ge}_{1-\mathrm{x}}\right)_{3}$ compound has also been observed in samples of $\mathrm{Er}_{5}\left(\mathrm{Si}_{\mathrm{x}} \mathrm{Ge}_{1-\mathrm{x}}\right)_{4}$, suggesting that the "lines" observed in $\mathrm{Gd}, \mathrm{Tb}$, Dy and $\mathrm{Er}$ alloys are analogous 5:3-type compounds.

This paper presents the results of a study aimed at understanding the crystallographic relationship that exists between the matrix 5:4 and the 5:3 plates present in $\mathrm{RE}_{5}\left(\mathrm{Si}_{\mathrm{x}} \mathrm{Ge}_{1-\mathrm{x}}\right)_{4}$ type compounds. In addition to a detailed description of the orientation relationship, possible mechanisms for growth of the $5: 3$ phase are also discussed. 


\section{Experimental Details}

Single crystals of $\mathrm{Gd}_{5} \mathrm{Si}_{2} \mathrm{Ge}_{2}, \mathrm{Gd}_{5} \mathrm{Si}_{0.33} \mathrm{Ge}_{3.67}$ and $\mathrm{Gd}_{5} \mathrm{Ge}_{4}$ compounds were prepared using a tri-arc crystal pulling method. Only cleaned, high-purity powders of Gd ( 99.996 wt.\%), $\mathrm{Si}(99.9999$ wt.\%) and $\mathrm{Ge}(99.999$ wt.\%) were used in sample preparation and the triarc melting method used allowed single crystals to be obtained. Due to differences in composition $\mathrm{Gd}_{5} \mathrm{Si}_{2} \mathrm{Ge}_{2}$ has a monoclinic crystal structure while $\mathrm{Gd}_{5} \mathrm{Si}_{0.33} \mathrm{Ge}_{3.67}$ and $\mathrm{Gd}_{5} \mathrm{Ge}_{4}$ have an orthorhombic structure [13]. Back-reflection Laue $\mathrm{x}$-ray diffraction and 2- $\theta$ scans were used to orient the as grown crystals to their major crystallographic directions. Oriented specimens were then obtained by cutting the crystal using spark erosion. $\mathrm{Gd}_{5} \mathrm{Si}_{2} \mathrm{Ge}_{2}$ samples showing both [010] and [001] sides for SEM examination were obtained using mechanical polishing. Samples for Transmission Electron Microscope (TEM) studies were mechanically ground, dimpled and cold-stage ion-milled to electron transparency. A Philips CM30 TEM operated at $300 \mathrm{kV}$ equipped with a Themo Noran energy dispersive spectrometer (EDS) was used for all the bright field (BF) images, selected area diffraction (SAD) patterns and High Resolution TEM (HRTEM) images in this study. Qualitative and quantitative EDS was used to confirm the composition of the observed phases, and were found to be in agreement with previous studies $[17,18]$. Computer simulations of the HRTEM images and atomic structures were calculated using MacTempas and Crystal Maker, respectively. The crystal structure data used for the simulations of the orthorhombic matrix and hexagonal thin-plate phases can be found in previous studies $[13,19]$.

\section{Results}

The backscattered electron (BSE) image in Figure 1 shows the [010] and [001] faces of a $\mathrm{Gd}_{5} \mathrm{Si}_{2} \mathrm{Ge}_{2}$ single crystal, where one can see the cross section of the $\mathrm{Gd}_{5}(\mathrm{Si}, \mathrm{Ge})_{3}$ thin plates (hereafter referred to as 5:3) and their continuity on both surfaces. Figure 1 also 
clearly shows the nature of the two sets of plates, growing in specific directions on the [010] surface with an $\sim 80^{\circ}$ angle between them.

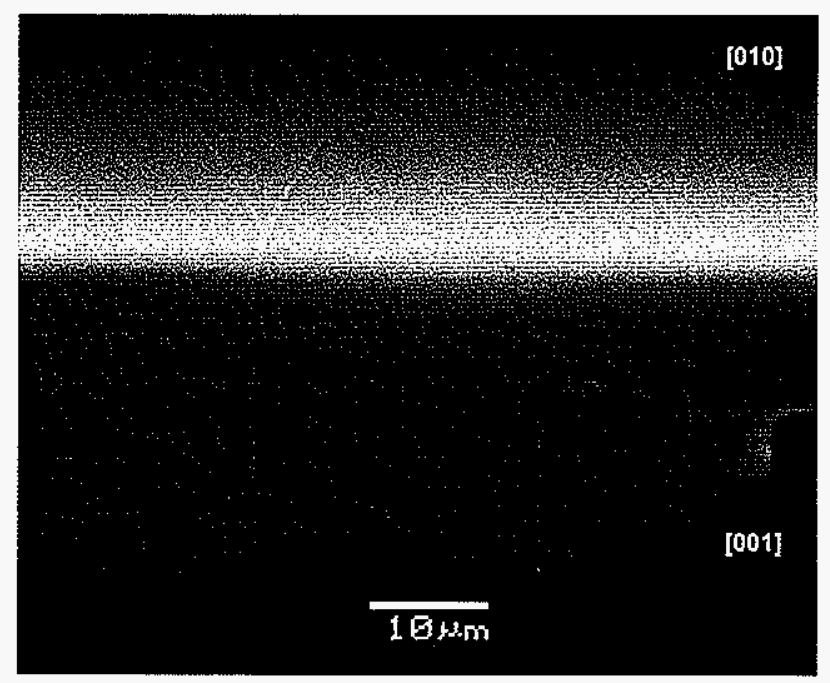

Figure 1 -- Backscatter image of a $45^{\circ}$ tilted $\mathrm{Gd}_{5} \mathrm{Si}_{2} \mathrm{Ge}_{2}$, showing the thin plates on [010] and [001] surfaces.

Bright-field TEM images of similar plates present in a $\mathrm{Gd}_{5} \mathrm{Si}_{2} \mathrm{Ge}_{2}$ monoclinic single crystal sample are shown in Figure 2. The angle between these two 5:3 plates is $\sim 80^{\circ}$, and the diffracting conditions are shown in the inset. Since the width of the plates is smaller than the SAD aperture, diffraction from both the matrix and the plates can be seen and different lines were used to outline the patterns corresponding to each phase (white lines: matrix, gray lines: plate). The orientation of the plates is such that the electron beam is parallel to $[010]_{\mathrm{m}}$ $\approx / /[-1010]_{\mathrm{p}}$, the actual alignment between matrix and precipitate zone axes differing by less than one degree from parallel. It can be seen from the schematic insert and the SAD patterns that the diffraction pattern of the $5: 3$ plates are rotated $\sim 7^{\circ}$ relative to the matrix's pattern, one variant being rotated clockwise $(\mathrm{CW})$ with the second counterclockwise (CCW). 

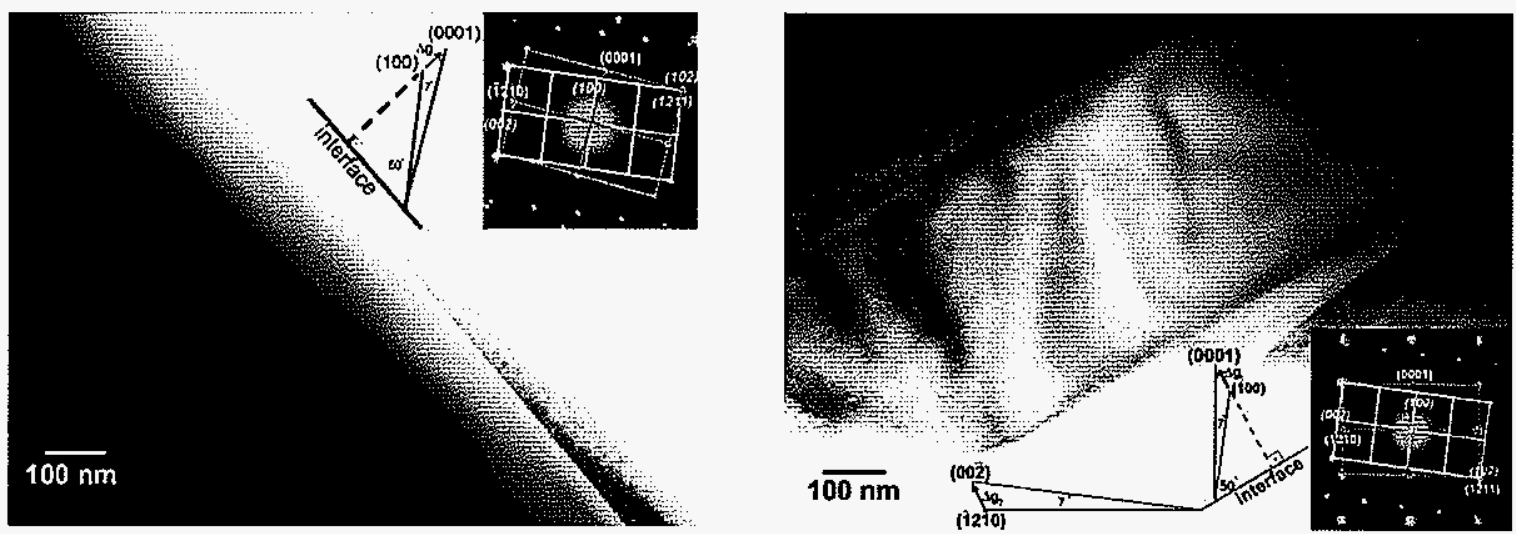

Figure 2 -- Bright field images and diffraction patterns of 2 thin-plates, growing in two different directions in the same $\mathrm{Gd}_{5} \mathrm{Si}_{2} \mathrm{Ge}_{2}$ single crystal. $\mathrm{B}=[010]_{\mathrm{m}} /[-1010]_{\mathrm{p}}$.

Another interesting feature observed in Figures 2 (a) and 2 (b) is best illustrated by the included schematic insets. In these schematics it can be seen that the vector that connects the low index reflections of matrix and 5:3 phases is perpendicular to the interface between the phases. In other words, $\Delta \mathrm{g}=\mathrm{g}_{(0001)}-\mathrm{g}_{(100)}$ is perpendicular to the interface. It can also be seen from the schematic that the angle between the interface and $[100]_{\mathrm{m}}$ direction is $\sim 50^{\circ}$ as observed in a previous study [18].
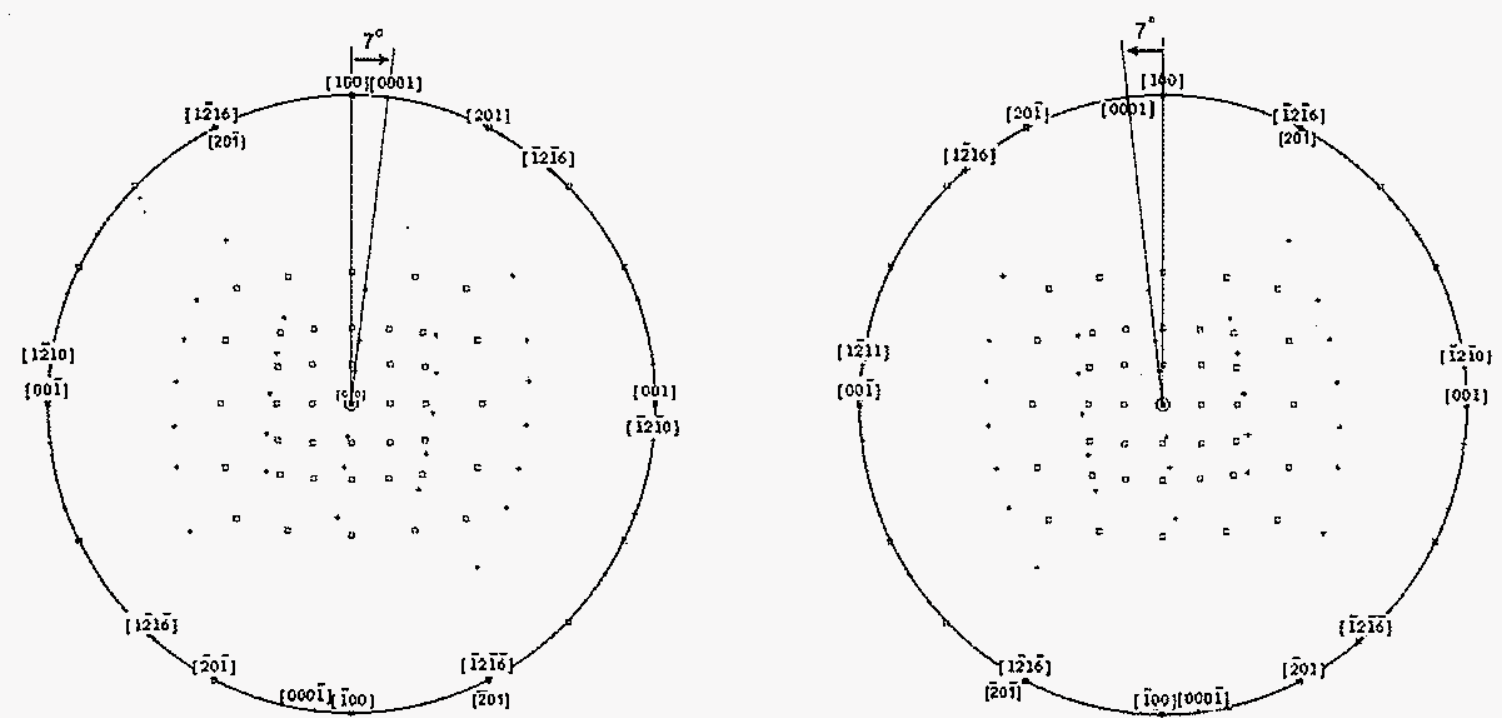

Figure 3 -- Stereographic projections plotted according to diffraction patterns shown on Fig.2. 
Stereographic projections depicting the crystallographic relationships between the plates displayed in Figure 2 are shown in Figures 3 (a) and 3 (b), respectively. It can be seen clearly that after rotating the 5:3 thin-plate projections $7^{\circ}$ in both directions ( $\mathrm{CW}$ and $\mathrm{CCW}$ ), 2 out of 4 sets of $\langle 201\rangle_{m}$ and $\langle 1216\rangle_{p}$ directions come into alignment. This situation is shown in Figure 4, where the diffracting conditions are such that $[201]_{\mathrm{m}} \sim /[-12-16]_{\mathrm{p}}$. This orientation not only provides good matching along the indicated directions, but $(10-10)_{\mathrm{p}} / /$ $(020)_{\mathrm{m}}$ and $(1-211)_{\mathrm{p}} \sim / /(10-2)_{\mathrm{m}}$ are also nearly parallel with only slight differences between their $d$-spacings, as shown in Table 1 .

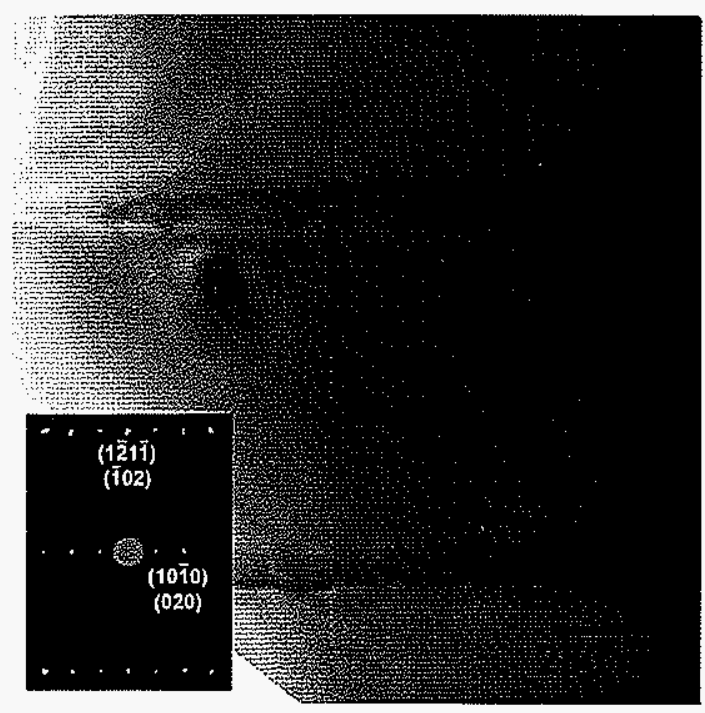

Figure 4 -- Field image and diffraction pattern of a thin-plate. $B=[201]_{\mathrm{m}} \sim /[-12-16]_{\mathrm{p}}$

Table I -- $d$-spacing values of the planes used in this study.

\begin{tabular}{llll}
\hline 5:4 Matrix Phase & d-space $(\AA)$ & 5:3 Thin-Plate & d-space $(\AA)$ \\
\hline$(020)$ & 7.415 & $(-1010)$ & 7.387 \\
$(100)$ & 7.697 & $(0001)$ & 6.4 \\
$(102)$ & 3.473 & $(1-211)$ & 3.549 \\
\hline
\end{tabular}


Previous studies have shown that the observed 5:3 thin-plates are present in all three different crystal structures of $\mathrm{Gd}_{5}\left(\mathrm{Si}_{\mathrm{x}} \mathrm{Ge}_{1-\mathrm{x}}\right)_{4}$ [17]. This indicates a similar formation mechanism which is relatively crystal structure independent, and the possibility that the plates form at high temperature upon cooling from a common orthorhombic structure was discussed in ref. [18]. Based on this hypothesis $\mathrm{Gd}_{5} \mathrm{Ge}_{4}$-type orthorhombic samples were used for the HRTEM part of this study. Using a compound with an orthorhombic matrix structure instead of a monoclinic one not only allowed more accurate representation of the conditions assumed at high temperature, but also served to decrease the complexity of the crystallographic analysis, which, in turn, made the simulations more accurate.

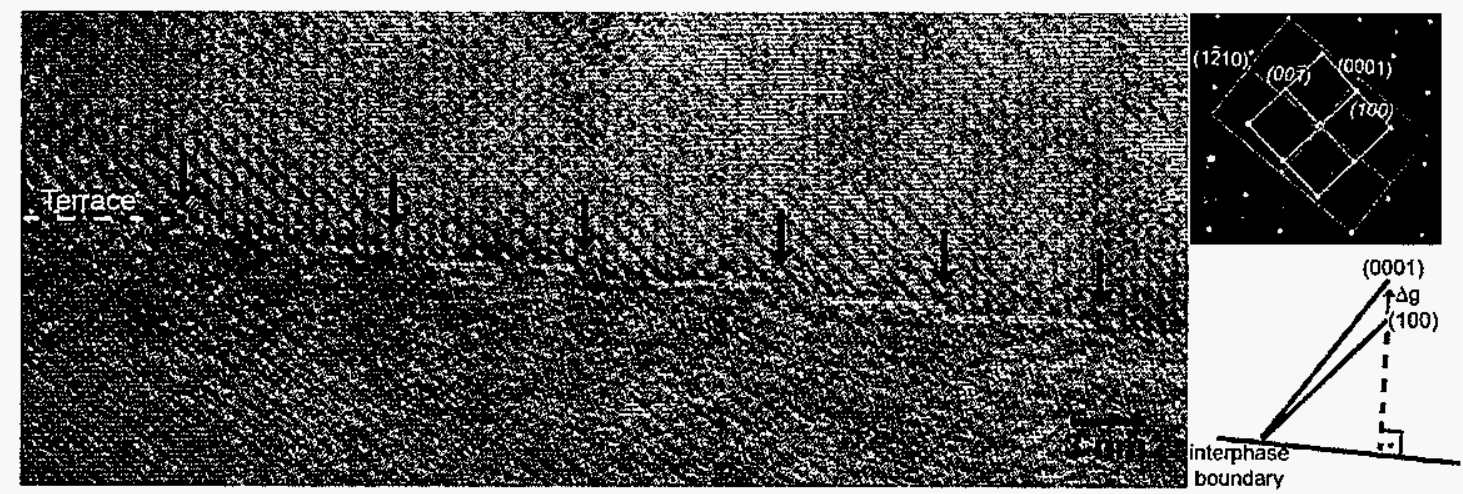

Figure 5 -- High Resolution Electron Microscope (HREM) image taken from a Gd5Ge4 single crystal showing the ledge-wise interface between the thin-plates and matrix. $B=[010] \mathrm{m} / /[-1010] p$ (Risers shown with black arrows and one terrace shown with dashed line).

Figure 5 shows a HRTEM image of the interface between a 5:3 thin-plate and the matrix phase taken with $B=[010]_{\mathrm{m}} / /[-1010]_{\mathrm{p}}$. Periodic risers (arrowed) can be seen in Figure 5 joining terraces; note that the terraces are not parallel to the interface. However, the $\Delta \mathrm{g}$ between $\mathrm{g}_{(0001)}$ and $\mathrm{g}_{(100)}$ remains perpendicular to the interface plane as noted earlier for the monoclinic matrix. Figures 6 (a) and 6 (b) show HRTEM images of the interface with the same beam conditions $\left(B=[010]_{\mathrm{m}} / /[-1010]_{\mathrm{p}}\right)$, but with different defocus values. Due to thickness differences between the matrix and the thin-plates, a HRTEM image showing good 
contrast in both phases could not be obtained from a single area at the same time. Therefore, Figures 6 (a) and 6 (b) were taken from two different plates in the same sample, but in slightly different thickness regions within the foil. The image orientation was exactly the same for both, only the thickness and defocus values were different. In Figure 6 (b) it can be seen clearly that $(0001)_{\mathrm{p}}$ and $(100)_{\mathrm{m}}$ planes meet edge-to-edge across the interface. A slight rotation angle of $7^{\circ}$ exists between the planes of atoms, and the $\Delta \mathrm{g}$ between matrix and precipitate is perpendicular to the interface (see Figures 2 (a) and 2 (b)). Figure 6 (c) shows the atomic model of the matrix and 5:3 plate interface, where the ledges and their associated terrace planes can be seen clearly as well as the $7^{\circ}$ rotation angle between the $(0001)_{\mathrm{p}}$ and $(100)_{\mathrm{m}}$ planes.

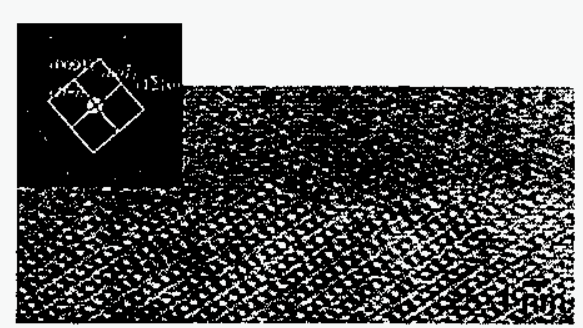

(a)

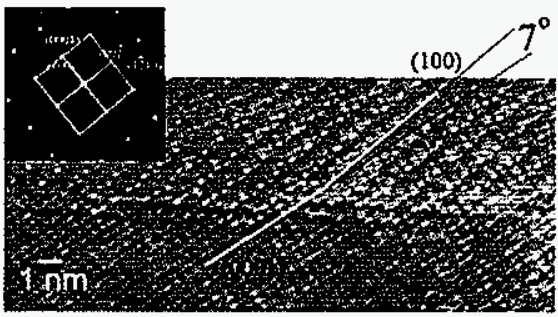

(b)

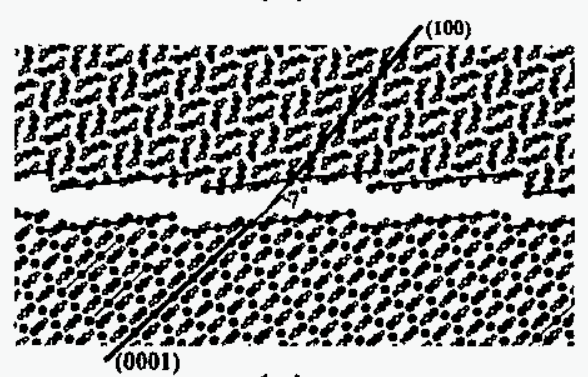

(c)

Figure 6 -- HREM image taken at $B=[010]_{m} / /[-1010]_{p}$, showing planes on (a) precipitate (b) matrix. (b) also shows the $7^{\circ}$ angle between $(100)_{m}$ and $(0001)_{p}$. (c) schematic of atoms showing the ledge-wise interface. 


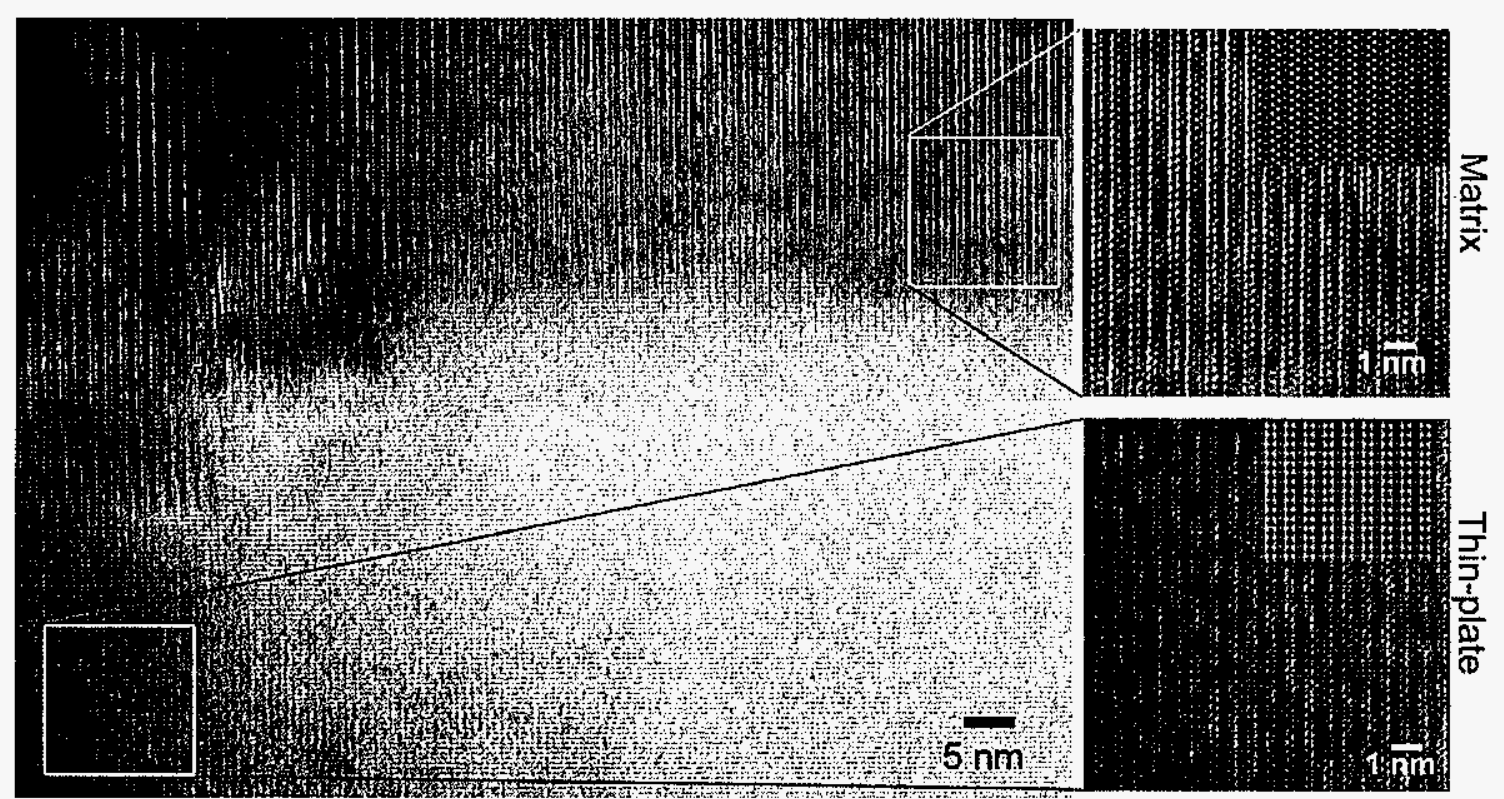

Figure 7 -- HREM taken at $B=[201]_{\mathrm{m}} \sim / /[-12-16]_{\mathrm{p}}$, showing both matrix and thin-plate. HREM images and their simulations showed on right.

The HRTEM image shown in Figure 7 was taken with the beam orientation $B=$ $[201]_{\mathrm{m}} / /[-12-16]_{\mathrm{p}}$, which is the second aligned direction observed (see Figures 3 (a) and 3 (b)). On this occasion a single plate was found extending through a large region of varying thickness so distinctive HRTEM images of both matrix and 5:3 plate could be obtained from slightly different regions of the same plate. Those areas are enlarged to show the details clearly, with simulated images of each phase shown in the upper right corner. In Figure 8 a the simulated images of the phases using MacTempas are shown overlapped with the simulated atomic structure (open circles) produced using the Crystal Maker software. For clarity just the atomic structure simulation is shown in Figure $8 \mathrm{~b}$, where the $(020)_{\mathrm{m}} / /(-$ $1010)_{\mathrm{p}}$ and $(10-2)_{\mathrm{m}} / /(1-211)_{\mathrm{p}}$ plane alignment can be seen.

\section{Discussion}

The orientation relationship between the matrix phase and the 5:3 thin-plates initially determined using a monoclinic matrix sample as $[-1010](1-211)_{\mathrm{p}} /\left[[010](10-2)_{\mathrm{m}}\right.$, and summarized in Figure 3, is also seen for the orthorhombic matrix crystal structure used in the 


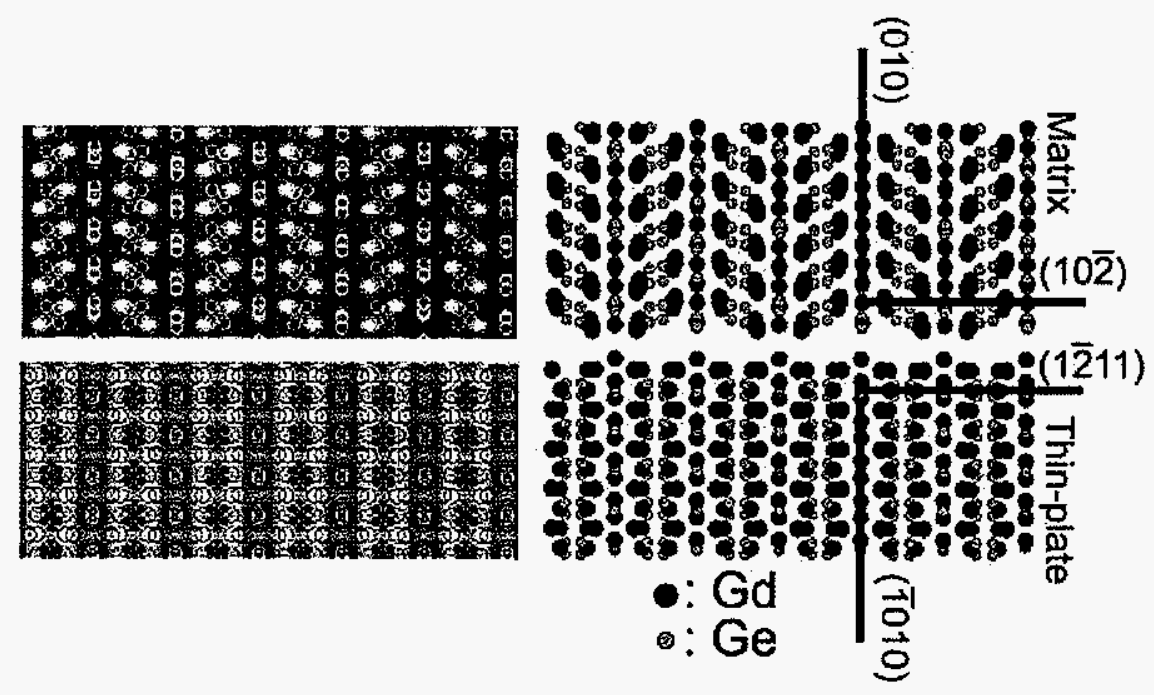

Figure 8 -- Atomic structure (a) overlapped on HREM simulations and (b) simulated with crystal maker showing the parallel planes.

HRTEM studies (Figures 6 and 7). This is not surprising since the very slight differences between these two structures in terms of lattice parameters and atom positions have been discussed extensively elsewhere [13].

Numerous studies have noted that the interface plane between the matrix and the thinplates is not parallel to any low-index planes in the matrix $[15,17,18]$. This can be understood if one considers the formation of the plates in terms of the invariant line (IL) theory, which, unlike planar alignment of atoms, involves a direction that remains unrotated and unstretched during the transformation [20]. An IL interface has a zero misfit strain and, thus, it has a low interfacial energy. Dahmen [20] showed that instead of having a low-index interface plane with a significant mismatch across the planes of the interface, which also requires unit-vector-type misfit dislocations, an IL boundary will form parallel to the IL direction to have a completely unstrained coherency. Since the IL boundary usually has a low atomic density, it adopts a ledged structure with terraces and risers to increase the atomic density. This description accurately reflects what has been observed in this study (Figure 5). It can be seen from Figure 6 (c) that the terrace planes are much more densely packed than 
the IL boundary (i.e. the interface boundary). If the difference between interplanar spacings (d-space) of the edge-on matrix and precipitate planes is too great, a rigid body rotation about a principal axis will be necessary to convert the general transformation strain into the invariant line strain. This rotation can be calculated using Equation 1, which has been derived from matrix algebra[20], where, $a$ and $b$ are the principal distortions required to make the two lattices coincident, and $\theta$ is the angle of rigid body rotation.

$$
\cos \theta=\frac{1+a b}{a+b}
$$

The interplanar misfit between the $(100)_{\mathrm{m}}$ matrix and $(0001)_{\mathrm{p}}$ precipitate planes, the edge-on planes of Figure $6 \mathrm{~b}$, is $15.6 \%$, which necessitates a rigid body rotation to maintain an invariant line strain. According to Eqn 1., the principle distortions, a and b, required to make the precipitate lattice coincident with the matrix lattice in the $B=[010]_{m} / /[-1010]_{p}$ direction are calculated as 0.91 along [001] and 1.2 along [100]. Using these values the required rotation of the $5: 3$ thin-plate phase relative to the matrix phase about $[010]_{\mathrm{m}} / /[-$ $1010]_{\mathrm{p}}$ can be calculated as 7.4 degrees, which is very close to the experimentally measured $7^{\circ}$. Note from Eqn. 1 that the direction of rotation is unspecified, implying that identical results can be obtained with either a $\mathrm{CW}$ or $\mathrm{CCW}$ rotation. Thus, the observations of this study (namely, the rotation of the 5:3 thin-plates around $[010]_{\mathrm{m}} / /[-1010]_{\mathrm{p}}$ ) are consistent with what would be expected in a transformation involving an invariant line strain. The two observed variants as clearly illustrated in Figures 2(a) and 2(b) are a direct result of the $7.4^{\circ}$ $\mathrm{CW}$ or $\mathrm{CCW}$ rotation necessary to produce an invariant line strain, resulting in two variants which are approximately $\pm 50^{\circ}$ to the $[100]_{\mathrm{m}}$ direction.

The interface plane direction, when viewed along $[201]_{\mathrm{m}} / /[-12-16]_{\mathrm{p}}$ direction, is determined parallel to $[010]_{\mathrm{m}}$ and [-1010] $]_{\mathrm{p}}$. This situation is shown simulated in Figure 8 . In this orientation the mismatch between the $d$-spacings of the $(020)_{\mathrm{m}}$ and $(-1010)_{\mathrm{p}}$ matching 
planes is very small $\left(0.4 \%\right.$ compared to $15.6 \%$ for the $\left.(100)_{m} / /(0001)_{p}\right)$. Thus, rotation of the structure is not required in order to reduce the transformation strain and maintain an invariant line transformation. It is interesting that what appear to be regularly spaced mismatch dislocation are observed at the interface when viewed in this orientation (see Figure 4). Their presence presumably account for the slight $0.4 \%$ difference measured in $\mathrm{d}$-spacings.

The experimental results of this study are also consistent with the $\Delta \mathrm{g}$ approach introduced by Purdy and Zhang [21], which was an extension of the coincident site lattice (CSL) or o-lattice model of Bollmann [22]. When overlapping electron diffraction patterns obtained from both matrix and precipitate phases are observed along a specific direction parallel to the interface plane, the $\Delta \mathrm{g}$ approach says that the difference vector $\Delta \mathrm{g}$ joining the pairs of reciprocal lattice vectors of the edge-on-planes of the matrix and the precipitate should be perpendicular to the interface plane. This alignment should be observed when the beam direction corresponds to a reasonably low-index direction in both phases. These conditions are fulfilled in the results seen in this study, where it has been observed that when viewed along $B=[010]_{\mathrm{m}} / /[-1010]_{\mathrm{p}}$ directions (Figure 2) the difference vector $\Delta \mathrm{g}_{1}$ of the $(100)_{\mathrm{m}}$ and $(0001)_{\mathrm{p}}$ edge-on-planes is perpendicular to the interface plane. In a similar way it can be shown that the $\Delta \mathrm{g}_{2}=\mathrm{g}(-12-10)_{\mathrm{p}} \mathrm{g}(00-2)_{\mathrm{m}}$ is also perpendicular to the interface plane (Figure $2 \mathrm{~b}$ ). Using the fact that the $\Delta \mathrm{g}$ vector is perpendicular to the macroscopic habit plane of the thin plates, the habit plane has been determined as (22 019$)$ and $(-22019)$ by calculating $\Delta \mathrm{g}$ from the observed reciprocal lattice vectors of the matrix and precipitate using vector algebra.

While the $(0001)_{\mathrm{p}}$ and $(100)_{\mathrm{m}}$ planes match edge-to-edge at the interface as shown in Figure 6, it has already been discussed that the mismatch between their $d$-spacing values (Table I) is too high for them to be parallel. Thus, the rigid-body rotation of approximately $7^{\circ}$, as explained and calculated previously, is necessary to maintain an invariant line. After 
the rotation, the shared interface distance between the planes $(0001)_{\mathrm{p}}$ and $(100)_{\mathrm{m}}$ planes becomes $\sim 11.9 \AA$ at an angle of $40^{\circ}$ to the $(100)_{\mathrm{m}}$ plane, Figure 9 .

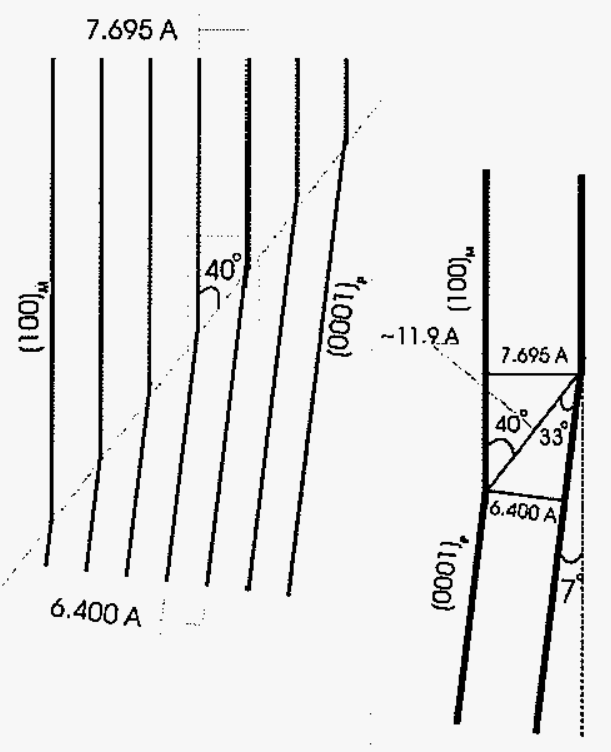

Figure 9 -- Schematic diagram of edge-to-edge $(100)_{\mathrm{m}}$ and $(0001)_{\mathrm{p}}$ planes and the interface.

It is believed that a displacive transformation mechanism plays the most active role in the formation of 5:3 thin-plates. The presence of the plates even in arc-melted samples where the cooling rate is extremely high suggests a rapid rate of formation, precluding the normal, more slowly paced transformation usually associated with a Widmanstaetten transformation. However, a displacive transformation does not appear to be the only active mechanism in this system, as the composition difference between the matrix and the product phase also indicates a diffusional component. The orientation results indicate the presence of an invariant line strain, which is equally applicable to either a displacive $[23,24]$ or a diffusional $[20,25,26]$ transformation. Therefore, the transformation is believed to be best described as displacive - diffusional where the diffusion process is a short-range shuffling of atoms that occurs at high temperatures. As suggested in ref. [17] formation of the 5:3 thinplates at high temperatures in a common orthorhombic structure would not only account for 
their observed presence in both orthorhombic and monoclinic structures, but would also imply that sufficient atomic mobility is present at these high temperatures for atoms to shuffle and form the 5:3 structure fairly easily.

It has been observed that the 5:3 thin plates have a thickness $<250 \mathrm{~nm}$, but extremely long lengths, up to hundreds of microns [18]. The reason for the 5:3 phase adopting this shape during transformation is believed to be related to the suspected displacive-diffusional transformation. Since the $d$-spacings of the $(0001)_{\mathrm{p}}$ and $(100)_{\mathrm{m}}$ edge-to-edge planes are large as previously discussed, the interface plane may correspond to an atomic arrangement that possesses low minimum interface energy. If one assumes that low energy interfaces have low mobility, the interface should transform into terraces and risers [27]. This exactly described the interface as observed in HRTEM images (Figure 5). After the transformation, the terraces will still have a low mobility due to their quite densely packed planes, which prevent them from migrating easily in the direction normal to themselves. However, the risers will have a higher mobility due to kinks that form on them, which provide disordered areas at the interface [28]. These disordered areas facilitate atomic attachment and detachment, which allows the risers to move parallel to the interface habit plane as shown in Figure 10. Gliding of the risers produces displacements in the matrix, which are called transformation dislocations. These transformation dislocations generate the shape strain necessary to obtain the product lattice [29]. Additional displacements can also occur within transformation dislocations, such as shuffling of atoms as mentioned in the previous paragraph. As a transformation dislocation glides parallel to the habit plane, the thickness of the plate will increase equal to the step height of the riser. Since the rate of migration of transformation dislocations is high due to the disordered areas on the risers, the length-tothickness ratio of the plate will be high. 


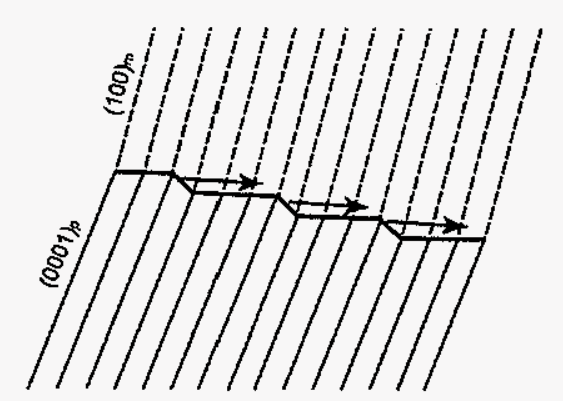

Figure 10 -- Schematic diagram showing the formation of the interface with ledges.

If the overall composition of the compound is stoichiometric 5:4 then transformation of the 5:4 phase into the 5:3 phase should yield extra Si-Ge in the matrix, since 5:3 is more Si-Ge deficient than 5:4. However, no Si-Ge rich areas have been detected in the matrix. Loss of $\mathrm{Si}-\mathrm{Ge}$ due to evaporation during melting is possible, and may have occurred. However, the 5:3 phase has been observed in 5:4 areas of alloys which were deliberately designed to be both rich and deficient in Si-Ge [30]. Therefore, 5:3 formation does not appear to be due simply to Si-Ge deficiency. Most probably, any extra Si-Ge that results due to transformation of $5: 4$ to $5: 3$ is distributed homogeneously in the matrix where the slight difference in composition is undetectable.

\section{Conclusion}

The 5:3 plates examined in this study have been observed in several systems including $\mathrm{Gd}, \mathrm{Tb}$, Dy and Er involving matrix crystal structures of $\mathrm{Gd}_{5} \mathrm{Si}_{4}$-type orthorhombic, $\mathrm{Gd}_{5} \mathrm{Si}_{2} \mathrm{Ge}_{2}$-type monoclinic, and $\mathrm{Sm}_{5} \mathrm{Ge}_{4}$-type orthorhombic. The orientation relationship between the hexagonal 5:3 thin-plate phase and the matrix phase (both orthorhombic and monoclinic) in $\mathrm{Gd}_{5}\left(\mathrm{Si}_{\mathrm{x}} \mathrm{Ge}_{1-\mathrm{x}}\right)_{4}$ alloys has been determined as [-1010](1$211)_{\mathrm{p}} / /[010](10-2)_{\mathrm{m}}$. HRTEM images revealed the atomic structure of the interface when viewed along $B=[010]$ to consist of a series of regularly spaced risers and terraces aligned along an irrational interface habit plane. In additional, a $7^{\circ}$ rotation about the $[010]_{\mathrm{m}} /[\mathrm{I}$ 
$1010]_{p}$ is observed, which results in better matching of the d-spacings of the edge-on planes. These observations can be explained in terms of the invariant line (IL) theory and a $\Delta \mathrm{g}$ difference vector approach. By adopting a riser and terrace interface, coupled with the rotation to provide better edge-on matching, the interface can decrease its overall surface energy while increasing atomic density. The mechanism proposed for formation of the plates is a displacive-diffusional transformation based on the evidence presented. Formation of terraces on the interface boundary results in a low mobility perpendicular to the interface, but a high mobility along the risers in the approximate direction of the interface. This explains the extremely high length-to-thickness aspect ratio of the observed plates. A displacive component also would account for the speed with which the plates form when cooling $\mathrm{RE}_{5}\left(\mathrm{Si}_{\mathrm{x}} \mathrm{Ge}_{1-\mathrm{x}}\right)_{4}$ type compounds from high temperatures.

Most available current binary phase diagrams for these systems show the 5:4 and 5:3 compounds as line compounds. It has been suggested that a common high temperature orthorhombic structure exists for all these systems and the proposed solid-state displacive diffusional mechanism for formation would imply that a region of solid solubility may also exist at high temperatures for the 5:4 phase.

\section{Acknowledgements}

This work was performed at Ames Laboratory under contract No. W-7405-Eng-82 with the US Department of Energy. This research was supported by the Office of Basic Energy Sciences, Materials Science Division of the US DOE. The authors wish to thank B. Muddle and V. K. Pecharsky for helpful discussions in the preparation of this manuscript.

\section{References}

1. Pecharsky VK, Gschneidner Jr KA. Phys Rev Lett 1997;78(23):4494-7.

2. Pecharsky VK, Gschneidner Jr KA. Appl Phys Lett 1997;70(24):3299-301. 
3. Levin EM, Pecharsky VK, Gschneidner Jr KA. Phys Rev B1999;60(11):7993.

4. Morellon L, Blasco J, Algarabel PA, Ibarra MR. Phys Rev B2000;62:1022.

5. Morellon L, Algarabel PA, Ibarra MR, Blasco J, Garcia-Landa B, Arnold Z, et al. Phys Rev B 1998;58(22):R14721-4.

6. Gschneidner Jr KA, Pecharsky VK, Pecharsky AO, Zimm CB. Mater Sci Forum $1999 ; 315-317: 69-76$.

7. Gschneidner KAJ, Pecharsky VK. J Appl Phys 1999;85(8 pt. 2B):5365.

8. Morellon L, Stankiewicz J, Garcia-Landa B, Algarabel PA, Ibarra MR. Appl Phys Lett 1998;73(23):3462.

9. Morellon L, Algarabel PA, Magen C, Ibarra MR. J Magn Magn Mater 2001;237:119_ 23.

10. Del Moral A, Algarabel PA, Arnaudas JI, Benito L, Ciria M, De la Fuente C, et al. Magnetostriction effects. In: Proceedings of the joint European magnetic symposia (JEMS 2001), August 28 to September 1 2001. Grenoble: Elsevier Science; 2002.

11. Smith GS, Tharp AG, Johnson Q. Acta Crystallogr 1967;22:940-3.

12. Holtzberg F, Gambino RJ, McGuire TR. J Phys Chem Solids 1967;28:2283-9.

13. Pecharsky VK, Gschneidner Jr KA. J Alloys Compd 1997;260:98-106.

14. Pecharsky VK, Gschneidner KA. J Adv Mater 2001;13(9):683-6.

15. Szade J, Skorek G, Winiarski A. J Cryst Growth 1999;205:289-93.

16. Meyers JS, Chumbley LS, Laabs F, Pecharsky AO. Scr Mater 2002;47:509-14.

17. Ugurlu O, Chumbley LS, Schlagel DL, Lograsso TA, Tsokol AO. Scr Mater $2005 ; 55(3): 373-7$.

18. Ugurlu O, Chumbley LS, Lograsso TA, Schlagel DL. Acta Mater 2005;53:3525-53.

19. Baenziger NC, Hegenbarth JJ. Acta Crystallogr 1964;17:620-1.

20. Dahmen U. Acta Metall 1982;30(1):63-73.

21. Zhang W-Z, Purdy G. Philos Mag 1993;68:291. 
22. Bollmann W. Crystal defects and crystalline interfaces. New York (NY): Springer; 1970.

23. Wechsler MS, Lieberman DS. Trans AIME 1953;197:503-15.

24. Bowles JS, Mackenzie JK. Acta Metall 1953;2:29-37.

25. Dahmen U, Ferguson P, Westmacott KH. Acta Metall 1984;32(5):803-10.

26. Dahmen U, Westmacott KH. Acta Metall 1986;34(3):475-82.

27. Zhang W-Z, Purdy G. Philos Mag 1993;68:279-90.

28. Aaronson HI, Furuhara T, Rigsbee JM, Reynolds WT, Howe JM. Metall Trans A 1990;21A(9):2369-409.

29. Bowles JS, Wayman CM. Acta Metall 1979;27:833-9.

30. Ugurlu O, Chumbley LS, Schlagel DL, Lograsso TA. Unpublished research; 2005. 


\section{GENERAL CONCLUSIONS}

The microstructural characterization of linear features seen in $\mathrm{RE}_{5}\left(\mathrm{Si}_{\mathrm{x}}, \mathrm{Ge}_{1-\mathrm{x}}\right)_{4}$ alloys was the main interest of this research. The objectives of this study were to: 1) determine the extent of linear features in rare-earth 5:4 alloys and identify their morphology, 2) determine the crystal structure and accurately measure the composition of the features, 3) determine their growth direction and the growth mechanism. The following conclusions summarize the major findings in this dissertation as they are related to these research objectives.

\section{Observation and Morphology}

Linear features have been observed in polished cross-sections of many $\mathrm{RE}_{5}\left(\mathrm{Si}_{\mathrm{x}}, \mathrm{Ge}_{1-}\right.$ x) ${ }_{4}$ alloys prepared from different rare-earths ( $\mathrm{Gd}, \mathrm{Tb}$, Dy and $\mathrm{Er}$ ). The crystal structures of the alloys varied from the $\mathrm{Sm}_{5} \mathrm{Ge}_{4}$-type orthorhombic to monoclinic to $\mathrm{Gd}_{5} \mathrm{Si}_{4}$-type orthorhombic depending on the composition. Regardless of the parent matrix or the exact composition the linear features were present in all the alloys studied. This showed that the existence of linear features is independent of the specific crystal structure and the rare-earth component of the matrix phase. Linear features have also been seen in samples prepared with various process methods such as arc-melting, induction melting and Bridgman and Czochralski single crystal pulling. It is clear that formation of this phase is highly favored by nature in 5:4 compounds although the exact driving force is unknown.

Systematic SEM studies have showed that the morphology of the linear features is a thin-plate as opposed to a rod as suggested by previous studies [1,2]. The average width of the thin-plates, measured from TEM and Back-scattered electron micrographs, is found to be on the order of $250 \mathrm{~nm}$ with the plate dimensions running to hundreds of microns. The observed plate widths are much thicker in SEM micrographs then TEM due to etching effects. 


\section{Crystal Structure and Composition}

Using selected area diffraction (SAD), the crystal structure of the linear features in $\mathrm{Gd}_{5}\left(\mathrm{Si}_{\mathrm{x}} \mathrm{Ge}_{1-\mathrm{x}}\right)_{4}$ has been determined as hexagonal and the lattice parameters have been calculated as $\mathrm{a}=\mathrm{b}=8.53 \AA$ and $\mathrm{c}=6.40 \AA$. SAD diffraction studies have been confirmed with convergent beam electron diffraction (CBED) patterns and high-resolution TEM images taken at $\mathrm{B}=[0001]$ (see Appendix B - Fig. 1).

The initial composition measurements of the thin-plates, which were carried out using SEM equipped with an EDS, showed a consistent increase of the rare-earth content in all of the $\mathrm{RE}_{5}\left(\mathrm{Si}_{\mathrm{x}}, \mathrm{Ge}_{1-\mathrm{x}}\right)_{4}$ alloys prepared from various rare-earths with different compositions. Using EDS in TEM made it possible to acquire more accurate quantitative results. Accurate EDS results together with the SADs indicated that the second phases in $\mathrm{Gd}_{5} \mathrm{Si}_{2} \mathrm{Ge}_{2}$ and $\mathrm{Er}_{5} \mathrm{Si}_{4}$ alloys have lattice parameters and compositions that match extremely well to compounds of $\mathrm{Gd}_{5} \mathrm{Si}_{1} \mathrm{Ge}_{2}$ and $\mathrm{Er}_{5} \mathrm{Si}_{3}$, respectively.

The source of the increased rare-earth content of the thin-plates has been revealed with the help of detailed TEM-EDS line-scan studies. These studies showed a rare-earth deficient region within the matrix phase next to the thin-plate interface, typical of a diffusion profile. The width of the depleted regions was approximately $1 / 4^{\text {th }}$ of the observed thin-plate thickness (see Appendix A - Fig. 6).

\section{Growth Direction and Growth Mechanism}

The [010]-oriented SEM micrographs have shown that the linear features have two variants with an $80^{\circ}$ angle between them. Both SEM and TEM studies confirmed that the lines are not parallel to any low-index crystal direction. The orientation relationship between the hexagonal thin-plates and the matrix phase was determined as $[-1010](1-211)_{\mathrm{p}} / /[010](10-$ $2)_{m}$ using SAD and confirmed with high resolution TEM (HRTEM). 
SAD patterns demonstrated that there is a $7^{\circ}$ rotation about the $[010]_{\mathrm{m}} / /[-1010]_{\mathrm{p}}$ between the reciprocal lattices of the thin-plates and the matrix phase. Further studies showed that this rotation can be in opposite directions ( $\mathrm{CW}$ and $\mathrm{CCW}$ ) resulting in two observed variants.

Comprehensive HRTEM images revealed a terrace-ledge structure at the interface, which plays a very important role in the determination of the growth direction and mechanism. Both the $7^{\circ}$ rotation and the terrace-ledge type interface can be explained in terms of invariant line (IL) theory. Calculations based on the angle of rotation have shown that the thin-plates grow along invariant line directions. By adopting a terrace-ledge type interface the thin-plates are able to grow along these directions with a minimum energy while retaining a high atomic density. The exact growth direction of the thin-plates has been calculated as (22 019$)$ and (22 0 -19) by applying the $\Delta \mathrm{g}$ approach of Zhang and Purdy $[3,4]$ to the SAD patterns.

High cooling rates during sample preparation indicate rapid growth rates for formation of the thin-plates. Coupled with the composition differences of the thin-plates with the matrix, this points out to a very unusual formation mechanism. A composition difference indicates some kind of an atomistic diffusion. However, a diffusion mechanism is not fast enough by itself to account for the extensive growth of the observed plates. A displacivediffusional growth mechanism has been suggested based on the observed peculiar terraceledge interface structure, the thin-plate shape and the rapid growth rates. Formation of terraces on the interface boundary results in low mobility perpendicular to the interface, but high mobility along the risers in the approximate direction of the interface. This explains why the plates grow so fast along one direction and are so thin along the other direction. When considering the rapid formation of the thin-plates, a displacive component is assumed to contribute to the phase formation. The complexity of the matrix crystal structure and the number of atoms (monoclinic or orthorhombic with 36 atoms) make this system unique when 
compared to previous studies, where only simple structures are observed to undergo displacive-diffusional formation (e.g. cubic with a maximum of 4 atoms [5-7]).

The unusual combination of features noted in this study, namely, the extremely extensive, yet thin, plate-shape, the rapid formation from the solid-state, and the similar appearance of the 5:3 phase in all RE 5:4 systems regardless of crystal structure or exact composition, all point to a rather unique phase formation mechanism. While the actual driving force for formation is unknown, it seems clear that thin plate formation of $5: 3$ is a highly favored structure, one which would appear to be thermodynamically stable. Accordingly, two sets of experiments were conducted testing the stability of the phase as a function of thermal cycling and the persistence of the phase as a result of varying the composition widely. The results are summarized in Appendix B.

Thermal cycling experiments to both low $\left(-1^{\circ} \mathrm{C}\right)$ and high $\left(320^{\circ} \mathrm{C}\right)$ temperatures have been carried out. Close observation of the structure has shown no difference in the presence of the 5:3 plates (Appendix B - Fig. 4). Studies of off-stoichiometric samples involving RE rich and poor alloys have shown that the 5:3 phase exists whenever there is a 5:4 phase in the system (Appendix B - Fig. 3). Both results point to the extreme stability of the 5:3 plate structure. The off-stoichiometry studies are especially telling since simple observation of the Er-Si equilibrium phase diagram would suggest that formation of the $5: 3$ phase should be difficult at best, if not impossible. Yet the fact remains that 5:3 is always seen within the $5: 4$ structure.

The unique phase transformation described by this thesis does not appear to have any other parallel in metallic systems. As such it provides a great opportunity for studying and understanding the fundamental relationships that lead to this most unusual solid-solid phase transformation. 


\section{Recommendations for Future Work}

1. It is known that the thicker appearance of the thin-plates on SEM images is because of the etching effects. It has also been shown that the matrix material piles up on the shoulders of the thin-plate phases and it has been suggested that this is due to the different hardness values of the phases. However, hardness values of the thin-plates have not been measured as yet. This could easily be done by using an in-situ nanohardness indenter stage on a TEM.

2. $\mathrm{RE}_{5}\left(\mathrm{Si}_{\mathrm{x}}, \mathrm{Ge}_{1-\mathrm{x}}\right)_{4}$ alloys are very important materials for magnetic refrigeration systems due to their giant magnetocaloric effect (MCE). This study has shown that the thinplates exists in all of the $\mathrm{RE}_{5}\left(\mathrm{Si}_{\mathrm{x}}, \mathrm{Ge}_{1-\mathrm{x}}\right)_{4}$ alloys. If an absolutely phase pure $\mathrm{RE}_{5}\left(\mathrm{Si}_{\mathrm{x}}, \mathrm{Ge}_{1-\mathrm{x}}\right)_{4}$ alloy can be prepared, it's MCE properties could be compared to a non-phase-pure alloy. While no processing technique is known to produce a phasepure sample a focused ion beam could be used to remove a phase pure area from a non-phase-pure sample. The MCE properties of this small sample could then be tested.

3. Even though this study identified most of the structural properties of the thin-plates, the actual formation temperature is still unknown. In-situ high temperature experiments under controlled atmosphere may help to enlighten this area. However, the small volume percentage of the thin plates in the matrix phase prevents the use of many in-situ instruments like XRD, Magnetometer and DSC. The best technique to observe the thin-plates is electron microscopy. However, a stage capable of extremely high temperatures $\left(\sim 1200^{\circ} \mathrm{C}\right)$ is required.

4. A displacive-diffusional transformation has been suggested as the growth mechanism. Atomistic simulation of the phases involved coupled with ab-initio calculations of phase stability would greatly contribute to our understanding of the mechanism driving this unusual reaction. 
5. Other micro and macro scale features have been observed in $\mathrm{RE}_{5}\left(\mathrm{Si}_{\mathrm{x}}, \mathrm{Ge}_{1-\mathrm{x}}\right)_{4}$ alloys. In addition to this study to which focused on the thin-plates, microscopic twins have been characterized [8] and a macroscopic twin-like feature has been observed.

HRTEM coupled with CBED could be used to investigate the nature and formation of the macro-twin, which as yet are not fully understand or characterized.

\section{References}

1. Szade J, G.Skorek, Winiarski A. Journal of Crystal Growth 1999;205:289 - 93.

2. Meyers JS, Chumbley LS, Laabs F, Pecharsky AO. Scripta Materialia 2002;47:509 14.

3. Zhang W-Z,Purdy G. Philosophical Magazine 1993;68:279 - 90.

4. Zhang W-Z,Purdy G. Philosophical Magazine 1993;68:291.

5. Furuhara T, Howe JM, Aaronson HI. Acta Metallurgica et Materialia 1991;39(11):2873-86.

6. Rigsbee JM,Aaronson HI. 1979;27(3):365-76.

7. Chen JK, Purdy GR, Weatherly GC, Kroupa A. Metallurgical and Materials Transactions A: Physical Metallurgy and Materials Science 1998;29A(8):2049-58.

8. Meyers JS, Chumbley S, Laabs F, Pecharsky AO. Acta Materialia 2003;51(1):61-70. 


\title{
APPENDIX A: LINEAR MICROSTRUCTURAL FEATURES IN $\mathrm{RE}_{5}(\mathrm{Si}, \mathrm{Ge})_{4}$-TYPE ALLOYS: DIFFICULTIES IN IDENTIFICATION
}

\author{
A paper to be submitted to \\ Physical Review B Condensed Matter and Materials Physics. \\ O. Ugurlu ${ }^{1,2}$, L.S. Chumbley ${ }^{1,2}$
}

\begin{abstract}
Since the discovery of the giant magnetocaloric effect (MCE) in $\mathrm{Gd}_{5} \mathrm{Si}_{2} \mathrm{Ge}_{2}$ alloys, compounds based upon the $\mathrm{RE}_{5}\left(\mathrm{Si}_{\mathrm{x}} \mathrm{Ge}_{1-\mathrm{x}}\right)_{4}$ structure have been the subject of numerous attempts to characterize the microstructure. The earliest attempt by Szade et al.reported the existence of what were termed "linear features" visible on the surface of samples of compositions $\mathrm{Gd}_{5} \mathrm{Si}_{4}, \mathrm{Gd}_{5} \mathrm{Si}_{2} \mathrm{Ge}_{2}$ and $\mathrm{Gd}_{5} \mathrm{Ge}_{4}$. Since that time the appearance of these features has been verified by a number of authors who have investigated various aspects of the microstructure of these alloys using a variety of techniques. Rather than becoming clearer and better understood, contradictions in the reported literature as to the nature of specific features noted within the microstructures of these alloys have resulted in much confusion. This paper consists of a brief review of the current literature in an attempt to clarify the situation and eliminate certain misconceptions that exist concerning various features that have been observed and studied.

\footnotetext{
'Department of Materials Science and Engineering, Iowa State University, Ames IA 50011 USA

${ }^{2}$ Ames Laboratory (DOE), Iowa State University, Ames IA 50011-3020, USA
} 


\section{Introduction}

Since the discovery of the giant magnetocaloric effect (MCE) in $\mathrm{Gd}_{5} \mathrm{Si}_{2} \mathrm{Ge}_{2}$ alloys in 1997[1], compounds based upon the $\mathrm{RE}_{5}\left(\mathrm{Si}_{\mathrm{x}} \mathrm{Ge}_{1-\mathrm{x}}\right)_{4}$ structure have been the subject of numerous attempts to characterize the microstructure. The earliest reported attempt was by Szade et al., who first reported the existence of what were termed "linear features" visible on the surface of samples of compositions $\mathrm{Gd}_{5} \mathrm{Si}_{4}, \mathrm{Gd}_{5} \mathrm{Si}_{2} \mathrm{Ge}_{2}$ and $\mathrm{Gd}_{5} \mathrm{Ge}_{4}$ [2]. Since that time additional work has been conducted by a number of authors [3-13] who have investigated various aspects of the microstructure of these alloys using a variety of techniques. Rather than becoming clearer and better understood, contradictions in the reported literature as to the nature of specific features noted within the microstructures of these alloys have resulted in much confusion. There are a number of reasons why this situation has arisen. Differences in quality of equipment from one institution to another, and in the types of techniques employed to study these materials are believed to be a major contributing factor. Many of the stated contradictions could be due to false assumptions that have been made based upon inadequate data, or an incorrect interpretation of the results of others. This paper consists of a brief review of the current literature in an attempt to clarify the situation and eliminate certain misconceptions that exist concerning various features that have been observed and studied.

As a starting point, it first should be stated that numerous microstructural features exist in these alloys. These include obvious second phases inherent in the system as well as impurities introduced due to sample preparation [4]. Of more interest, and more confusion, are a series of linear features that may be observed at different length scales in the material, using different microscopy techniques. Three different types of features have been observed (see Table I) and for clarity in this discussion they will be designated as follows. 
Table I -- Types of different microscopic features and the techniques that are used to observe them.

\begin{tabular}{lll}
\hline Feature type & First Observed & Technique \\
\hline Linear Feature & Szade et al. [2], 1999 & Auger/ SEM, optical \\
Microscopic Twin & Meyers et al. [3, 5] 2002 & HRTEM \\
Macroscopic Twin & Meyers et al. [3, 5] 2002 & TEM \\
\hline
\end{tabular}

Linear Feature: This structure was first observed by Szade using scanning electron microscopy (SEM) / auger electron spectrometer (AES). It has since been observed in almost any study of these materials, the lone exception being one early study where the authors did not observe any linear features on arc-melted samples [4]. However, Linear Features in arc-melted samples have been observed in recent studies [8-12].

Microscopic Twin: This structure consists of what appear to be extremely small microscopic faults or twins visible in high resolution electron micrographs. First identified by Meyers, this structure has been attributed as confirmation of twinning which is predicted to exist in these materials on the basis of $x$-ray diffraction studies[14], and has been seen in several papers $[3,15]$.

Macroscopic Twin: The least investigated of the three, this structure was also first seen by Meyers [3,5] and has since been seen by others [11].

Since different studies have used different techniques to examine samples it is difficult to say whether all of these three features are present in every sample. The micro and macroscopic twins described above only appear to exist in samples exhibiting the monoclinic crystal structures $[14,15]$. However, the linear features have been seen at one time or another in all samples and crystal structures, even in those deemed to be "phase pure" by various techniques. Thus, of these three, the Linear Features have attracted the most interest and investigation. As a result, they have also been the topic of much discussion and the source of 
most of the confusion that presently exists. This paper will therefore only concern itself with a discussion of the Linear Features as defined above.

\section{Microscopical Observations and Diffraction Data}

When first noted by Szade these features were described as a structure of regular lines on the surface of as-grown single crystals. The lines appeared to consist of two variants, each variant having an observed fixed angular relationship with the other. When using the back-reflection Laue method the authors stated that the lines were not parallel to any crystallographic directions with low indices. The composition as measured using auger electron spectroscopy (AES) revealed that there was an increase in oxygen and gadolinium in the area of the lines. (Difficulties associated with accurately determining the composition of these features are dealt with in section 4 below.) The appearance of the Linear Features as initially described has since been verified numerous times [2, 4, 7-12]. The reason for the observed angular arrangement of the Linear Features was explained by Ugurlu $[8,9]$, who determined that the Linear Features were, in fact, not linear at all, but large thin plates which he identified as $\mathrm{Gd}_{5}(\mathrm{Si}, \mathrm{Ge})_{3}$ on the basis of selected electron diffraction (SAD) and energy dispersive spectroscopy (EDS) using TEM. The orientation of the Linear Features was described and a possible mechanism of formation was subsequently suggested in [9]. All of these studies employed TEM, coupled with high resolution imaging and EDS. Despite these early reports, subsequent papers have appeared stating that the observed "Linear Features" can not be $\mathrm{Gd}_{5}(\mathrm{Si}, \mathrm{Ge})_{3}$. Many of these statements are made on the basis of x-rays studies [11] and magnetometer studies that declare the material to be "phase pure". A limited number of studies employing TEM have also stated that no diffraction intensity was observed [11].

In order to evaluate the applicability of x-rays in establishing phase purity, one first needs to establish with some reliability what the minimum detection limits are for this 
specific case. In an attempt to do this, $x$-ray diffraction simulations of different volume percentages of $\mathrm{Gd}_{5} \mathrm{Si}_{3}$ in a matrix of $\mathrm{Gd}_{5} \mathrm{Si}_{4}$ have been run using the program GSAS to determine the minimum detectability limits. These results are shown in Figures 1(a) and 2 are calculated on the basis of a $\mathrm{Cu} \mathrm{K}_{\alpha}(\lambda=1.54056 \AA)$ and synchrotron $(\lambda=0.124665 \AA) \mathrm{x}$-ray sources, respectively. All the simulations have been produced with no backgrounds and with extremely narrow peak shapes to clearly show the differences in patterns as the volume percentage change from $0 \mathrm{vol} \%$ to $20 \mathrm{vol} . \% \mathrm{Gd}_{5} \mathrm{Si}_{3}$. As such, they represent the most favorable conditions possible for observing any extra reflections due to $\mathrm{Gd}_{5} \mathrm{Si}_{3}$, much better than what could be expected for typical experimental scans. For comparison, actual data obtained using $\mathrm{Cu} \mathrm{K} \alpha$ radiation is included in Figure 1(b). For the $\mathrm{Cu} \mathrm{K}_{\alpha}$ case, $2 \theta=35.1$ is the highest intensity peak for the $\mathrm{Gd}_{5} \mathrm{Si}_{3}$ phase, and might be expected to be the most noticeable peak. However, this peak is very close to $2 \theta=35.4$ peak of $\mathrm{Gd}_{5} \mathrm{Si}_{4}$. Due to peak broadening (e.g. Figure 1 (b)) this peak would not be detectable up to approximately 5 vol. $\%$. The effect of peak broadening on the $2 \theta=25.1,27.9$ and 30.4 peaks of $\mathrm{Gd}_{5} \mathrm{Si}_{3}$ will be less serious since they are relatively far away from the $\mathrm{Gd}_{5} \mathrm{Si}_{4}$ peaks, however their intensities are much lower than the $2 \theta=35.1$ peak of $\mathrm{Gd}_{5} \mathrm{Si}_{3}$. With the normal background values expected of $\mathrm{Cu} \mathrm{K} \mathrm{K}_{\alpha} \mathrm{x}$-ray sources the detectability limit for these peaks again can not be expected to be better than 5 vol.\% in most cases or even 10 vol\% in an extreme case. For the synchrotron data (Figure 2) the only differentiable peak is $2 \theta=2.8$ of $\mathrm{Gd}_{5} \mathrm{Si}_{3}$, which is the highest intensity peak. Due to the small wavelength of the synchrotron $\mathrm{x}$-ray source all the peaks are compressed into a much narrower angular range causing a higher degree of peak overlap. Even with the high intensity of synchrotron x-ray sources $\left(\sim 30\right.$ times higher than $\left.\mathrm{Cu} \mathrm{K}_{\alpha}\right)$, the detectability limit of $\mathrm{Gd}_{5} \mathrm{Si}_{3}$ should be expected to be no better than 5 vol. \% even under the most favorable conditions as was used for the simulations. 

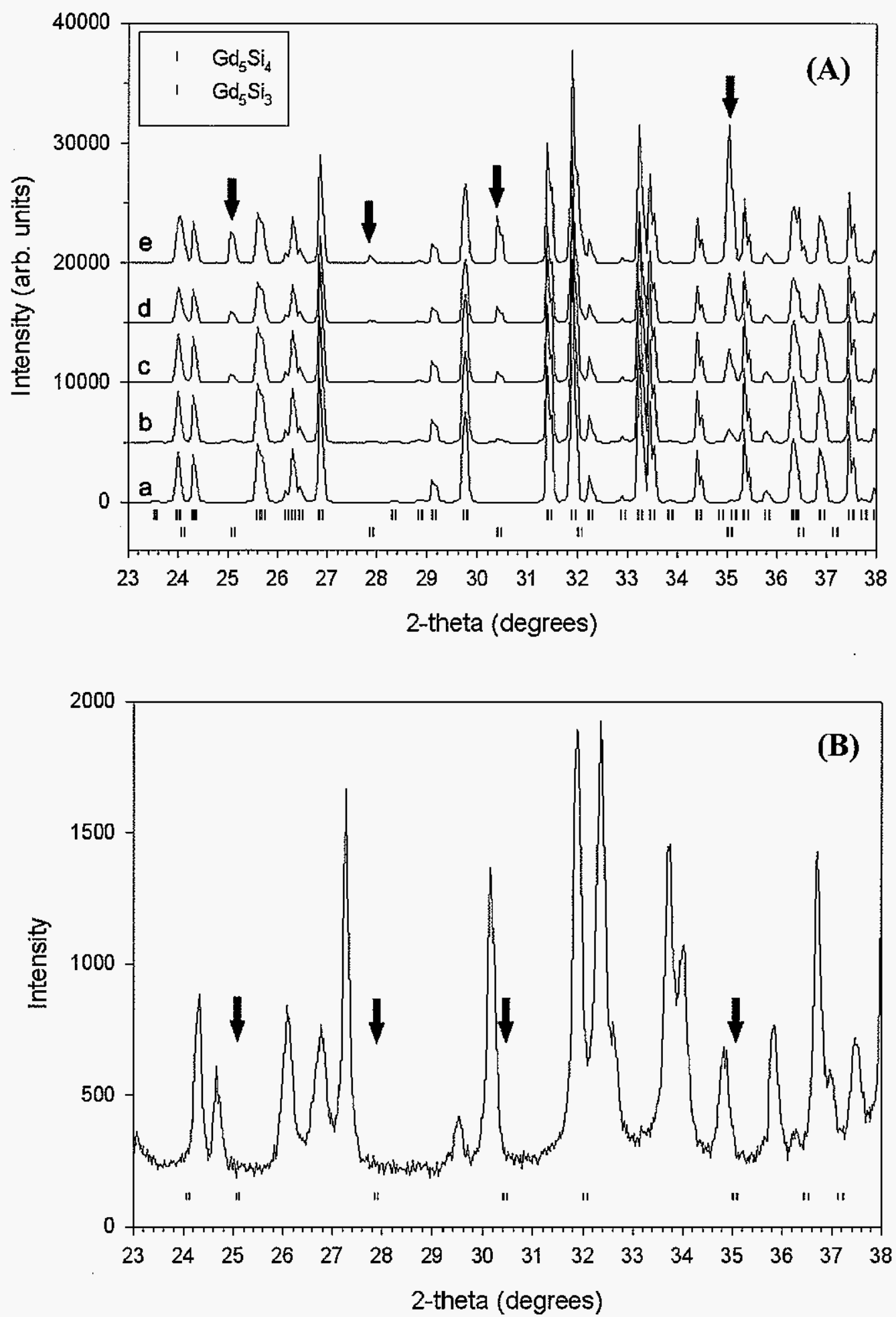

Figure 1 -- (A) $\mathrm{Cu} \mathrm{K}_{\alpha} \mathrm{X}$-ray diffraction simulations of $\mathrm{Gd}_{5} \mathrm{Si}_{4}$ with (a) 0 vol. \%, (b) 2 vol $\%$, (c) 5 vol \%, (d) 10 vol. \%, (e) 20 vol. \% $\mathrm{Gd}_{5} \mathrm{Si}_{3}$.

(B) $\mathrm{Cu} \mathrm{K} \alpha \mathrm{X}$-ray diffraction of an actual $\mathrm{Gd}_{5} \mathrm{Si}_{4}$ sample. It is estimated that this sample contains approximately $2-3 \mathrm{vol} \%$ of the linear features. 


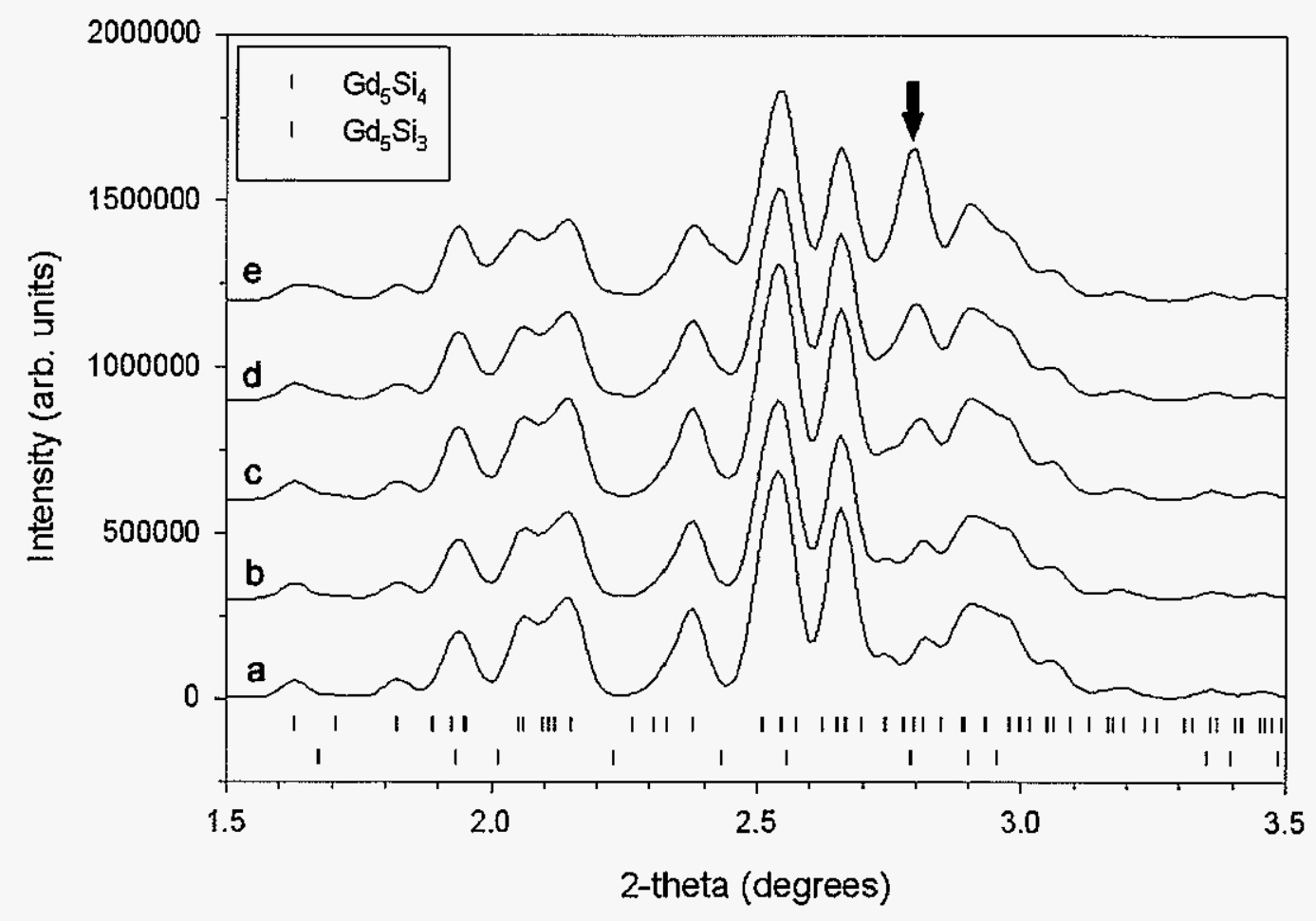

Figure 2 -- Syncrotron $\mathrm{X}$-ray diffraction simulations of $\mathrm{Gd}_{5} \mathrm{Si}_{4}$ with (a) 0 vol. \%, (b) 2 vol \%, (c) 5 vol \%, (d) 10 vol. \%, (e) 20 vol. $\% \mathrm{Gd}_{5} \mathrm{Si}_{3}$.

Upon first examination it would appear that this minimum level of $5 \mathrm{vol} \%$ is exceeded in a number of studies where the Linear Features are noted. For example, using Figures from $[2,4,10,11]$ computer analysis of scanned SEM images from these papers give a range between 5 to 16 vol. $\%$ of linear features (average $=\sim 10.6$ vol. \%), Table I. These numbers would appear to be in rough agreement with what one might estimate by observing figures from other sources. However, it has been suggested that images obtained using optical or SEM techniques significantly overestimate the width of the observed linear features [8]. This claim is made on the basis of TEM results where the Linear Features observed in the TEM are always much smaller in width than what is observed optically or using SEM. 
Table II -- Computer analysis of images from various publications.

\begin{tabular}{ccccc}
\hline Figure & Reference & $\begin{array}{c}\text { Volume \% } \\
\text { from Image }\end{array}$ & $\begin{array}{c}\text { Observed Thickness } \\
\text { (microns) }\end{array}$ & $\begin{array}{c}\text { Volume \% after } \\
\text { recalculation }\end{array}$ \\
\hline $1-\mathrm{b}$ & {$[10]$} & $12.6 \pm 2.5$ & $2.6 \pm 0.3$ & $1.2 \pm 0.1$ \\
$1-\mathrm{c}$ & {$[10]$} & $10.0 \pm 1.3$ & $2.3 \pm 0.1$ & $1.1 \pm 0.1$ \\
$1-\mathrm{g}$ & {$[10]$} & $12.6 \pm 0.3$ & $0.7 \pm 0.1$ & $4.6 \pm 0.5$ \\
$1-\mathrm{i}$ & {$[10]$} & $11.0 \pm 1.0$ & $0.9 \pm 0.1$ & $3.1 \pm 0.1$ \\
$1-\mathrm{j}$ & {$[10]$} & $16.0 \pm 1.0$ & $0.7 \pm 0.1$ & $5.8 \pm 0.5$ \\
7 & {$[11]$} & $11.7 \pm 1.1$ & $0.8 \pm 0.1$ & $3.7 \pm 0.1$ \\
3 & {$[2]$} & $4.7 \pm 1.8$ & $1.5 \pm 0.6$ & $0.8 \pm 0.1$ \\
$4-\mathrm{a}$ & {$[4]$} & $6.4 \pm 1.9$ & $2.0 \pm 0.4$ & $0.8 \pm 0.1$ \\
\hline
\end{tabular}

If the thicknesses noted using TEM are true then reasons must exist for the Linear Features appearing larger in optical and SEM images reported in the literature. Review of published images reveals that the majority of images have been obtained from samples that have been either ion- or chemically-etched. Hardness differences between materials create differences in ion-etching rates and can result in shadowing, producing a lower etch rate immediately adjacent to a harder feature. In this case this effect might be causing the Linear Features to appear wider optically than they are in actuality. This would explain the images noted in Figure 7 of [11], Figure 2 of [2] and Figure 5 of [4], and is supported by SEM pictures of samples where a rather wide ridge of material is present upon either side of the Linear Feature, Figure 1b of [8]. In this image the true width of the feature may correspond to the narrow white line observed, which is much thinner. This possibility is illustrated in Figure 3, where an ion-etched sample (a) and an as-polished sample (b) are viewed using SEM. The thin white line in the ion-etched sample (Fig. 3a), which might easily be overlooked as simply due to increased secondary electron emission at the apex, corresponds very well in width to the linear feature seen in the as-polished, unetched sample (Fig. 3b). Note that both images were taken at the same crystallographic orientation.

Alternatively, samples are often chemically etched to give better images for optical or SEM viewing. This method was employed in [11] and [13]. In this case the attack of the etchant may result in a channel that is much wider than the actual feature, and this certainly 
appears to be the case for Fig. 7 of [11]. This is supported by the EDS analysis of the objects in [11] which shows the impurity elements of $\mathrm{Ca}, \mathrm{P}$, and $\mathrm{Cl}$. It is not uncommon to find such trace elements left behind with debris associated with attack by an etchant, as the authors acknowledge in this publication.

If an artificial thickening of the Linear Features is occurring then estimates of phase percentages based upon such images can be greatly in error. Measurements on the aspolished image of Figure $3 \mathrm{~b}$ show that the average thickness of the linear feature is $\sim 0.24 \mu \mathrm{m}$, and this is in excellent agreement with the widths measured by TEM in [8]. The average width of the readily observed linear feature of Figure $3 \mathrm{a}$ is $\sim 4.11 \mu \mathrm{m}$, which means that the linear features look $\sim 17 \mathrm{x}$ wider than their actual thickness due to etching effects. If one returns to Table I and recalculates the phase percentages using as a correction factor the ratio between an assumed true width of 250nm (based upon the TEM measurements of Ugurlu and the example shown on Figure 3) and the visible line thickness seen in each figure, then the average estimated volume percentage drops from the calculated $10.6 \%$ to an average of 3.0 $\%$. This amount now falls below the minimum detectability limit as determined for the $\mathrm{Cu} \mathrm{K}_{\alpha}$ and synchrotron $\mathrm{x}$-ray simulations of Section 1.
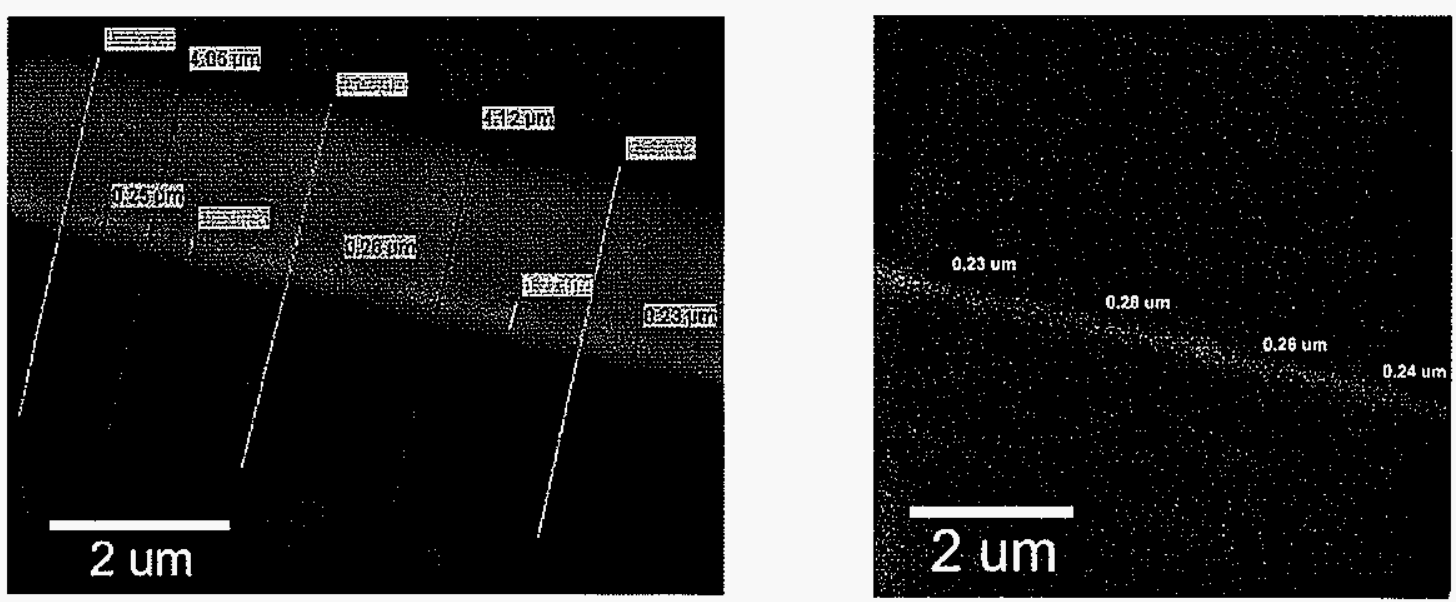

Figure 3 -- Measurement of the actual thickness and the artificial thickness of the linear features on (a) Ion-etched sample with secondary electrons and (b) polished sample with backscattered electrons. 
It seems probable that the difficulties associated with determining true volume percentages and the detectability limits of second phases in $\mathrm{Gd}_{5}(\mathrm{Ge}, \mathrm{Si})_{4}$, when taken together, mean that any study that relies upon x-ray diffraction must be extremely careful in ruling out the presence of said phases, at least in the case of $\mathrm{Gd}_{5} \mathrm{Si}_{3}$ for which the simulations were run. The amount of background intensity, overall intensity, peak broadening etc. will of course vary from instrument to instrument yet only in the most ideal cases as was used for the simulations might one expect to detect amounts below 2 vol. \%, with $5 \%$ being questionable even for reasonable diffraction systems.

The same cautions urged above must also be associated with studies that rely upon magnetometer measurements to establish phase purity. Difficulties associated with these techniques are discussed next.

\section{Magnetometer Measurements}

As for x-ray diffraction, the minimum detectable amounts present using magnetization measurements depend heavily on the relative response of the phases in question. In order to estimate the sensitivity of these techniques to the detection of $\mathrm{Gd}_{5} \mathrm{Si}_{3}$ in a matrix of $\mathrm{Gd}_{5} \mathrm{Si}_{2} \mathrm{Ge}_{2}$, samples were prepared of both materials and magnetization data was obtained. In this discussion it is important to keep in mind that the "pure" 5:4 material undoubtedly contains a few volume percent of the phase associated with the "Linear Features" which is the subject of this paper.

The magnetization curves for these compounds are shown in Figure 4 taken at 1000oe. Note that the response for the 5:4 compound is much higher in intensity than for the 5:3 material, Figure $4 \mathrm{a}$. If one uses a simple rule of mixing approach the only difference that will be observed on the combined magnetization will be the decrease in saturation magnetization (Figure 4b). However, since we don't know where the actual "pure" 

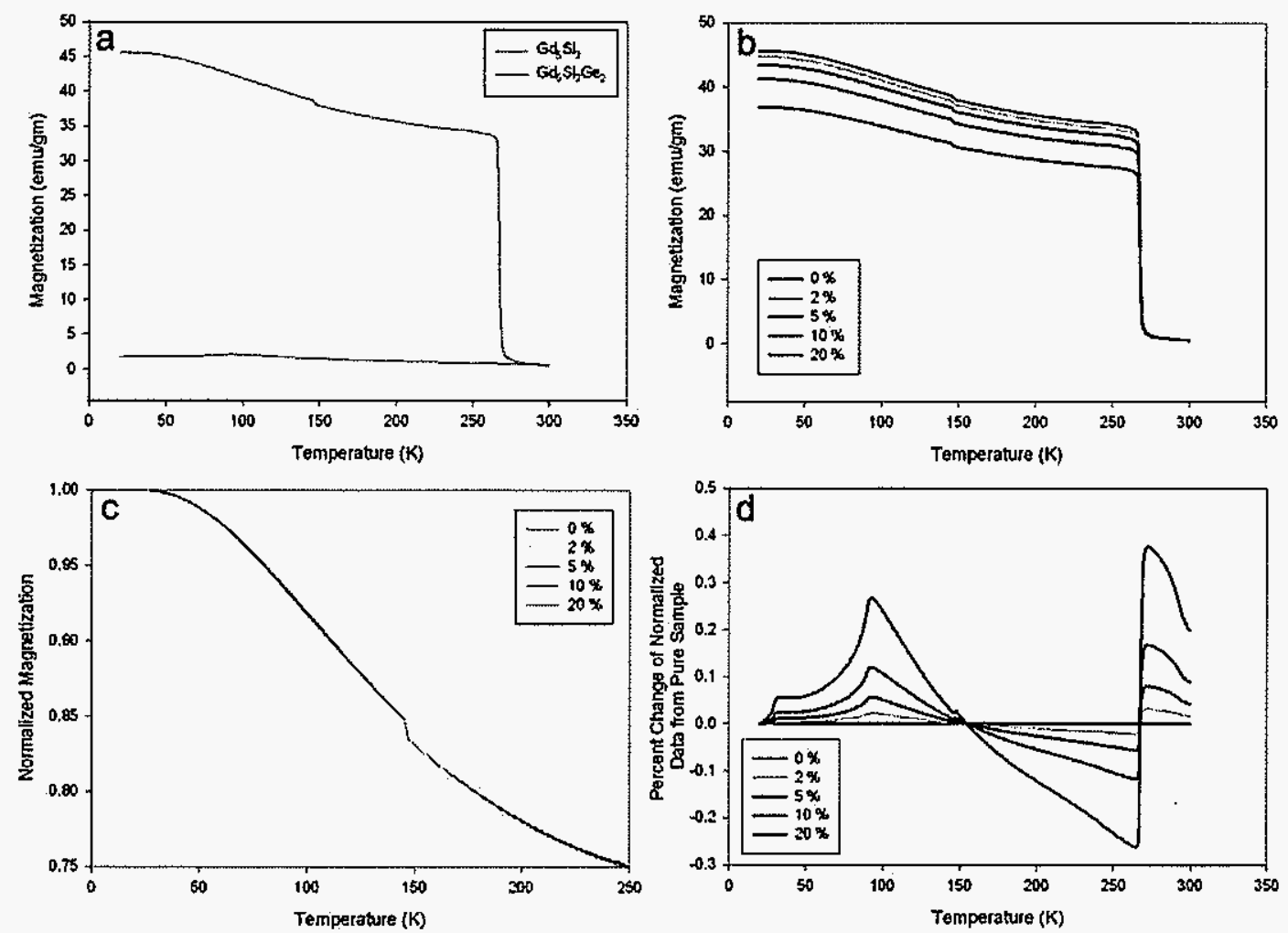

Figure 4 -- Magnetization measurements (a) "Pure" $\mathrm{Gd}_{5} \mathrm{Si}_{2} \mathrm{Ge}_{2}$ and $\mathrm{Pure} \mathrm{Gd}_{5} \mathrm{Si}_{3}(\mathrm{~b})$ $\mathrm{Gd}_{5} \mathrm{Si}_{2} \mathrm{Ge}_{2}$ with different volume percentages of $\mathrm{Gd}_{5} \mathrm{Si}_{3}$ (c) Normalized graph of b (d) Percent change of normalized data.

$\mathrm{Gd}_{5} \mathrm{Si}_{2} \mathrm{Ge}_{2}$ line will be, this can not be used to determine the presence of $\mathrm{Gd}_{5} \mathrm{Si}_{3}$. If one normalizes the magnetization of both phases (Figure 4c) there are no detectable differences between the different volume percentages of $\mathrm{Gd}_{5} \mathrm{Si}_{3}$ in the overall shape of the curve. Figure $4 \mathrm{~d}$ shows the normalized percentage change from a pure sample as the volume percentage of $\mathrm{Gd}_{5} \mathrm{Si}_{3}$ increased from $0 \%$ to $20 \%$. There are two points where the difference is high, one at the Neel temperature of $\mathrm{Gd}_{5} \mathrm{Si}_{3}(\sim 92 \mathrm{~K})$ and the other one at the Curie temperature of $\mathrm{Gd}_{5} \mathrm{Si}_{2} \mathrm{Ge}_{2}(\sim 267 \mathrm{~K})$; the highest difference is not more than $0.4 \%$ even with a 20 vol\% $\mathrm{Gd}_{5} \mathrm{Si}_{3}$ sample. All these results show that a considerable amount of $\mathrm{Gd}_{5} \mathrm{Si}_{3}$ is most likely necessary before an unambiguous determination can result from a simple observation of a magnetization curve. 


\section{Compositional Measurements}

The exact composition of the Linear Features has also been the subject of much debate since Szade et al. first stated that they appeared to be high in $\mathrm{Gd}$ and $\mathrm{O}$ and low in $\mathrm{Si}$ in $\mathrm{Gd}_{5} \mathrm{Si}_{4}$, and low in both $\mathrm{Si}$ and $\mathrm{Ge}$ in $\mathrm{Gd}_{5}(\mathrm{Si}, \mathrm{Ge})_{4}$ samples. This result was obtained using Auger electron spectroscopy on an as-prepared crystal. Thus, in a spatial sense the data should be very good since the distance over which auger analysis is viable is limited to 10-30 $\AA$. However, the data is only qualitative in nature and is limited to the surface of the sample and does not represent a bulk measurement. Subsequent studies that employed EDS in the SEM (Meyers and Ugurlu), which by their nature will sample a large amount of material, have found that the composition tended to be high in $\mathrm{Gd}$ and low in Si with the Ge level being approximately the same. It was this result that caused Meyer to first suggest the Linear Features to be $\mathrm{Gd}_{5}(\mathrm{Si}, \mathrm{Ge})_{3}$. Other studies employing EDS in the SEM have found significantly different compositions, although the fact that these studies were performed on etched samples rather than flat polished samples calls their validity into question, as recognized by the authors [11].

In any attempt to determine the exact composition of the alloys the size scale of the feature and the limitations of the employed technique need to be considered if one is to asses the reliability of any particular measurement. As detailed above, the TEM studies of Ugurlu have shown that the width of the Linear Features is far below the minimum required for accurate determination using EDS in the SEM, which is estimated to be approximately 2.8 $\mu \mathrm{m}$ for a $\mathrm{Gd}_{5} \mathrm{Si}_{4}$ sample using the Kanaya-Okayama electron range and width calculation $[16,17]$. Thus, the composition studies of $[4,8,10,11]$ can at best only be used in a qualitative sense in relation to the nearby matrix since they all must be a mixture of the composition of the linear features and the surrounding matrix. Care must also be taken in 
ensuring that the obtained data comes from the Linear Feature and is not a result of contaminants or impurities that may be present due to etching, or by introducing anomalous absorption problems that might result from having a non-flat sample [16], as may also be a problem with the data of [11].

Given these considerations the most reliable data that can be obtained from the Linear Features (which, if we remember, are actually thin plates) should come from TEM examinations where the operator can ensure that the probe size used to obtain characteristic $\mathrm{x}$-rays stays within the confines of the thin dimensions of the plates. However, even in this situation variations can be introduced if the geometry and orientation of the plates is not taken into account. Since TEM produces a two-dimensional image of a 3-dimentional transparent sample, it is possible that one may be taking data from a feature embedded in a matrix of a second phase (and composition) rather than of simply the desired phase. This scenario is very likely in the case of the Linear Features unless the proper observation direction is selected. The idea behind this confusion is illustrated below in Figure 5 .

As can be seen in Figure 5 (a) and 5 (c), when the plate is inclined to the plane of the TEM foil the e-beam may pass through a large amount of the matrix material surrounding the plate. Although this may not be readily apparent in the 2-d image visible to the user, a slight degradation in the sharpness of the image at the edges of the plate is also observed. Only for the case illustrated by Figure 5 (b) will the beam remain entirely within the plate and produce the most accurate compositional determination as well as the sharpest image of the plate / matrix interface. With this constraint in mind, compositional measurements have been taken using EDS in the TEM. Figure 6 shows line scan EDS profiles taken from samples whose 


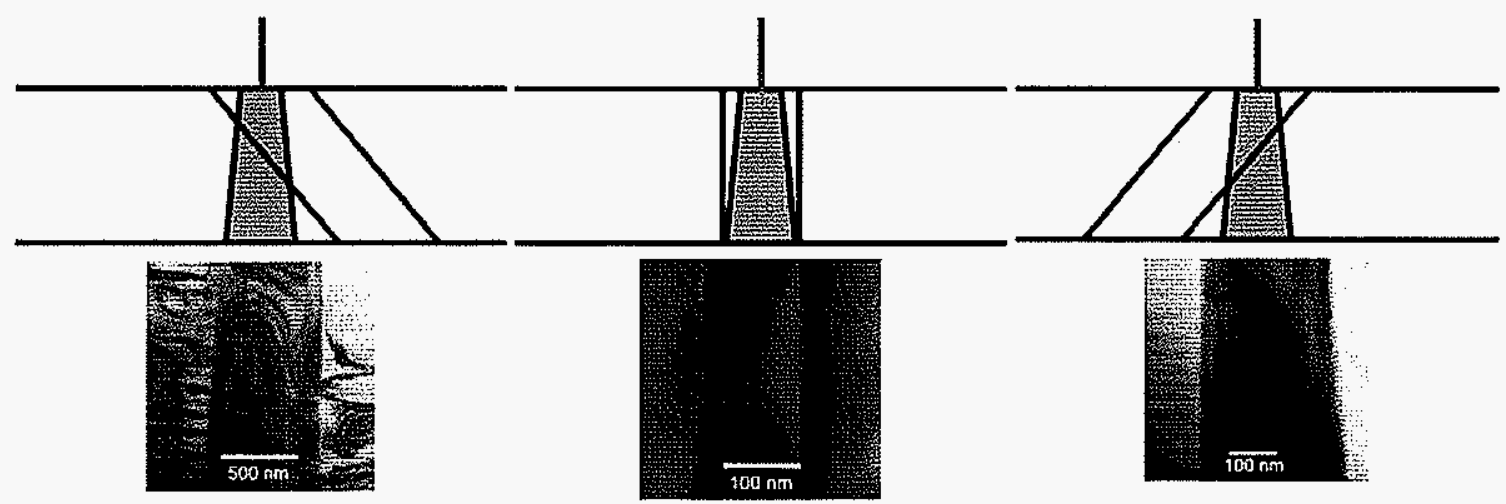

(a)

(b)

(c)

Figure 5 - Actual inclination of the plate and apparent 2-D images that result in TEM when viewed along: (a) $B=[100]$, (b) $B=[010]$, (c) $B=[001]$.

surface are perpendicular to the [010] and [100] directions. It can be seen that the data taken from the [010]-oriented sample (Fig. 6 (b)) clearly shows the slight depletion of Gd in the shoulder region of the linear features and the enrichment in Gd of the features as the composition change from $5: 4$ to $5: 3$. A similar trend is seen for the Ge, although the effect is much less, while Si shows a shoulder enrichment / feature depletion profile. It has been postulated that the true composition of the features lies near $\mathrm{Gd}_{5}\left(\mathrm{Si}_{1} \mathrm{Ge}_{2}\right)$ [ref], and the data of this study would appear to support this.

It is interesting to also observe how the composition profile changes if one does not ensure that the beam stays within the confines of the plate. This is illustrated in Figure $6 \mathrm{~b}$ for the situation where the plate is viewed along the [100] direction. As illustrated in Figure 5a, the plate is inclined to the direction of the beam at this orientation and overlap with the matrix is possible. Although the same general trends are noted, at this orientation the changes in the composition profile are much less apparent due to overlap with the matrix. It should also be mentioned that many TEMs require the sample to be tilted toward the EDS detector in order to acquire sufficient counts for analysis. Care must be taken in these situations to ensure that a suitable Linear Feature is chosen which faces the detector in such a manner that overlap with the matrix does not result due to this tilt. 

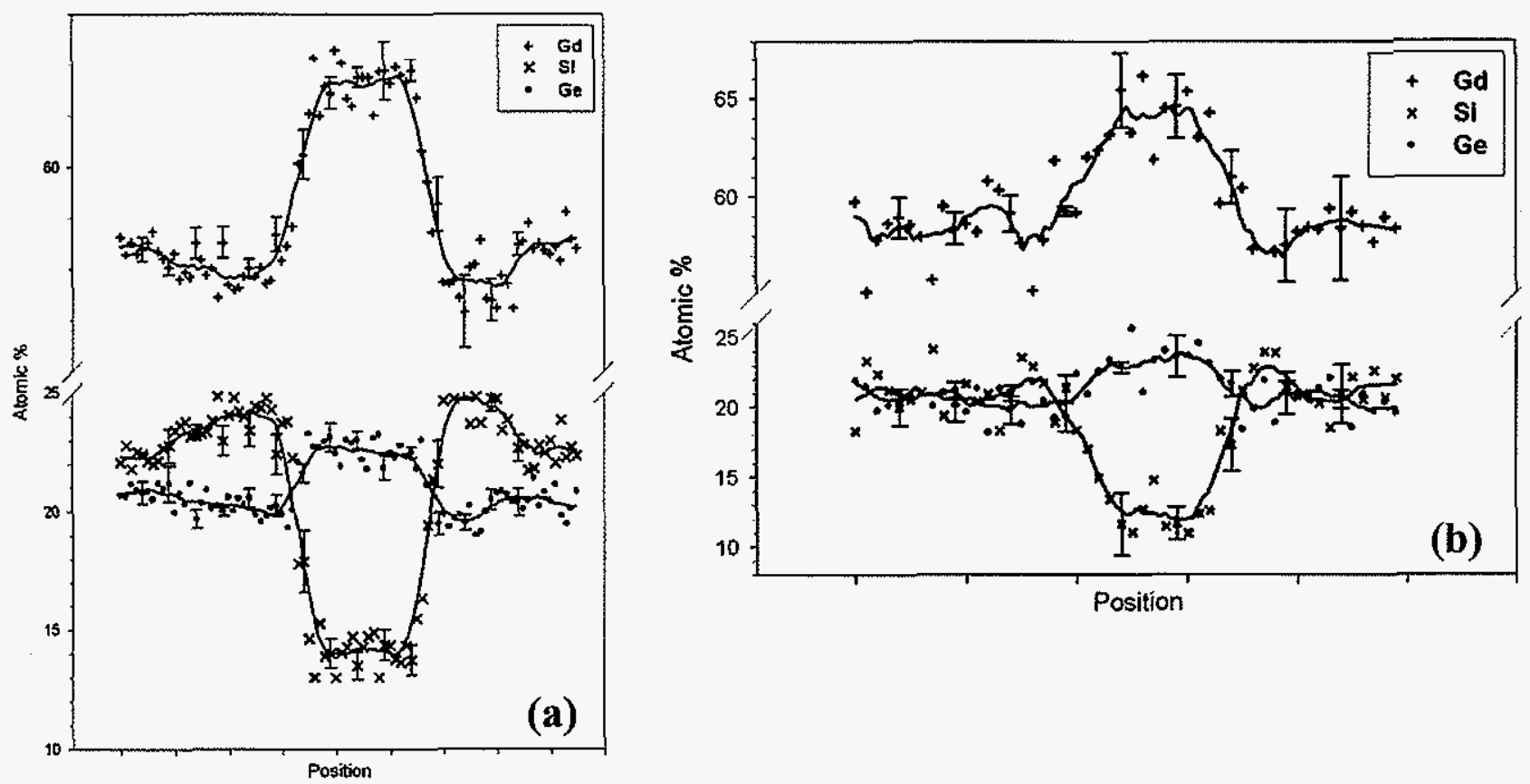

Figure 6 -- Line scan EDS profiles of linear features from (a) [010] and (b) [100] oriented $\mathrm{Gd}_{5} \mathrm{Si}_{2} \mathrm{Ge}_{2}$ samples.

Given what appears to be reliable compositional data from the Linear Features it is now possible to comment on the various values reported by other investigations. The increase in $\mathrm{Gd}$ and decrease in $\mathrm{Si}$ seen by Szade in $\mathrm{Gd}_{5} \mathrm{Si}_{4}$ corresponds well with the TEM results, the increased $O$ being expected due to the surface nature of the analysis. The decrease in Ge seen in the $\mathrm{Gd}_{5}(\mathrm{Si}, \mathrm{Ge})_{4}$ samples is not supported, although a decrease in both would still lead to the conclusion that the Linear Feature is tending toward a 5:3 ratio compound. The results seen in [11] cannot be trusted as an accurate measure of the composition due to the aforementioned beam spreading effects, the fact that the sample was etched which may have chemically removed the Linear Feature at the surface, and the presence of numerous impurities associated with the etching. 


\section{Summary}

In summary, it seems that when all factors are considered identification of the Linear

Features as $\mathrm{Gd}_{5}\left(\mathrm{Si}_{1} \mathrm{Ge}_{2}\right)$ appears most plausible. This conclusion is based on a proper consideration of the difficulties of analyzing such an unusual feature and is supported by the extensive electron diffraction and high resolution TEM studies that have been carried out. It also seems reasonable, given the observed similarities in shape and the limited studies carried out in other $\mathrm{RE}_{5}(\mathrm{Si}, \mathrm{Ge})_{4}$ systems, that the Linear Features seen in all such systems is a form of $\mathrm{RE}_{5}(\mathrm{Si}, \mathrm{Ge})_{3}$.

\section{References}

1. Pecharsky VK,Gschneidner Jr. KA. Physical Review Letters 1997;78(23):4494 - 7.

2. Szade J, G.Skorek, Winiarski A. Journal of Crystal Growth 1999;205:289 - 93.

3. Meyers JS, Chumbley LS, Choe W, Miller GJ. Physical Review B 2002;66:012106.

4. Meyers JS, Chumbley LS, Laabs F, Pecharsky AO. Scripta Materialia 2002;47:509 14.

5. Meyers JS, Chumbley S, Laabs F, Pecharsky AO. Acta Materialia 2003;51(1):61-70.

6. Gama S, Alves CS, Coelho AA, Ribeiro CA, Persiano AIC, Silva D. Journal of Magnetism and Magnetic Materials, Proceedings of the International Conference on Magnetism, Jul 27-Aug 12003 2004;272-276:848-9.

7. $\quad F u$ H, Chen Y, Tu M, Zhang T. Acta Materialia 2005;53(8):2377-83.

8. Ugurlu O, Chumbley LS, Lograsso TA, Schlagel DL. Acta Materalia 2005;53:3525 53.

9. Ugurlu O, Chumbley LS, Schlagel DL, Lograsso TA. Acta Materalia 2005;in-press.

10. Ugurlu O, Chumbley LS, Schlagel DL, Lograsso TA, Tsokol AO. Scripta Materialia 2005;55(3):373 - 7 .

11. Fu H, Zhang T, Chen Y, Tu M. J. Chin. RE Soc. (in chinese) 2005;23:49. 
12. Ugurlu O, Chumbley LS, Schlagel DL, Lograsso TA, Pecharsky AO.

Characterization of $R_{5}\left(S_{i} G e_{1-x}\right)_{4}$ alloys, where $R$ is $G d, T b$, Dy and Er. in 134th TMS Annual Meeting, Feb 13-17 2005. 2005. San Francisco, CA, United States: Minerals, Metals and Materials Society, Warrendale, PA 15086, United States.

13. Fu H, Tu M, Chen Y, Zhang T, Zhang L. Xiyou Jinshu Cailiao Yu Gongcheng/Rare Metal Materials and Engineering 2005;34(8):1314-7.

14. Pecharsky VK,Gschneidner Jr. KA. Journal of Alloys and Compounds 1997;260:98 106.

15. Choe W, Pecharsky VK, Pecharsky AO, Gschneidner KAJ, Young VGJ, Miller GJ. Physical Review Letters 2000;84(20):4617 - 20.

16. Goldstein J, Newbury D, Echlin P, Joy D, Fiori C, Lifshin E, Scanning Electron Microscopy and X-ray Microanalysis. 1984, New York: Plenum Press. 267-9.

17. Brundle CR, Charles A. Evans J, Wilson S, Encylopedia of Materials Characterization. 1992: Butterworth-Heinemann. 


\title{
APPENDIX B: Persistence of 5:3 plates in $\mathrm{RE}_{5}\left(\mathrm{Si}_{\mathrm{x}} \mathrm{Ge}_{1-\mathrm{x}}\right)_{4}$ Alloys
}

A paper to be submitted to Scripta Materialia.

\author{
O. Ugurlu ${ }^{1,2}$ and L.S. Chumbley ${ }^{1,2}$
}

Ames Laboratory, Iowa State University

\begin{abstract}
Studies of $\mathrm{RE}_{5}\left(\mathrm{Si}_{\mathrm{x}} \mathrm{Ge}_{1-\mathrm{x}}\right)_{4}$ alloys, where $\mathrm{RE}=$ rare-earth, have revealed a second-phase having a thin-plate morphology in essentially every alloy examined, independent of exact composition and matrix crystal structure. Identified as having a composition approximating $\mathrm{Gd}_{5}\left(\mathrm{Si}_{\mathrm{x}} \mathrm{Ge}_{1-\mathrm{x}}\right)_{3}$ and an hexagonal crystal structure in the Gd-based system, it has been suggested that the observed thin-plate second phases seen in this family of rare earth alloys are all most likely of the form $\mathrm{RE}_{5}\left(\mathrm{Si}_{\mathrm{x}} \mathrm{Ge}_{1-\mathrm{x}}\right)_{3}$. A number of interesting observations suggest that the formation of these second phase plates is somewhat unusual. The purpose of this paper is to investigate the stability of this second phase in Gd and Er-based compounds. The stability was investigated as a function of thermal cycling and large-scale composition fluctuations. The results of scanning and transmission electron microscopy (SEM, TEM) studies indicate that the $\mathrm{RE}_{5}\left(\mathrm{Si}_{\mathrm{x}} \mathrm{Ge}_{1-\mathrm{x}}\right)_{3}$ phase is extremely stable once it forms in a $\mathrm{RE}_{5}\left(\mathrm{Si}_{\mathrm{x}} \mathrm{Ge}_{1-\mathrm{x}}\right)_{4}$ matrix.
\end{abstract}

\footnotetext{
${ }^{1}$ Department of Materials Science and Engineering, Iowa State University, Ames IA 50011 USA

${ }^{2}$ Ames Laboratory (DOE), Iowa State University, Ames IA 50011-3020, USA
} 


\section{Introduction}

The unusual properties [1-6] of $\mathrm{RE}_{5}\left(\mathrm{Si}_{\mathrm{x}} \mathrm{Ge}_{1-\mathrm{x}}\right)_{4}$ alloys, where $\mathrm{RE}=$ rare-earth, have caused alloys of this type to be the focus of numerous studies in recent years[7]. Such studies have included examination of alloys whose compositions and crystal structures ranged from stoichiometric $\mathrm{RE}_{5} \mathrm{Si}_{4}$ to $\mathrm{RE}_{5} \mathrm{Ge}_{4}$. In the course of these studies a second-phase, having a thin-plate morphology, has been seen in essentially every alloy examined, independent of exact composition and matrix crystal structure. To date this includes $\mathrm{RE}_{5}\left(\mathrm{Si}_{\mathrm{x}} \mathrm{Ge}_{1-\mathrm{x}}\right)_{4}$ samples (hereafter referred to as "5:4" alloys) based on Gd, Er, Dy and Tb [8-11]. In studies of $\mathrm{Gd}_{5} \mathrm{Si}_{2} \mathrm{Ge}_{2}$ and $\mathrm{Er}_{5} \mathrm{Si}_{4}$ that used energy dispersive spectroscopy (EDS) and transmission electron microscopy (TEM) this phase was identified as having a composition approximating $\operatorname{RE}_{5}\left(\mathrm{Si}_{\mathrm{x}} \mathrm{Ge}_{1-\mathrm{x}}\right)_{3}$ and an hexagonal crystal structure $[9,12]$. These results led the authors to suggest that the observed thin-plate second phases seen in the 5:4 family of rare earth alloys are all most likely of the form $\mathrm{RE}_{5}\left(\mathrm{Si}_{\mathrm{x}} \mathrm{Ge}_{1-\mathrm{x}}\right)_{3}$ (hereafter referred to as 5:3), based on the observed morphology and a consideration of the similarities between the phase diagrams of the studied systems. Subsequent studies of single crystal $\mathrm{Gd}_{5} \mathrm{Ge}_{4}$ identified the orientation and formation mechanism for the 5:3 phase in this particular system. In this study it became clear that the formation of the 5:3 occurred as a result of a rapid solid-solid transformation which the authors proposed as being displacive-diffusional in nature.

A number of interesting observations suggest that the formation of the 5:3 plates is somewhat unusual. The presence of 5:3 thin-plates in as-solidified samples using a variety of techniques including arc-melting [8,9], induction melting [10], and single crystal growth [11-13] indicates that formation is extremely rapid. The fact that the structure is observed in

different matrix crystal structures suggests that formation occurs at high temperatures in a common crystal structure that is not represented on current phase diagrams. The common morphology and crystal structure of the 5:3 phase indicates a substantial driving force for formation and implies that a high degree of stability may be associated with this phase once it 
forms. While small deviations from ideal 5:4 stoichiometry may be the root cause for the presence of the $5: 3$ phase in samples slightly rich in rare-earth, it is somewhat surprising that all samples studied thus far contain 5:3. This suggests that either every sample examined has been slightly rare-earth rich, or that formation of 5:3 is relatively insensitive to small composition fluctuations.

The purpose of this paper is to investigate the stability of the $5: 3$ phase in a $\mathrm{Gd}_{5} \mathrm{Si}_{2} \mathrm{Ge}_{2}$ and $\mathrm{Er}_{5} \mathrm{Si}_{4}$ samples. The stability was investigated as a function of thermal cycling and largescale composition fluctuations. The results of scanning and transmission electron microscopy (SEM, TEM) studies are presented.

\section{Experimental Procedure}

At room temperature $\mathrm{Gd}_{5} \mathrm{Si}_{2} \mathrm{Ge}_{2}$ has a monoclinic structure; upon cooling the crystal structure transforms reversibly to the $\mathrm{Gd}_{5} \mathrm{Si}_{4}$-type orthorhombic at approximately $-1^{\circ} \mathrm{C}$. When heated the monoclinic structure transforms to the $\mathrm{Gd}_{5} \mathrm{Ge}_{4}$-type orthorhombic. This transformation is more sluggish, occurring at temperatures between $320^{\circ} \mathrm{C}$ and $600^{\circ} \mathrm{C}$, and, unlike the low temperature counterpart, is irreversible at rapid cooling rates and if the material becomes contaminated with oxygen [14]. Single crystal $\mathrm{Gd}_{5} \mathrm{Si}_{2} \mathrm{Ge}_{2}$ samples were used to examine the effect of the structural changes that occur in the matrix as a function of temperature on the stability of the 5:3 thin-plates. Samples were prepared using a tri-arc crystal pulling method from high purity starting materials. All the samples for SEM observation were polished mechanically down to 0.125 microns and observed in the aspolished state using backscattered electron imaging (BSE). To test the effect of the low temperature transformation on 5:3 stability, one sample was initially examined using SEM, then immersed in a dry-ice + acetone mixture $\left(\sim-70^{\circ} \mathrm{C}\right)$, held for 5 minutes to allow time for the sample to go through the low temperature monoclinic - orthorhombic transformation, then removed and allowed to warm to room temperature. This cycle was repeated 50 times, 
followed by SEM examination. To further test temperature effects, TEM samples were prepared and observed in-situ using TEM during both low and high temperature phase transformations using cold and hot stage sample holders, respectively. Samples for TEM studies were mechanically thinned and dimpled, then ion-milled to electron transparency.

The effect of large-scale deviations from the ideal 5:4 stoichiometry was tested using two off-stoichiometric arc-melted Er-Si samples [15]. Sample A was Er-rich, having an approximate ratio of $\mathrm{Er}_{6.18} \mathrm{Si}_{4}$ relative to the stoichiometric $\mathrm{Er}_{5} \mathrm{Si}_{4}$ while Sample B was Erdeficient, with an approximate ratio of $\mathrm{Er}_{4.20} \mathrm{Si}_{4}$. Samples were mechanically polished then examined using BSE imaging in the SEM.

\section{Experimental Results}

\section{Thermal Effects:}

A composite image of the $\mathrm{Gd}_{5} \mathrm{Si}_{2} \mathrm{Ge}_{2}$ single crystal comprising 49 (7x7) micrographs and merged into a single file, taken before the start of thermal cycling, is shown in Figure 1. The white bulky precipitates scattered throughout the sample were determined to be tungsten using energy dispersive spectroscopy (EDS). A tungsten crucible was used in the single crystal pulling method employed, and similar impurities have been seen in previous studies [10]. Their presence was extremely helpful as they served as reference points for microstructure comparisons before and after cycling, and close-ups of three regions are shown in Figure 1,b-d. The 5:3 phase can be seen quite clearly as a series of thin white lines at fixed angles within the crystal. Figure 2 shows the same crystal after cycling, again with close-ups provided in Figures 2, b-d. If one compares the Figures 1 and 2, no difference is seen when considering the 5:3 thin-plates; their orientation, density, thickness and lengths are exactly the same as before, as least to within the resolution of the micrograph. The only visible difference between the samples is the formation of new cracks and the propagation of existing ones. In-situ TEM observations (Fig. 3a), of samples cooled below the low 


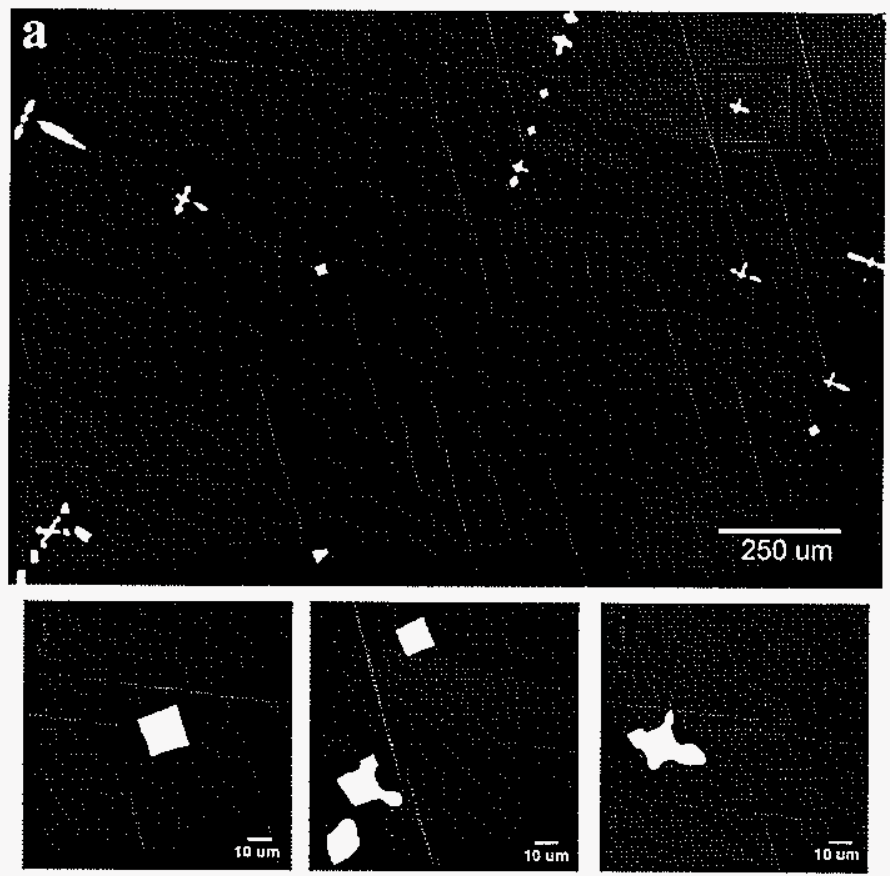

Figure 1 -- (a) Composite SEM image of a $\mathbf{G d}_{5} \mathrm{Si}_{2} \mathbf{G e}_{2}$ sample before thermal cycling, $(b, c, d)$ close-up views of different regions

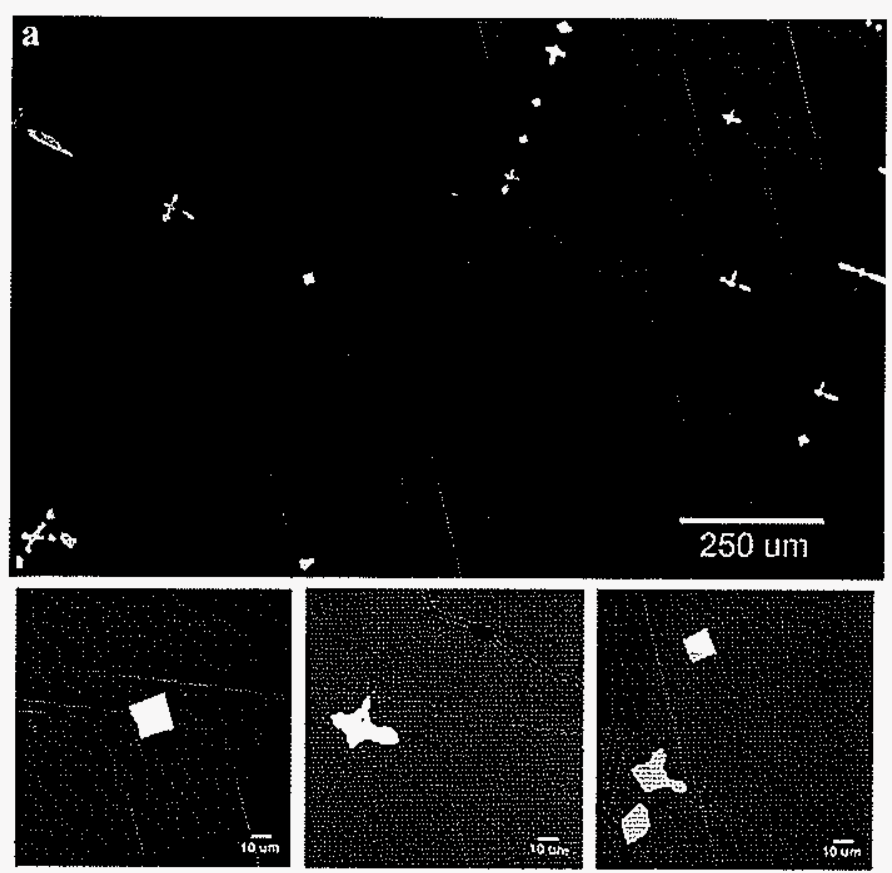

Figure 2 - (a) Composite SEM image of the same $\mathrm{Gd}_{5} \mathrm{Si}_{2} \mathrm{Ge}_{2}$ sample after thermal cycling, $(b, c, d)$ close-up views of different regions 
temperature $\left(-1^{\circ} \mathrm{C}\right)$ phase transformation point showed no difference in the thin plate morphology (Fig. 3b), at least for the area observed. The 5:3 thin-plates remain unchanged when the sample returns again to room temperature and the matrix assumes the monoclinic structure, Figure $3 b$.

Also visible in Figure $3 \mathrm{a}$ are a series of linear features that run perpendicular to the 5:3 plates. It is interesting to note that these features disappear from the matrix upon transformation from monoclinic to orthorhombic, Figure $3 b$, then reappear once the structure reversibly transforms back to monoclinic upon heating, Figure $3 \mathrm{c}$, although the position of the features appears to have changed slightly.
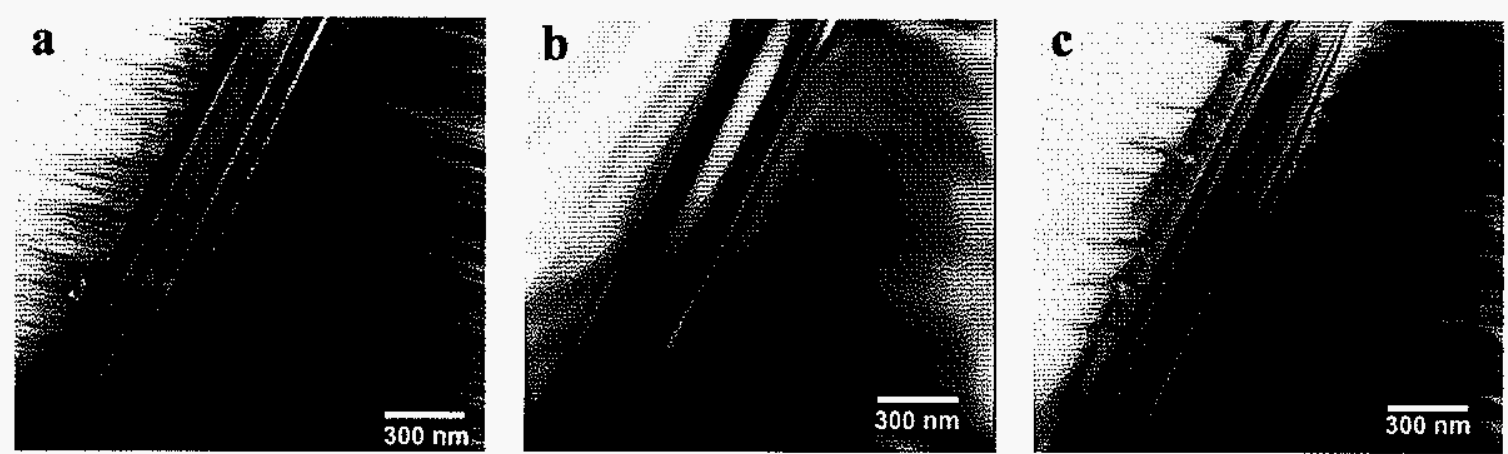

Figure 3 -- Bright field (BF) TEM images of a thin-plate (a) at room temperature, (b) below $-1^{\circ} \mathrm{C}$, (c) at room temperature after cycling.

A second in-situ TEM sample (Fig. 4a) was heated to $850^{\circ} \mathrm{C}$ through the high temperature transformation from monoclinic to orthorhombic. This transformation starts around $320^{\circ} \mathrm{C}$ and should be substantially finished by the time the sample reaches $600^{\circ} \mathrm{C}$. The initial appearance of a 5:3 thin-plate is shown in Figure 4a. Note that the linear features are visible in this sample also. Upon heating a considerable amount of oxidation of the sample occurs, Figure 4b. However, the thin-plate morphology of the 5:3 phase was still visible at $850^{\circ} \mathrm{C}$ (Shown with the arrow, Fig. 4b). Although the poor quality of the image due to oxidation makes it difficult to see, observations in the TEM during the experiment 
revealed that the linear features seen at room temperature once again disappeared at high temperature.
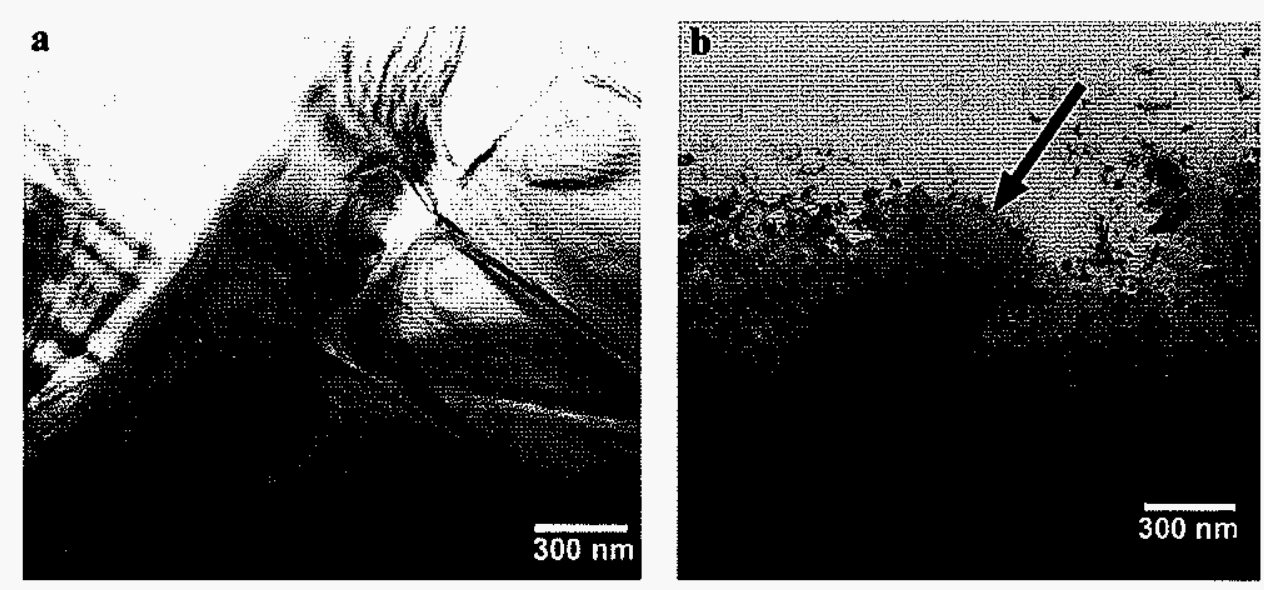

Figure 4 -- Bright Field (BF) TEM image of a thin-plate (a) at room temperature, (b) at $850^{\circ} \mathrm{C}$

\section{Composition Effects:}

According to the phase diagram published in 1996 [16], in the Er-Si system 5:3 and 5:4 phases exist as adjacent line compounds, Figure 5. The sample compositions prepared for this study are indicated on this diagram. If one assumes equilibrium conditions, Sample A should consist of a two-phase mixture of 5:3 and 5:4 phases. In Figure 6 it can be seen that these two phases are present, with the $\mathrm{Er}_{5} \mathrm{Si}_{3}$ compound appearing as both large grains and thin-plates. These results agree with what is expected from the phase diagram. However, the results for Sample B, the Er-deficient sample, are quite different. While from the phase diagram one would again expect a two-phase mixture, this time consisting of $\mathrm{Er}_{5} \mathrm{Si}_{4}$ and $\mathrm{ErSi}_{1-\mathrm{x}}$ (or possibly ErSi), a three phase mixture is encountered. Analysis using EDS indicates the large grains are $\mathrm{ErSi}$ and $\mathrm{Er}_{5} \mathrm{Si}_{4}$, with thin-plates of $\mathrm{Er}_{5} \mathrm{Si}_{3}$ again being present within the 5:4 phase. Interestingly, the plates thicken at the interface of the 1:1 and 5:4 compounds as the 1:1 regions try to lower their rare-earth content by rejecting Er to the rareearth rich 5:3. 


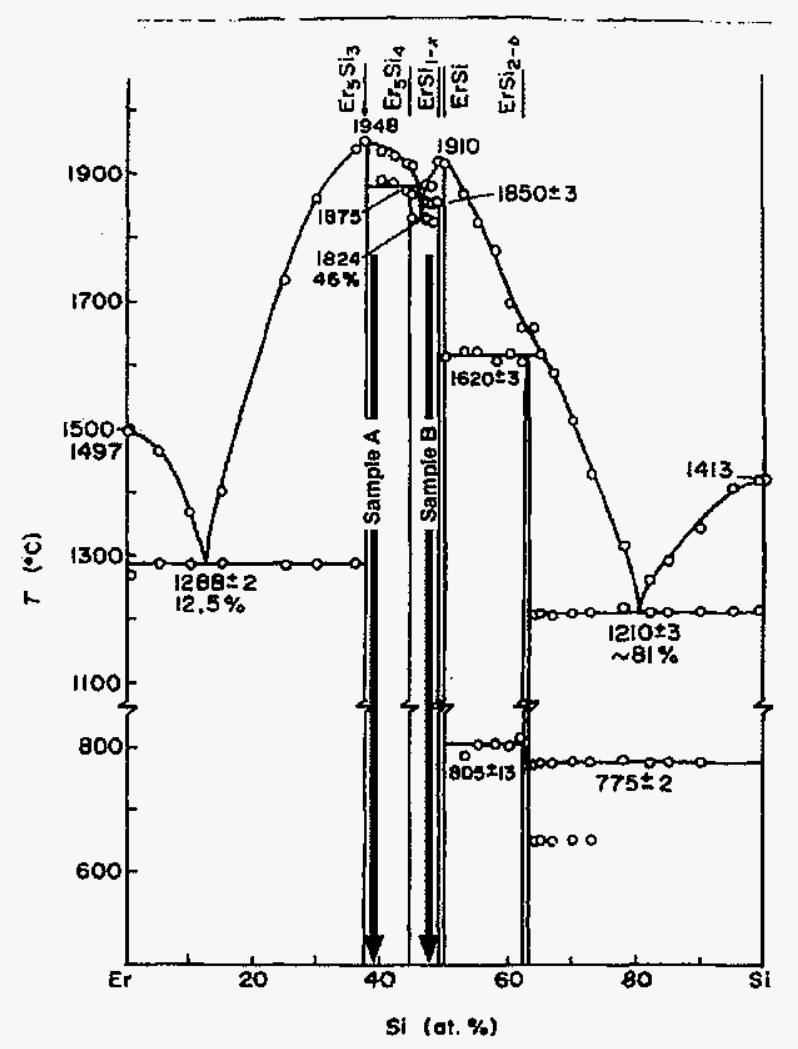

Figure 5 -- Binary phase diagram of the Er-Si system

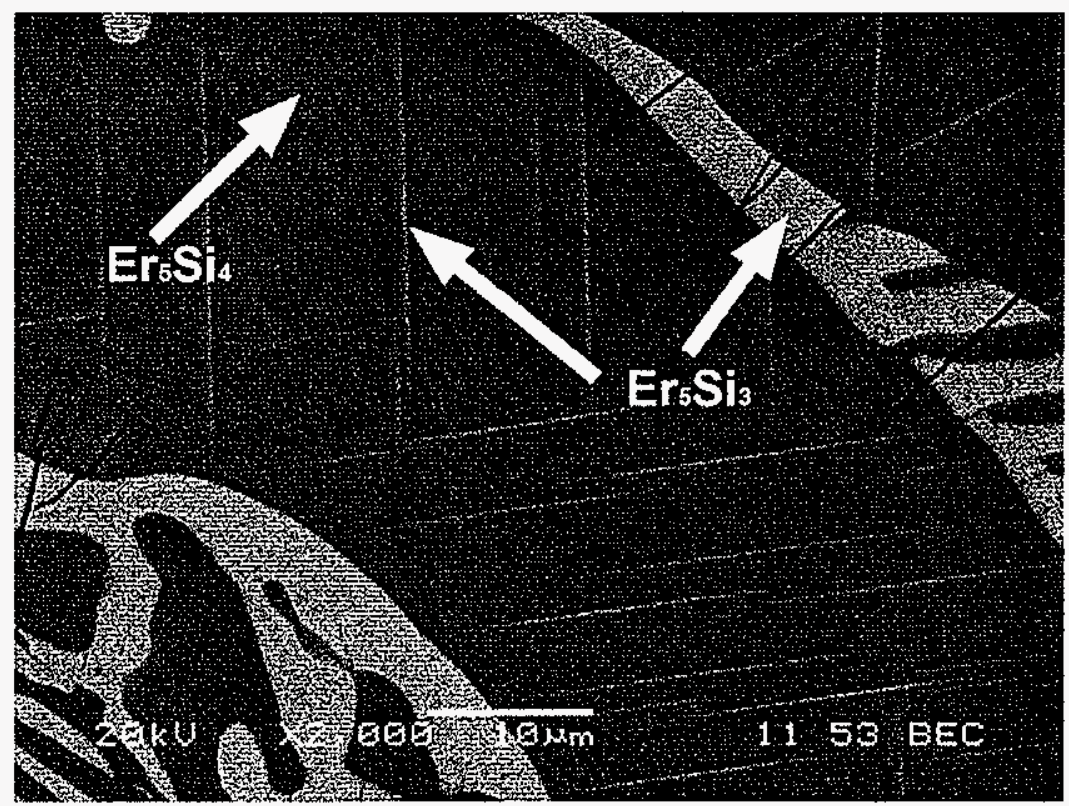

Figure 6 -- Back scatter electron image of the Er-rich $\mathrm{Er}_{6.18} \mathrm{Si}_{4}$ sample (Sample A) 


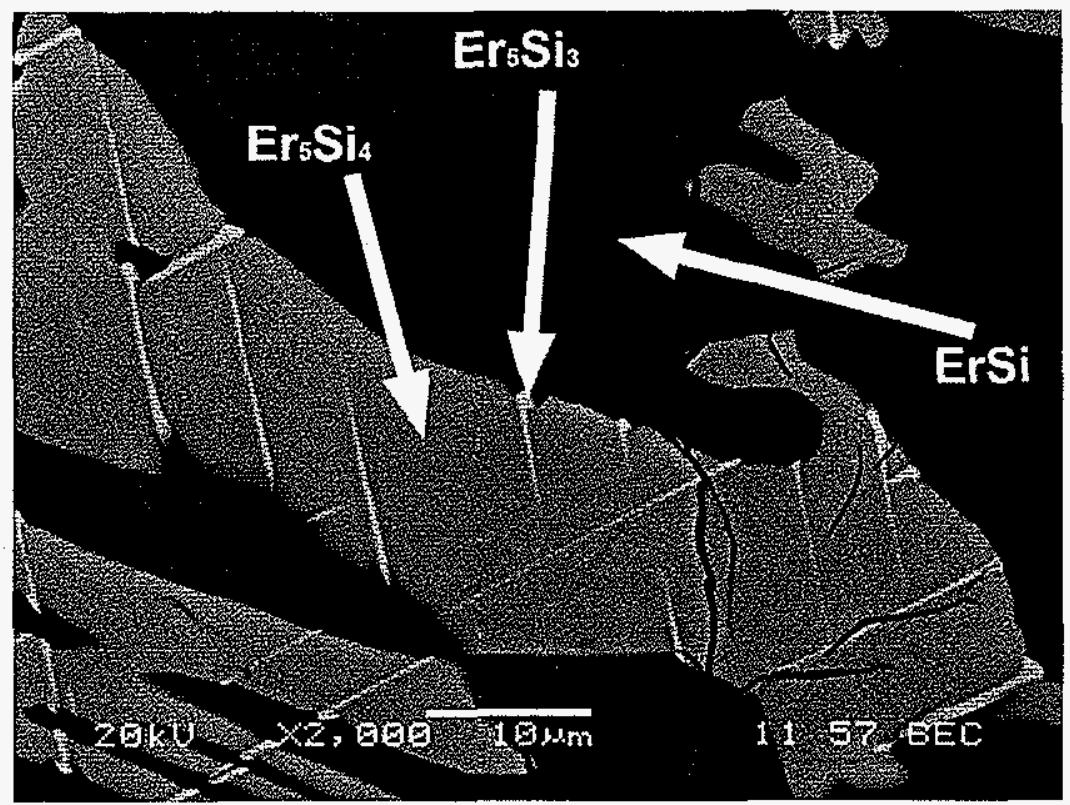

Figure 7 -- Electron backscatter image of the $\mathrm{Er}$-deficient $\mathrm{Er}_{4.20} \mathrm{Si}_{4}$ sample (Sample B)

\section{Discussion}

Thermal cycling to low temperatures appears to have little or no effect upon the structure of the 5:3 plates, although increased cracking of the sample is observed. The reason for that is the $\sim 1.1 \AA$ movement of slabs that occurs during the structure change from monoclinic to the $\mathrm{Gd}_{5} \mathrm{Si}_{4}$-type orthorhombic places a large stress on the material [17]. However, the formation of 5:3 thin-plates is not associated with these extreme slab movements. TEM studies $[12,18]$ have shown that the thin-plates grow perpendicular to the slab movement direction. Thus, the perpendicular orientation of the 5:3 plates may cause them to act as a strain source, resulting in more cracking of the matrix. While no cracking was seen around the 5:3 plate in the in-situ TEM experiment, it is possible that in these thin TEM samples the strain is simply too low to have any visible effect, either on the 5:3 plates or the matrix. 
Severe oxidation of the sample during heating prevented detailed in-situ observations of the 5:3 phase from being made. However, it can certainly be said that heating to a temperature of $850^{\circ} \mathrm{C}$ does not cause the $5: 3$ plates to go into solution or result in the formation of new 5:3 material. Cycling of macroscopic samples similar to what was done for the low temperature phase transformation is impractical since the high temperature transition was irreversible due to oxidation of the sample.

The linear features that appear perpendicular to the 5:3 thin-plates in TEM samples do appear to be affected by low temperature cycling, and were observed to disappear at high temperatures as well. Meyers et al. [19] proposed that these lines could be the macroscopic twins seen in previous $x$-ray diffraction (XRD) studies $[7,20]$ of the monoclinic structure. Further work is needed to ascertain the exact nature of these features, although a twinning mechanism certainly appears plausible at this time.

The appearance of the 5:3 thin-plates in the rare-earth deficient samples is extremely interesting. If one assumes the proposed phase diagram is correct, the only way one could logically be expected to obtain 5:3 in a cast structure would be through non-equilibrium solidification. While certainly possible, this would require a large degree of undercooling. Given the present shape of the phase diagram, and the fact that the rare-earth-rich alloy which was solidified under similar conditions gave no indication of high undercooling, this possibility seems unlikely. The appearance of 5:3 within 5:4 in these samples, in the same morphology as previous studies, indicates that the structural relationship that exists between 5:3 and 5:4 as detailed in [18] is an extremely favorable one for growth and subsequent phase stability. It also adds further evidence that the present phase diagrams for this family of $\mathrm{RE}_{5}\left(\mathrm{Si}_{\mathrm{x}} \mathrm{Ge}_{1-\mathrm{x}}\right)_{4}$ alloys are incorrect at the highest temperatures. 


\section{Conclusion}

Temperature changes in the range $-70^{\circ} \mathrm{C}$ to $850^{\circ} \mathrm{C}$ did not show any effect on the morphology of 5:3 thin-plates in Gd and Er-based 5:4 compounds, even though the monoclinic matrix phase underwent both reversible (low $\mathrm{T}$ ) and irreversible (high $\mathrm{T}$ ) transformations to an orthorhombic structure. This was not true for a suspected twin structure noted in TEM images. In both cases this structure seemed to disappear once the matrix transformed. Off-stoichiometric samples prepared to produce rare-earth rich and poor specimens were still found to contain the $5: 3$ phase within the $5: 4$ compound even when the equilibrium phase diagram would indicate that this is unlikely. The existence of 5:3 thinplates in the 5:4 phase regions of rare-earth poor samples, as well as in samples prepared with various cooling rates and matrix crystal structures, is another indication that the current phase diagrams for these systems are inaccurate at high temperatures. It is believed the $5: 3$ thin-plates are forming at higher temperatures $\left(>850^{\circ} \mathrm{C}\right)$, possibly aided by the favorable structural orientation that exists between the $5: 4$ and $5: 3$ phases.

\section{Acknowledgements}

This work was performed at Ames Laboratory under contract No. W-7405-Eng-82 with the US Department of Energy. This research was supported by the Office of Basic Energy Sciences, Materials Science Division of the US DOE. The authors wish to thank V. K. Pecharsky and T.A. Lograsso for helpful discussions and D.L. Schlagel for single crystal sample preparation. Authors also wish to thank to Materials Preparation Center (MPC) at Ames Laboratory for providing high quality arc-melted samples. 


\section{References}

1. Morellon L, Blasco J, Algarabel PA, Ibarra MR. Physical Review B 2000;62(2):1022-6.

2. Morellon L, Algarabel PA, Ibarra MR, Blasco J, Garcia-Landa B, Arnold Z, Albertini F. Physical Review B 1998;58(22):R14721 - R4.

3. Levin EM, Pecharsky VK, Gschneidner Jr. KA. Physical Review B 1999;60(11):7993.

4. Levin EM, Pecharsky VK, Gschneidner KAJ, Tomlinson P. Journal of Magnetism and Magnetic Materials 2000;210(1-3):181-8.

5. Morellon L, Stankiewicz J, Garcia-Landa B, Algarabel PA, Ibarra MR. Applied Physics Letters 1998;73(23):3462.

6. Pecharsky VK,Gschneidner Jr. KA. Physical Review Letters 1997;78(23):4494 - 7.

7. Pecharsky VK,Gschneidner Jr. KA. Journal of Alloys and Compounds 1997;260:98 106.

8. Ugurlu O, Chumbley LS, Schlagel DL, Lograsso TA, Pecharsky AO. Characterization of $R_{5}\left(\mathrm{Si}_{x} G e_{I_{-x}}\right)_{4}$ alloys, where $R$ is $G d, T b, D y$ and Er. in 134th TMS Annual Meeting, Feb 13-17 2005. 2005. San Francisco, CA, United States: Minerals, Metals and Materials Society, Warrendale, PA 15086, United States.

9. Ugurlu O, Chumbley LS, Schlagel DL, Lograsso TA, Tsokol AO. Scripta Materialia 2005;55(3):373 - 7 .

10. Meyers JS, Chumbley LS, Laabs F, Pecharsky AO. Scripta Materialia 2002;47:509 14.

11. Szade J, G.Skorek, Winiarski A. Journal of Crystal Growth 1999;205:289 - 93.

12. Ugurlu O, Chumbley LS, Lograsso TA, Schlagel DL. Acta Materalia 2005;53:3525 53.

13. Ugurlu O, Chumbley LS, Schlagel DL, Lograsso TA. Acta Materalia 2005;54:1211. 
14. Mozharivskyj Y, Pecharsky AO, Pecharsky VK, Miller GJ. Journal of the American Chemical Society 2005;127(1):317-24.

15. Materials Preparation Center (MPC), Ames, IA, USA.

16. Luzan SP, Listovnichii VE, Buyanov YI, Martsenyuk PS. Journal of Alloys and Compounds 1996;239(1):77-82.

17. Pecharsky VK,Gschneidner K.A. J. Advanced Materials 2001;13(9):683-6.

18. Ugurlu O, Chumbley LS, Schlagel DL, Lograsso TA. Acta Materalia 2006;54:1211.

19. Meyers JS, Chumbley S, Laabs F, Pecharsky AO. Acta Materialia 2003;51(1):61-70.

20. Meyers JS, Chumbley LS, Choe W, Miller GJ. Physical Review B 2002;66:012106. 


\section{ACKNOWLEDGEMENTS}

I wish to express my gratitude to a number of people who became involved with this thesis. My advisor Scott Chumbley, who is a great advisor, teacher and by far the best person I ever worked with. His enthusiasm, motivation and encouragement helped me to get through all the bottlenecks I have encountered during my Ph.D. I would like to thank him for all of his guidance not only as an advisor but also as a great friend, too. I had the best 3 years of my life working under his supervision. I also would like to thank to Karl Gschneidner and Vitalij Pecharsky, who have always offered their generous help through out this research, and Matt Kramer, Will McCallum, Kevin Dennis and Fran Laabs for helping me with the instruments and answering my non-ending questions. I believe I owe deepest thanks to my family who has supported me since I was born.

This work was performed at Ames Laboratory under Contract No. W-7405-Eng-82 with the U.S. Department of Energy. The United States government has assigned the DOE Report number IS-T 2797 to this thesis. 